PREVISÃO COM MODELOS ESTRUTURAIS DE COMPONENTES NÃO OBSERVADOS: APLICAÇÕES A SÉRIES DE AGREGADOS MONETÁRIOS BRASILEIROS.

Roberto Francisco Casagrande Herdeiro

Orientador: Prof. Dr. Pedro Luiz Valls Pereira

Dissertação apresentada junto ao Departamento de Estatística do Instituto de Matemática e Estatística da Universidade de São Paulo para obtenção do título de mestre em Estatística

São Paulo 1998 


\section{PREVISÃO COM MODELOS ESTRUTURAIS DE COMPONENTES NÃO OBSERVADOS: APLICAC̣ÕES \\ A SÉRIES DE AGREGADOS MONETÁRIOS BRASILEIROS}

Este exemplar corresponde à redação final da dissertação devidamente corrigida e defendida por Roberto Francisco Casagrande Herdeiro e aprovada pela comissão julgadora.

São Paulo, 29 de junho de 1998.

\section{Banca Examinadora:}

- Prof. Dr. Pedro Luiz Valls Pereira - (Orientador) - IME-USP

- Profa. Dra. Mariane Streibel - IME-USP

- Prof. Dr. Luiz Koodi Hotta - IMECC-UNICAMP 
Aos meus familiares, amigos, professores e colegas. 


\section{Sumário}

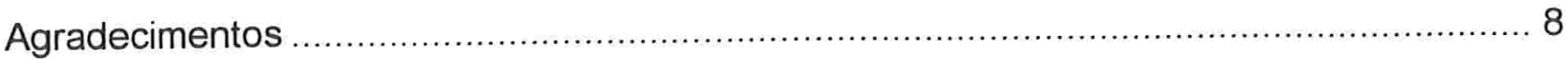

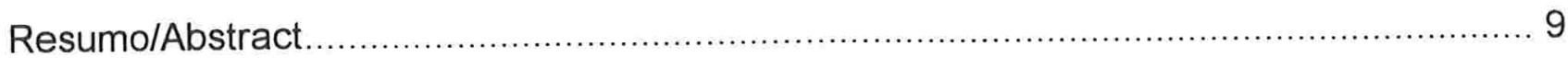

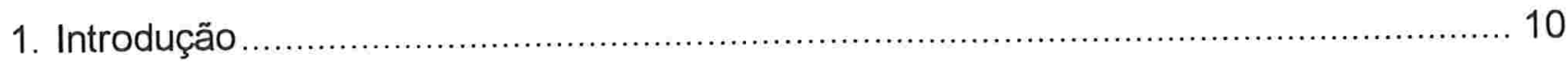

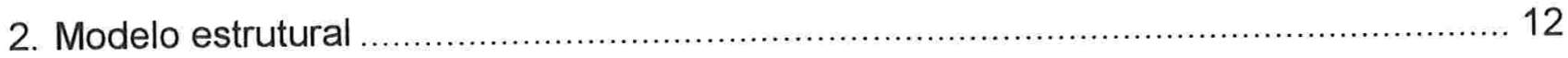

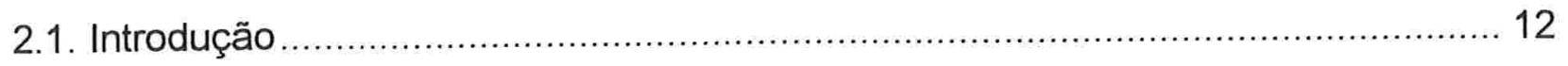

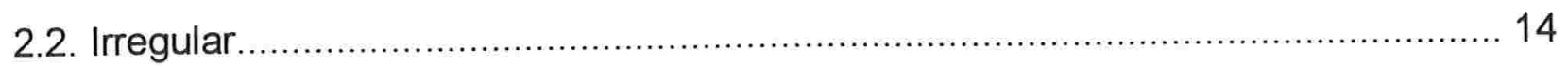

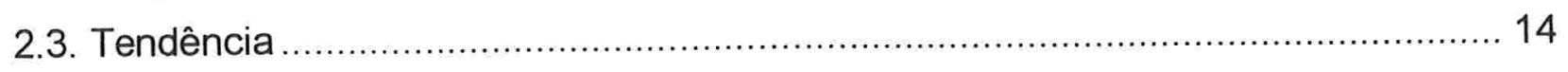

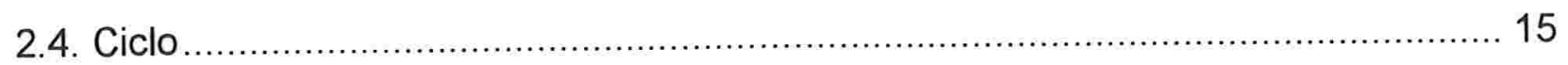

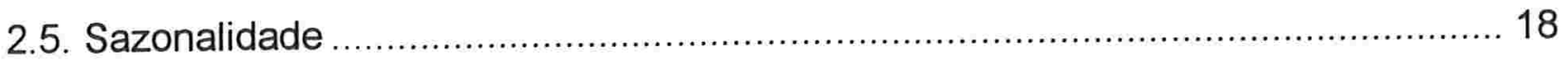

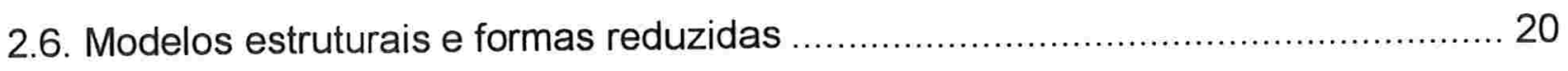

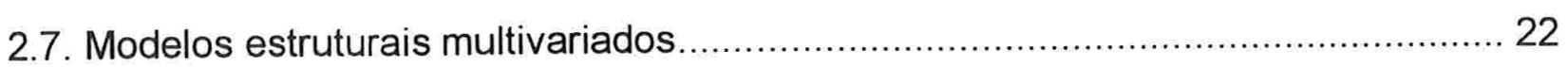

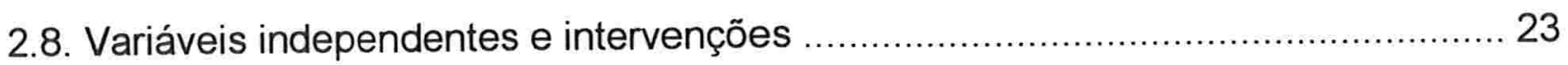

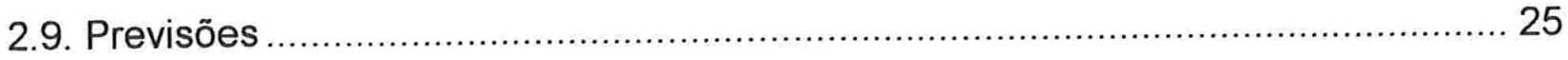

3. Filtro de Kalman e representação espaço de estado ............................................... 26

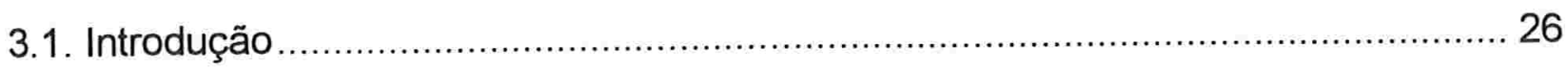

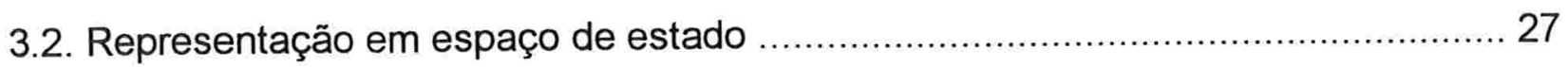

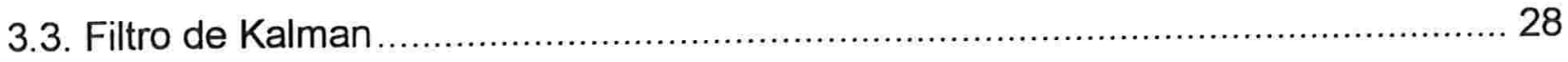

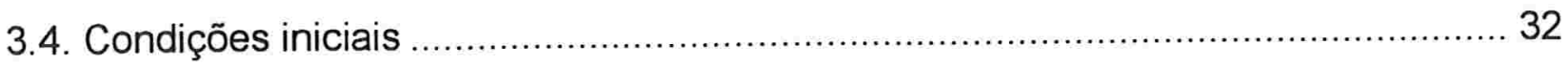

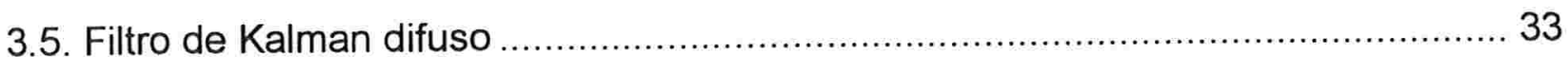

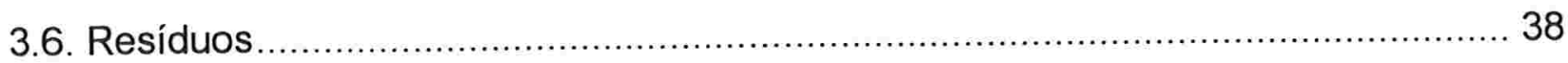

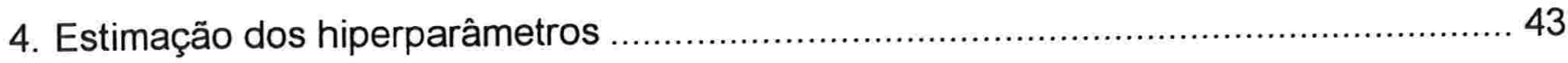

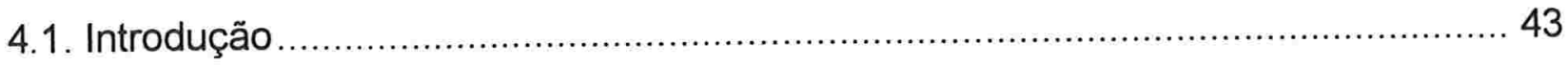

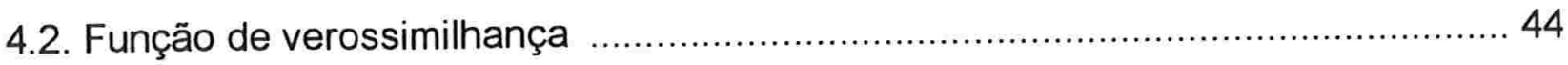

4.3. Método numérico para maximização da verossimilhança...................................... 47

5. Testes de especificação e falta de especificação ....................................................... 48

6. Aplicações a séries de agregados monetários brasileiros ....................................... 54

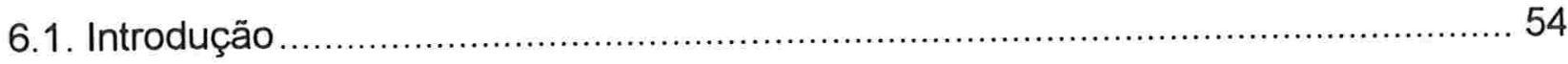

6.2. Modelo estrutural univariado para a base monetária......................................... 55

6.2.1. Análise da série base monetária .............................................................. 55

6.2.2. Especificação e estimação do modelo estrutural para a base monetária......... 59

6.2.3. Poder preditivo do modelo para base monetária .......................................... 71 
6.2.4. Modelo para prever a base monetária

6.3. Modelo estrutural multivariado para depósito a vista e papel moeda em poder do público. 77

6.3.1. Análise das séries papel moeda em poder do público e depósito a vista. 77

6.3.2. Especificação e estimação do modelo bivariado papel moeda em poder do público e depósito a vista.

6.3.3. Poder preditivo do modelo bivariado papel moeda em poder do público e depósito a vista

7. Conclusão: previsões condicionais 103

8. Referências bibliográficas 109

9. Apêndice 110 


\section{Índice de tabelas}

TABELA 6.2.1.1 Testes de raiz unitária Dickey-Fuller aumentado: BM original e sua primeira diferença.

TABELA 6.2.1.2 Testes de raiz unitária Dickey-Fuller aumentado: BM logaritmada e sua primeira diferença .................................................. 58

TABELA 6.2.2.1 Estimativas para os coeficientes das variáveis explicativas (modelo 1)

TABELA 6.2.2.2 Estimativas dos hiperparâmetros (modelo 1) ............................6. 62

TABELA 6.2.2.3 Maiores valores dos resíduos do nível (modelo 1) ........................63

TABELA 6.2.2.4 Estimativas dos hiperparâmetros (modelo 2) ...............................6 64

TABELA 6.2.2.5 Estimativas para os coeficientes das variáveis explicativas e intervenções (modelo 2) .................................................6 64

TABELA 6.2.2.6 Maiores valores dos resíduos do nível (modelo 2) ........................64

TABELA 6.2.2.7 Estimativas dos hiperparâmetros (modelo 3) ...............................6 65

TABELA 6.2.2.8 Estatísticas para a sazonalidade do último período da amostra (modelo 3)

TABELA 6.2.2.9 Coeficientes estimados para o último vetor de espaços de

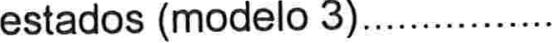

TABELA 6.2.2.10 Estatísticas para os coeficientes das variáveis explicativas e intervenções (modelo 3) ......................................................6 68

TABELA 6.2.2.11 Estatísticas de qualidade de ajuste (modelos 2 e 3) .....................6.69

TABELA 6.2.2.12 Correlações seriais e estatísticas para os residuos (modelo 3) ........ 70

TABELA 6.2.2.13 Maiores valores dos resíduos do nível (modelo 3) ........................ 71

TABELA 6.2.3.1 Previsões e seus erros relativos para a série transformada

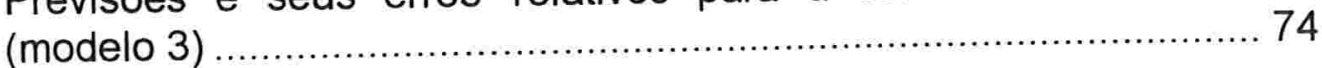

TABELA 6.2.3.2 Previsões e seus erros para a série original (modelo 3)................... 74

TABELA 6.2.3.3 Avaliação do poder preditivo dos modelos (7 valores externos) ....... 75

TABELA 6.2.4.1 Estimativas dos hiperparâmetros (modelo 4) ................................ 75

TABELA 6.2.4.2 Estatísticas de qualidade de ajuste (modelos 3 e 4) .......................76

TABELA 6.2.4.3 Estatísticas dos coeficientes das variáveis explicativas e intervenções (modelo 4) 76

TABELA 6.2.4.4 Estatísticas para os componentes no último período da amostra (modelo 4)

TABELA 6.2.4.5 Avaliação do poder preditivo 6 valores internos (modelo 4) ............. 77

TABELA 6.3.2.1 Coeficientes de correlação linear entre as primeiras diferenças das variáveis transformadas dependentes com inflação 79

TABELA 6.3.2.2 Testes raiz unitária Dickey-Fuller aumentado: PMPP logaritmado e sua primeira diferença. 
TABELA 6.3.2.3 Testes raiz unitária Dickey-Fuller aumentado: DV logaritmado e sua primeira diferença..

TABELA 6.3.2.4 Estimativas dos hiperparâmetros (modelo I)

TABELA 6.3.2.5 Estimativas e estatísticas para os coeficientes das variáveis

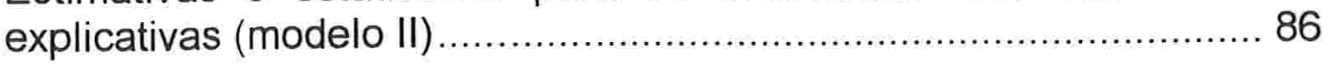

TABELA 6.3.2.6 Maiores valores dos resíduos do nível (modelo II). 86

TABELA 6.3.2.7 Estimativas e estatísticas para os coeficientes das variáveis explicativas (modelo III).

TABELA 6.3.2.8 Estimativas e estatísticas para os coeficientes das variáveis explicativas (modelo IV) ............................................................. 88

TABELA 6.3.2.9 Estimativas e estatísticas para os coeficientes das variáveis

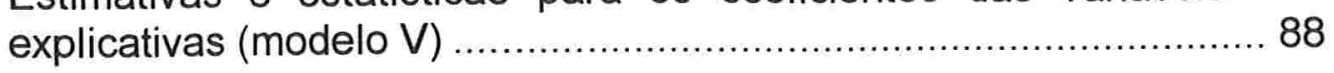

TABELA 6.3.2.10 Estimativas dos hiperparâmetros (modelo VI) .................................. 89

TABELA 6.3.2.11 Variâncias, covariâncias e correlações(em itálico) das perturbações dos componentes

TABELA 6.3.2.12 Estimativas e estatísticas para os coeficientes das variáveis explicativas (modelo VI) ............................................................ 93

TABELA 6.3.2.13 Covariâncias dos erros de previsão ................................................ 93

TABELA 6.3.2.14 Estatísticas da qualidade de ajuste (modelo VI)............................. 94

TABELA 6.3.2.15 Correlações seriais e estatísticas sobre suas significâncias para

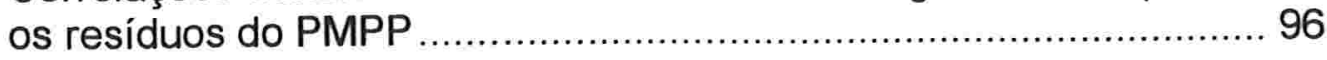

TABELA 6.3.2.16 Correlações seriais e estatísticas sobre suas significâncias para

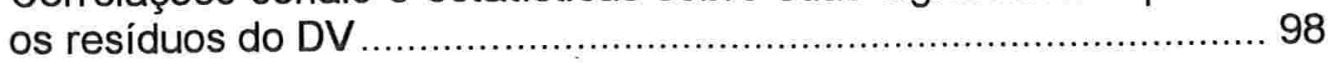

TABELA 6.3.3.1 Níveis descritivos dos testes e estatísticas da capacidade preditiva (modelo VI) .............................................................. 99

TABELA 6.3.3.2 Previsões a um passo para as séries originais e seus erros relativos..... 99

TABELA 6.3.3.3 Previsões a vários passos para as séries originais e seus erros

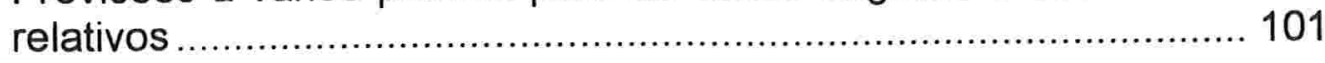

TABELA 6.3.3.4 Maiores valores dos resíduos auxiliares......................................... 102

TABELA 6.3.3.5 Coeficientes estimados e significâncias para o último ponto da

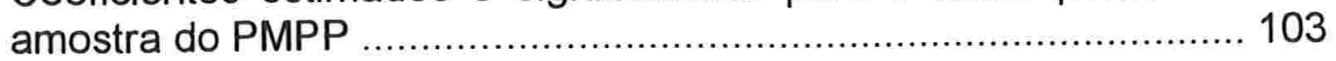

TABELA 6.3.3.6 Coeficientes estimados e significâncias para o último ponto da

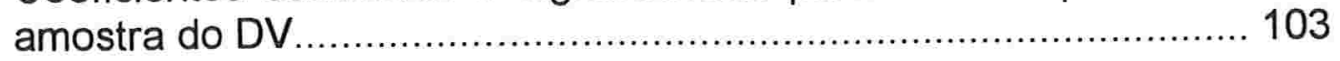

TABELA 7.1 Cenário e valores observados para a inflação (IGP-DI) .................. 104

TABELA 7.2 Valores observados e previstos para a BM média mensal............. 106

TABELA 7.3 Valores observados e previstos para o DV médio mensal .............. 107

TABELA 7.4 Valores observados e previstos para o PMPP médio mensal ......... 108 


\section{Índice de gráficos}

GRÁFICO 6.2.1.1 Base monetária média mensal, a preços constantes de out/96 ........ 56

GRÁFICO 6.2.2.1 Base monetária média mensal e IGP-DI transformados ................... 60

GRÁFICO 6.2.2.2 Componente tendência combinada com variáveis explicativas (modelo 3)

GRÁFICO 6.2.2.3 Sazonalidade e fatores ao longo da amostra para a série original (modelo 3) 66

GRÁFICO 6.2.2.4 Comportamento dos resíduos do modelo 3 70

GRÁFICO 6.2.3.1 Previsões a um passo para 7 meses fora da amostra para BM transformada (modelo 3).

GRÁFICO 6.2.3.2 Previsões vários passos para 7 meses fora da amostra transformada (modelo 3)

GRÁFICO 6.3.1.1 DV e PMPP a preços de outubro de 1996 78

GRÁFICO 6.3.2.1 DV, PMPP e I transformadas 80

GRÁFICO 6.3.2.2 Componente sazonal e seus fatores mensais para o PMPP (modelo I) 83

GRÁFICO 6.3.2.3 Componente sazonal e seus fatores mensais para o DV (modelo I)

GRÁFICO 6.3.2.4 Componentes estimados para o PMPP (modelo VI) ......................... 91

GRÁFICO 6.3.2.5 Componentes estimados para o DV (modelo VI) ............................. 92

GRÁFICO 6.3.2.6 Estimativas para os resíduos do PMPP (modelo VI) ........................ 95

GRÁFICO 6.3.2.7 Estimativas para os resíduos do DV (modelo VI) ............................ 97

GRÁFICO 6.3.3.1 Previsões a um passo para as séries transformadas (modelo VI)... 100

GRÁFICO 6.3.3.2 Previsões a vários passos para as séries transformadas (modelo $\mathrm{VI})$

GRÁFICO 7.1 Previsões para a BM transformada e original.................................. 106

GRÁFICO 7.2 Previsões para o PMPP e o DV ..................................................... 107 


\section{Agradecimentos}

Muitas são as pessoas que merecem meu reconhecimento por terem contribuído de alguma forma para que eu conseguisse apresentar esta dissertação. Agradecer nominalmente a todas elas é impossível. Assim, peço desculpas por não citá-las e conforto-as por, independentemente disto, terem minha eterna gratidão.

Em especial, agradeço a Eliana, a Roberta e a Fernanda por terem se privado de minha companhia em vários domingos, sábados, feriados, férias, noites e dias, um período irrecuperável, que espero, o mais breve possível, retribuir com momentos de alegrias e felicidades.

Ao meu pai e a minha mãe que, com dedicação, transmitiram-me ensinamentos decisivos para minha formação.

Ao chefe Mamede que, com desprendimento e estratégia, foi fundamental para minha fase de dedicação exclusiva aos estudos.

Ao Banco do Brasil que deu suporte financeiro em um período dos estudos.

Aos dedicados funcionários das secretarias do IME-USP que durante meu período de vínculo à universidade sempre foram muito prestativos e interessados em meus questionamentos.

Aos professores Luiz Koodi Hotta e Mariane Streibel, cujos comentários e sugestões em muito contribuíram para melhorar esta dissertação.

Por último, com gratidão infinita, ao grande professor Pedro Valls que colaborou decisivamente na elaboração deste trabalho com sua paciente orientação.

Evidentemente, eventuais erros na obra são de minha exclusiva responsabilidade. 


\section{Resumo}

Este estudo descreve a metodologia de modelos estruturais em séries temporais e sua utilização na previsão de séries econômicas brasileiras. É apresentado o modelo estrutural clássico que decompõe uma série em componentes não observados, a saber, tendência, sazonalidade, ciclo e irregular. A estimação dos hiperparâmetros, variabilidades dos componentes não observados é feita com o auxílio do procedimento filtro de Kalman difuso. Como um dos objetivos é previsão, é feita análise de diagnóstico para verificar a qualidade dos modelos.

São aplicados dois modelos para séries brasileiras, um, univariado, para a base monetária, e outro, bivariado, para o depósito a vista e para o papel moeda em poder do público; todas variáveis são medidas em médias mensais. O objetivo principal da modelagem é exclusivamente antecipar a trajetória futura das variáveis.

\section{Abstract}

Structural time series models are used to predict some brazilian economic's variables. The classical approach to structural models decomposes a serie into components: trend, seasonal, cycle and irregular. The estimation of the hyperparameters is done by the difuse Kalman filter procedure after writting the model into the state space form. Some diagnostic analysis is done in order to check the quality of the models.

Two models are used, one, univariate, to estimate the monetary basis, and another, bivariate, for currency outside banks and demand deposits, all variables are mesured in monthly average. The objective of this study is to forecast the future path of the economic variables. 


\section{1 - Introdução}

Uma das preocupações principais dos diversos agentes econômicos é ter mecanismos capazes de prever variáveis econômicas. As razões e necessidades para se prever são muitas e, por vezes, específicas para cada particular agente. Como exemplos, os formuladores de política econômica precisam realizar programações monetárias, definições de níveis de juros primários, planejamento orçamentário etc.; as instituições financeiras gerenciar riscos, política financeira, metas, estratégias de atuação etc.; enfim, os agentes têm nas previsões um importante meio de fornecer conhecimento para auxílio nas tomadas de decisões.

Os mecanismos para previsões podem ser non-model based ou model based. $\mathrm{Na}$ categoria dos non-model based os mais utilizados são extrapolações de tendência local, obtidos ajustando-se aos dados uma função do tempo que coloca maior peso nas observações mais próximas do final da série, a extrapolação desta função fornece então as previsões desejadas. Como estes mecanismos são ad hoc, tanto a extração do componente de tendência quanto a forma de fazer previsões, em geral, não têm embasamento estatístico.

Nessa classe de modelos, a função de previsão é obtida através de procedimentos de suavização exponencial. Estes mecanismos tornaram-se populares pois são de fácil implementação e fornecem resultados aceitáveis, apesar de não possuírem suposições probabilísticas. Alguns exemplos desses procedimentos são o de médias móveis exponencialmente ponderadas, 0 de tendência linear local de Holt-Winters. Alguns mecanismos podem, ainda, incorporar componente sazonal.

Contudo, por não serem estocásticos, os mecanismos non-model based são preteridos, considerando-se que, em alguns casos, não permitem: a estimação de parâmetros por métodos estatísticos com comprovada eficiência, por exemplo, máxima verossimilhança; a realização de análise de diagnóstico através de testes estatísticos sobre a adeqüabilidade de ajuste; e a construção de intervalos de confiança para as previsões. Os modelos ad hoc foram os precursores de alguns dos mecanismos model based.

Os procedimentos model-based possibilitam a obtenção de estimativas para seus parâmetros, freqüentemente utilizando-se o método de mínimos quadrados ou o de máxima verossimilhança, neste caso, quase sempre, pressupondo-se distribuição normal 
para os dados e por meio de procedimentos iterativos de otimização numérica. Assim, o conhecimento de propriedades sobre os estimadores permite que testes estatísticos sejam construídos para verificar a adequação do modelo, seja através de testes de diagnóstico ou de especificação.

A análise do modelo - cumprimento das suposições e qualidade do ajuste - inclui procedimentos gráficos e testes estatísticos, geralmente obtidos a partir dos resíduos do modelo estimado, os erros entre os valores observados e os obtidos pelo modelo. Resíduos aleatórios é o que se espera de um bom modelo.

Enfim, a introdução de suposições probabilísticas nos modelos permite uma ampla variedade de testes que, quase certamente, levarão à obtenção de melhores ajustes e previsões.

$\mathrm{Na}$ classe dos model based, diversas metodologias estão disponiveis. Os modelos econométricos ou de séries temporais têm sido os mais utilizados. Dentre os modelos de séries temporais destacam-se os modelos a componentes não observados. Estes modelos mostram-se mais adaptativos do que os modelos autoregressivos integrados de médias móveis (ARIMA), além de modelarem a série sem perda de informação de seu nível, já que não necessitam diferenciar a série para induzir estacionariedade, que é obrigatória na metodologia de Box \& Jenkins.

O modelo estrutural, denominação utilizada para modelos que tratam as séries decompondo-as em componentes não observados, é bastante natural, pois está associado a características ou padrões particulares da série, tornando sua utilização mais compreensiva e justificável. Com estes modelos há, em geral, possibilidade de se obter previsões melhores, principalmente para séries com poucas observações.

Nesse contexto, o presente estudo tem o objetivo de realizar previsões para as séries econômicas brasileiras da base monetária, do depósito a vista e do papel moeda em poder do público utilizando os modelos estruturais de componentes não observados. A escolha do tipo de modelo a ser utilizado deveu-se, além das vantagens intrínsecas do modelo estrutural, à presença de pelo menos um componente marcante nas séries e às amostras reduzidas de duas delas.

De modo geral, os roteiros usados na estimação de modelos estocásticos são bastante semelhantes. Assim, a partir da definição da metodologia e do modelo a serem 
utilizados, a regra é, basicamente, estimar os parâmetros do modelo e através de testes e estatísticas verificar as significâncias das estimativas, a validade das suposições, a qualidade do ajuste e principalmente o poder preditivo. Pode-se, ainda, caso haja mais de um modelo competitivo, realizar a comparação entre eles para se eleger o preferido.

Os capítulos seguintes trarão: a apresentação dos modelos estruturais e dos componentes; representação em espaço de estado (REE) e filtro de Kalman; a estimação e os testes estatísticos úteis na verificação de suposições e nas análises de diagnóstico e da capacidade preditiva; uma aplicação univariada; uma aplicação bivariada; e a conclusão apresentando as previsões das variáveis sob análise para alguns meses.

\section{2 - Modelo estrutural}

\section{1 - Introdução}

O ponto de partida para o desenvolvimento dos modelos estruturais é o modelo de regressão em que as variáveis explicativas são funções do tempo. Por exemplo, um modelo para representar a decomposição de uma série nos componentes de tendência, sazonalidade e irregular pode ser formulado como uma regressão, onde as variáveis explicativas são uma tendência linear determinística e um conjunto de variáveis dummies, para caracterizar a sazonalidade, isto é:

$$
y_{t}=\alpha+\beta t+\sum_{j=1}^{s-1} \gamma_{j} Z_{j t}+\varepsilon_{t}, \quad t=1,2, \ldots, T
$$

onde $\alpha$ e $\beta$ são coeficientes associados à tendência e os $\gamma_{j}^{\prime}$ 's às dummies, que somam zero a cada s períodos, uma característica dos componentes sazonais determinísticos. A restrição é efetivada com a seguinte definição da variável dummy $z_{j t}$, para $j=1,2, \ldots, s-1$,

$\mathrm{z}_{\mathrm{jt}}=\left\{\begin{array}{cc}1 & t=j, j+s, j+2 s, \ldots \\ 0 & t \neq j, j+s, j+2 s, \ldots \\ -1 & t=s, 2 s, 3 s, 4 s, 5 s, 6 s \ldots\end{array}\right.$

onde s é a periodicidade da sazonalidade

A única parte estocástica do modelo (2.1) é o irregular $\varepsilon_{t}$, sendo os outros componentes determinísticos, o que pode ser bastante inadequado para séries cujos componentes se alteram ao longo do tempo. A incorporação de variabilidade nos 
componentes do modelo (2.1) pode ser efetuada permitindo que os parâmetros $\alpha$, $\beta$, e $\gamma_{j}$ variem ao longo do tempo. Como escrito em Harvey (1993) página 121, os principais modelos estruturais de séries temporais nada mais são do que modelos de regressão nos quais as variáveis explicativas são funções do tempo e os parâmetros variam com o passar dos períodos.

Um modelo de regressão no tempo com parâmetros constantes, como (2.1), dá o mesmo peso na função de previsão para todos valores e é um caso particular dos modelos estruturais, que têm a possibilidade de dar mais peso às observações mais recentes, fato este que é incorporado na função de previsão. Isto é obtido transformandose a formulação estática (2.1) em um modelo dinâmico que permite a variação dos componentes.

Os modelos estruturais para séries temporais decompõem as séries estudadas em um ou mais componentes não observados que possuem uma interpretação direta e imediata, a saber: tendência, sazonalidade, ciclo e irregular. Uma característica marcante desses modelos é o modo da estimação dos seus parâmetros e da obtenção das previsões, feitas utilizando-se o filtro de Kalman, após a especificação do modelo em representação em espaço de estados.

Os parâmetros do modelo são medidas que espelham as variabilidades dos componentes. O interesse em estimá-los está em saber quais componentes a série realmente possui e em existindo se eles variam ao longo do tempo. Quanto maior o grau de variabilidade de um componente, menos peso é dado aos valores passados da série na função de previsão, a qual extrapola as estimativas para o tempo $T$ das componentes não observadas. Os parâmetros que representam as variabilidades das componentes são chamados na literatura de hiperparâmetros.

Uma série univariada com as quatro componentes pode ser representada pela equação

$$
y_{t}=\mu_{t}+\varphi_{t}+\gamma_{t}+\varepsilon_{t}, \quad t=1,2, \ldots, T
$$

onde $\mu_{t}$ representa a tendência, $\varphi_{t} \circ$ ciclo, $\gamma_{t}$ a sazonalidade e $\varepsilon_{t} \circ$ irregular. Estes componentes serão descritos adiante. Nota-se que esta especificação em forma aditiva, não é restritiva pois se $y_{t}$ é o logaritmo de uma série, ele é efetivamente um modelo multiplicativo para a série original se seu irregular for especificado de forma multiplicativa. 
Serão apresentados modelos estruturais lineares e com perturbações que supostamente possuam distribuições normais. Os modelos estruturais podem ser mais complexos, por exemplo, apresentarem não linearidade, perturbações não normais e outras particularidades.

Como será visto, os modelos estruturais multivariados são extensões dos univariados, com a peculiar característica que todas ou algumas séries podem possuir componentes comuns. Para se utilizar modelos multivariados exige-se que as séries analisadas conjuntamente possuam características comuns.

\section{2 - Irregular}

O componente irregular, $\varepsilon_{t}$, pode ser interpretado como um componente aleatório ou um erro de medida. Ele será especificado como um processo ruído branco, ou seja, uma seqüência de variáveis aleatórias não correlacionadas, com média e variância constantes, respectivamente iguais a zero e $\sigma_{\varepsilon}^{2}$. Ele pode ainda, quando serialmente correlacionado, ser modelado por um processo ARMA.

\section{3 - Tendência}

A idéia de tendência está relacionada com a direção geral dos dados. A tendência não tem que refletir as oscilações da série mas sim sua direção geral. Em geral, séries temporais possuem um componente de tendência.

Do ponto de vista preditivo a tendência é a parte da série que quando extrapolada fornece a mais nítida indicação dos movimentos de longo prazo da série.

A tendência pode possuir uma variedade de formas e serão estudadas somente as tendências lineares, apesar do modelo estrutural ser capaz de incorporar tendências não lineares.

Uma tendência linear determinística como $\mu_{\mathrm{t}}=\alpha+\beta \mathrm{t}$ pode ser estimada eficientemente e consistentemente por uma regressão de mínimos quadrados ordinários (MQO). Estas estimativas fornecem funções de previsões que colocam o mesmo peso em todos dados, independente de suas posições no tempo. Pressupondo-se alguma distribuição para a variável, quase sempre normal, intervalos de confiança para essas previsões são obtidos. Contudo, uma modelagem mais geral é conseguida permitindo que 
a tendência varie ao longo do tempo. Assim, uma tendência global para toda a série é substituída por uma tendência local que pode alterar sua direção ao longo da amostra; neste caso, a tendência mais próxima do final da amostra é extrapolada para obtenção de valores futuros, dando, conforme a necessidade, maior ênfase às observações mais próximas.

A tendência $\mu_{\mathrm{t}}=\alpha+\beta$ t pode ser transformada em estocástica permitindo que $\alpha$ e $\beta$ sejam passeios aleatórios, isto é, $\alpha_{t}=\alpha_{t-1}+\eta_{t}$ e $\beta_{t}=\beta_{t-1}+\zeta_{t}$, onde as perturbações são assumidas serem ruídos brancos, em geral, independentes entre si. Este procedimento poderia ocasionar descontinuidade na tendência. Uma forma de gerar continuidade é associar os dois componentes usando o fato que a variação do nível é a taxa de crescimento, isto é:

$$
\begin{aligned}
& \mu_{t}=\mu_{t-1}+\beta_{t-1}, \quad t=1,2, \ldots, T \\
& \beta_{t-1}=\beta_{t}
\end{aligned}
$$

com $\mu_{0}=\alpha$, suavidade nestes componentes é obtida introduzindo-se termos estocásticos, por exemplo, da seguinte maneira

$$
\begin{aligned}
& \mu_{t}=\mu_{t-1}+\beta_{t-1}+\eta_{t} \\
& \beta_{t}=\quad \beta_{t-1}+\zeta_{t},
\end{aligned} \quad t=1,2, \ldots, T
$$

onde $\eta_{\mathrm{t}} \mathrm{e} \zeta_{\mathrm{t}}$ são ruídos brancos não correlacionados entre si, com médias iguais a zero, e variâncias $\sigma_{\eta}^{2}$ e $\sigma_{\zeta}^{2}$, respectivamente. A perturbação $\eta_{t}$ permite que o nível $\mu_{t}$ da tendência varie ao longo do tempo e $\zeta_{t}$ faz o mesmo para a inclinação (taxa de crescimento) $\beta_{\mathrm{t}}$. Quanto maiores as variâncias $\sigma_{\eta}^{2}$ e $\sigma_{\zeta}^{2}$ das perturbações, maiores os movimentos estocásticos da série; se ambas forem iguais a zero (2.5) se reduz à tendência linear de (2.1).

\section{4 - Ciclo}

O componente cíclico é aquele que representa os movimentos transitórios de uma série, isto é, um movimento que, ao longo do tempo, se repete deterministicamente com período constante, ou estocasticamente com pequenas alterações de padrão e período aproximadamente constante. Entendendo-se período como o comprimento de tempo (duração) que o processo leva para completar um ciclo completo. Compreende-se o termo 
ciclo como movimentos com períodos longos, geralmente maiores do que um ano, e o termo sazonalidade como movimentos com períodos menores do que um ano.

Uma forma de especificar o componente cíclico, denotado por $\psi_{t}$ é através de funções trigonométricas do tipo seno ou co-seno. Então a função

$$
y=\cos x
$$

é definida em termos de um ângulo, $x$, medido em radianos. Como há $2 \pi$ radianos num círculo, y varia completamente em seus possíveis valores quando $x$ varia de 0 a $2 \pi$ e seu padrão é então repetido a medida que $x$ varia de $2 \pi$ em diante, assim, para qualquer inteiro $k, \cos (x+2 k \pi)=\cos x$. A função seno exibe propriedades similares.

A variável y pode ser expressa como uma função cíclica do tempo definindo-se um parâmetro, $\lambda_{c}$, medido em radianos e conhecido como freqüência (angular). Então $\lambda_{c} t$ substitui $x$ em (2.6). Conforme o valor de $\lambda_{c}$, a função se expande ou se contrai ao longo do domínio t e o período da função é igual a $2 \pi / \lambda_{c}$.

Maior flexibilidade para a função (2.6) é efetivada multiplicando-a por um parâmetro, $\mathrm{A}$, conhecido como amplitude, e introduzindo-se um ângulo, $\theta$, em radianos, chamado de fase, que possibilita que a função seja deslocada ao longo de t. Como conseqüência um componente cíclico $\psi_{t}$ determinístico pode ser expressa como

$$
\psi_{t}=A \cos \left(\lambda_{c} t-\theta\right), \quad t=1,2, \ldots, T
$$

Uma função cíclica trigonométrica pode ser escrita como uma mistura de senóides e cosenóides, os parâmetros da amplitude e da fase de (2.7) são substituídos pelos parâmetros $\phi$ e $\varphi$, então

$$
\psi_{t}=\phi \cos \lambda_{c} t+\varphi \operatorname{sen} \lambda_{c} t, \quad t=1,2, \ldots, T
$$

onde $\left(\phi^{2}+\varphi^{2}\right)^{1 / 2}=\mathrm{A}$ e $\operatorname{tang}^{-1}(\varphi / \phi)=\theta$.

Modelo para observações que possuam apenas os componentes ciclo e irregular é

$$
y_{t}=\psi_{t}+\varepsilon_{t}, \quad t=1,2, \ldots, T
$$

onde $\varepsilon_{t}$ é um ruído branco e $\psi_{t}$ é como dado em (2.8) com $\lambda_{c}$ conhecido. Tal modelo é estimado apropriadamente por mínimos quadrados não lineares e é convenientemente utilizado para padrões cíclicos fixos. Quando o ciclo varia ao longo do tempo, o componente $\psi_{\mathrm{t}}$ deve ser considerado estocástico e a modelagem pode ser efetivada 
permitindo-se que em (2.8) os parâmetros $\phi$ e $\varphi$ variem em função de t. Semelhantemente ao caso da tendência linear estocástica, a continuidade de $\psi_{t}$ é preservada através da utilização de uma forma recursiva para a construção de $\psi_{\mathrm{t}}$, dada por

$$
\left[\begin{array}{c}
\Psi_{t} \\
\Psi^{*}{ }_{t}
\end{array}\right]=\left[\begin{array}{cc}
\cos \lambda_{0} & \operatorname{sen} \lambda_{c} \\
-\operatorname{sen} \lambda_{0} & \cos \lambda_{c}
\end{array}\right]\left[\begin{array}{c}
\Psi_{t-1} \\
\Psi^{*}{ }_{t-1}
\end{array}\right]+\left[\begin{array}{c}
\kappa_{t} \\
\kappa^{*}{ }_{t}
\end{array}\right], \quad t=1,2, \ldots, T
$$

onde $\kappa_{\mathrm{t}} \mathrm{e} \kappa^{*}{ }_{\mathrm{t}}$ são perturbações aleatórias, ruídos brancos, $\psi_{0}=\phi$, e $\psi_{0}^{*}=\varphi$. Os parâmetros $\psi_{\mathrm{t}}$ representam, em cada $\mathrm{t}$, os valores correntes do ciclo e os $\psi^{*} \mathrm{t}$ aparecem por construção para formar $\psi_{t}$, não merecendo maiores considerações.

Para o modelo ser identificável é necessário uma suposição adicional. Por exemplo, que as perturbações $\kappa_{\mathrm{t}}$ e $\kappa^{*} \mathrm{t}$ têm a mesma variância, ou que elas são não correlacionadas; na prática ambas suposições são assumidas por parcimônia.

Para que a representação cíclica introduzida em (2.10) seja estacionária é necessário introduzir um fator de amortecimento, $\rho$, resultando

$$
\left[\begin{array}{c}
\Psi_{\mathrm{t}} \\
\Psi^{*}{ }_{\mathrm{t}}
\end{array}\right]=\rho\left[\begin{array}{cc}
\cos \lambda_{c} & \operatorname{sen} \lambda_{c} \\
-\operatorname{sen} \lambda_{c} & \cos \lambda_{c}
\end{array}\right]\left[\begin{array}{c}
\Psi_{\mathrm{t}-1} \\
\Psi^{*}{ }_{\mathrm{t}-1}
\end{array}\right]+\left[\begin{array}{c}
\kappa_{\mathrm{t}} \\
\kappa^{*}{ }_{\mathrm{t}}
\end{array}\right], \quad \mathrm{t}=1,2, \ldots, \mathrm{T}
$$

onde $0<\rho \leq 1$.

Sejam os valores esperados de $\psi_{\mathrm{t}}$ e $\psi^{*_{\mathrm{t}}}$ no tempo $\mathrm{T}$ representados por $\widetilde{\Psi}_{\mathrm{T}}$ e $\widetilde{\Psi}^{{ }_{\mathrm{T}}}$ a previsão $\ell$ passos a frente de $T$, sob a suposição de perturbações $\kappa_{t}$ e $\kappa^{*}$ independentes, é

$$
\widetilde{\Psi}_{T+\pi T}=\rho^{\prime}\left(\widetilde{\Psi}_{T} \cos \lambda_{c} l+\widetilde{\Psi}^{*} \operatorname{sen} \lambda_{c} \gamma, \quad l=1,2, \ldots\right.
$$

Se $0<\rho<1$ a função de previsão do ciclo é uma senóide ou co-senóide amortecida que oscila para zero, se $\rho=1$ o amortecimento desaparece da função de previsão. Para que 0 processo vetorial (2.11) seja estacionário é necessário assumir a condição $0<\rho<1$. Koopman, Harvey, Doornik and Shephard (1995) propõem uma especificação da variância do ciclo que permite que o coeficiente de amortecimento seja unitário e neste caso o ciclo passa a ser determinístico.

Para $\lambda_{c}=0$ ou $\pi$, o ciclo estocástico (2.11) torna-se um processo $A R(1)$, isto ocorre pois sen $\lambda_{c}$ é igual a zero nessas duas freqüências e a equação que gera $\psi^{*}$ t passa a ser redundante, então, quando $\lambda_{c}=0$ e quando $\lambda_{c}=\pi \circ$ ciclo torna-se, respectivamente 


$$
\begin{aligned}
& \psi_{t}=\rho \psi_{t-1}+\kappa_{t}, \quad t=1,2, \ldots, T \\
& \psi_{t}=-\rho \psi_{t-1}+\kappa_{t}, \quad t=1,2, \ldots, T
\end{aligned}
$$

Assim, apesar de $\rho$ ser positivo o parâmetro autoregressivo no modelo $A R(1)$ tanto pode ser positivo como negativo.

\section{5 - Sazonalidade}

O conceito de sazonalidade se aproxima do de um ciclo com padrão que se repete anualmente. Séries mensais e trimestrais costumam possuir tal padrão, principalmente séries relacionadas com fatores econômicos ou climáticos.

A sazonalidade é uma característica forte de uma série, no sentido que é freqüente que ela se mantenha ao longo do tempo sem alterações ou se altere lentamente.

O componente sazonal determinístico descrito em (2.1) pode ser apropriado para séries com sazonalidade constante. No entanto, séries econômicas, têm, não raramente, sazonalidade que se altera ao longo do tempo. Assim, é importante que na modelagem de uma série em que a sazonalidade varie, esta seja considerada estocástica e a alteração de padrão incorporada no modelo.

Uma maneira para permitir que um modelo considere a sazonalidade como estocástica é a partir da formulação dummy de (2.1) introduzindo-se uma perturbação aleatória $\omega_{t}$, com média 0 e variância $\sigma^{2} \omega$, isto é,

$$
\sum_{j=0}^{s-1} \gamma_{t-j}=\omega_{t} \quad \text { ou } \quad \gamma_{t}=-\sum_{j=1}^{s-1} \gamma_{t-j}+\omega_{t}
$$

onde s é a periodicidade da sazonalidade. Vale notar que a esperança da soma dos efeitos em um período sazonal s é igual a zero e na função de previsão estes efeitos embora se anulem em s períodos, são constantes e iguais aos dos s períodos anteriores. Quanto maior a variância $\sigma^{2}{ }_{\omega}$ quando comparada $a \sigma_{\varepsilon}^{2}$, variância do irregular $\varepsilon_{t}$, maior sua importância relativa na variabilidade da série e menor a influência de observações passadas na sazonalidade.

Outra modelagem para a sazonalidade estocástica é representá-la através de uma série de Fourier, um conjunto de termos trigonométricos nas freqüências sazonais $\lambda_{\mathrm{j}}=$ 
$2 \pi j / s, j=1,2, \ldots,[s / 2]$, onde $[s / 2]=s / 2$ se $s$ for par, e [s/2] $=(s-1) / 2$ se $s$ for ímpar. Então, o efeito sazonal em cada tempo té

$$
\gamma_{t}=\sum_{j=1}^{[s / 2]}\left(\gamma_{j} \cos \lambda_{j} t+\gamma_{j}^{*} \operatorname{sen} \lambda_{j} t\right)
$$

que é uma representação de Fourier de um conjunto de pontos que somam zero a cada período s, Priestley (1981) trata de análise de Fourier.

Quando s é par o último termo da somatória (2.16) é zero, portanto, têm-se parâmetros $\gamma_{t}$ 's e $\gamma^{*}{ }_{t}^{\prime}$ 's em mesmo número, $s-1$, aos da formulação dummy da sazonalidade determinística (2.1).

A vantagem da formulação trigonométrica é que usualmente os padrões sazonais variam lentamente tornando possivel a desconsideração de algumas altas freqüências, $\lambda_{\mathrm{j}}$, pouco importantes na determinação de $\gamma_{t}$ em (2.16). Em séries mensais, por exemplo, a freqüência fundamental $\lambda_{1}=2 \pi / 12$, que corresponde ao período de 1 ano, geralmente consegue, sem as outras freqüências, as harmônicas, explicar grande parte da variação do componente sazonal.

Uma modelagem trigonométrica da sazonalidade estocástica $\gamma_{t}$, obtida a partir de (2.16), é a soma de [s/2] componentes cíclicos que permitem a evolução dos parâmetros $\gamma_{t}^{\prime}$ 's e $\gamma^{*}$ 's com o tempo, então

$$
\gamma_{\mathrm{t}}=\sum_{j=1}^{[s / 2]} \gamma_{\mathrm{j}, \mathrm{t}}
$$

a continuidade de $\gamma_{t}$ é mantida escrevendo-se uma recursão para os [s/2] fatores, então:

$$
\begin{aligned}
& \gamma_{\mathrm{j}, t}=\gamma_{\mathrm{j}, \mathrm{t}-1} \cos \lambda_{\mathrm{j}}+\gamma_{\mathrm{j}, \mathrm{t}-1} \operatorname{sen} \lambda_{\mathrm{j}}+\omega_{\mathrm{jt}} \\
& \gamma_{\mathrm{j}, \mathrm{t}}^{*}=-\gamma_{\mathrm{j}, \mathrm{t}-1} \operatorname{sen} \lambda_{\mathrm{j}}+\gamma_{\mathrm{j}, \mathrm{t}-1}^{*} \cos \lambda_{\mathrm{j}}+\omega^{*}{ }_{\mathrm{jt}}
\end{aligned}
$$

onde $\omega_{j \mathrm{j}} \mathrm{e} \omega^{*}{ }_{\mathrm{j} t}$ são ruídos brancos não correlacionados entre si, com média zero e com variâncias comuns $\sigma^{2}$, para $\mathrm{j}=1,2, \ldots$, [s/2]. Quanto maiores estas variâncias, maior 0 desconto de observações passadas na estimação do padrão sazonal de um instante; $\gamma_{\mathrm{jt}}^{\star}$ aparece por construção. Quando s é par o componente para j = s/2 dispensa a presença de $\gamma^{*}{ }_{\mathrm{jt}}$, e é dado por

$$
\gamma_{j, t}=\gamma_{j, t-1} \cos \lambda_{j}+\omega_{j t} \quad j=s / 2
$$


Apesar de teoricamente se permitir que cada harmônica varie a taxas diferentes, na prática as variâncias $\sigma_{j}^{2}$ são consideradas iguais, pouco é perdido na qualidade da modelagem e há ganho de tempo computacional na estimação dos parâmetros.

As últimas estimativas para os $\gamma_{j \mathrm{j}}$ 's e $\gamma^{*} \mathrm{j}_{\mathrm{j}}$ 's referentes ao tempo $\mathrm{T}$ são os valores projetados para a sazonalidade nas previsões, isto é, o padrão sazonal no último período se repete a cada s períodos futuros.

\section{6 - Modelos estruturais e formas reduzidas}

Combinações dos componentes tendência, ciclo, sazonalidade e irregular acrescidas de suposições sobre as distribuições das perturbações dessas componentes especificam os modelos. A suposição para as distribuições é, quase sempre, a de que elas são normais com média zero e variância constante e não correlacionadas entre si.

O modelo estrutural mais simples é o de nível local ou passeio aleatório mais ruído, que constitui-se de uma tendência e do irregular,

$$
y_{t}=\mu_{t}+\varepsilon_{t}, \quad t=1,2, \ldots, T
$$

onde a tendência, $\mu_{\mathrm{t}}$ é um passeio aleatório

$$
\mu_{t}=\mu_{t-1}+\eta_{t}, \quad t=1,2, \ldots, T
$$

Um modelo de tendência local é a tendência mais perturbação aleatória. Sua formulação é dada por

$$
y_{t}=\mu_{t}+\varepsilon_{t}, \quad t=1,2, \ldots, T
$$

onde $\mu_{t}$ é a tendência dada pelas equações (2.5) e $\varepsilon_{t}$ um irregular, com média zero e variância $\sigma_{\varepsilon}^{2}$, não correlacionado com os termos estocásticos da tendência, $\eta_{t}$ e $\zeta_{t}$. $O$ efeito das suposições de que as três perturbações são não correlacionadas e serialmente independentes para um modelo estrutural qualquer é que sua função de previsão terá forma linear, no caso do modelo (2.22) dada por

$$
\tilde{y}_{T+\pi T}=\tilde{\mu}_{T}+\tilde{\beta}_{T} 4 \quad \ell=1,2, \ldots
$$

onde $\tilde{\mu}_{T}$ e $\tilde{\beta}_{T}$ são as esperanças condicionais de $\mu_{T}$ e $\beta_{T}$ no tempo $T$, e $\iota$ número de passos à frente da última observação, $\mathrm{y}_{\mathrm{T}}$, da série. 
O modelo ciclo mais tendência é descrito como

$$
y_{t}=\mu_{t}+\varphi_{t}+\varepsilon_{t} \quad t=1,2, \ldots, T
$$

onde $\mu_{t}$ pode ser descrito como em (2.5) e $\varphi_{t}$ como em (2.11).

O modelo estrutural básico é a generalização estocástica do modelo estático (2.1), e é escrito como

$$
y_{t}=\mu_{t}+\gamma_{t}+\varepsilon_{t},
$$

onde $\mu_{t}$ é a tendência (2.5), $\gamma_{t}$ é a sazonalidade dummy (2.15) ou trigonométrica (2.17) e $\varepsilon_{t}$ o irregular. As perturbações dos componentes são admitidas não correlacionadas entre si.

Outros modelos estruturais podem ser construidos combinando-se os componentes como descritos anteriormente ou modificando-os; por exemplo, colocando-se uma tendência quadrática ou polinomial no lugar da linear, ou formulando o irregular de modo que reflita características específicas do erro ou permitindo sazonalidade transitória.

Modelos estruturais lineares com perturbaçōes mutuamente não correlacionadas podem ser transformados em modelos estacionários mediante aplicações do operador diferença. Suas formas reduzidas comportam-se como modelos ARIMA nos quais os parâmetros estão restritos a determinadas regiões. A relação entre os dois modelos é verificada observando-se as autocorrelações dos modelos estruturais reduzidos e comparando-as ou com as de um processo ARIMA ou com as de um modelo sazonal SARIMA.

Assim, a escolha de um modelo estrutural aos dados pode ser corroborada, bastando que se compare a função de autocorrelação do modelo teórico com a obtida através da série tornada estacionária por diferenças.

Por exemplo, o modelo nível local (2.20) possui a forma reduzida de um processo $\operatorname{ARIMA}(0,1,1)$; o tendência local (2.22) a de um $\operatorname{ARIMA}(0,2,2)$; o estrutural básico (2.25) com sazonalidade de período $s$ a forma de um modelo $\operatorname{SARIMA}(0,1,1) \times(0,1,1)_{\mathrm{s}}$ ou a de um MA(s+1) quando aplicado o operador diferença nos lags 1 e s, isto é, $\Delta \Delta \Delta_{s} y_{i}$ o ciclo mais irregular a de um $\operatorname{ARMA}(2,2)$; e o ciclo mais tendência a de um $\operatorname{ARIMA}(2,2,4)$; ver Harvey (1989), páginas 68 a 70.

Portanto, embora as duas metodologias possam ser consideradas equivalentes em termos de formas reduzidas, são abordagens diferentes, uma vez que na metodologia de 
Box \& Jenkins é necessário tomar diferenças para induzir estacionariedade e, portanto, perde-se informação do nível da série, o que não acontece com a modelagem estrutural.

Os modelos ARIMA têm seu valor, mas apresentam algumas complicações e limitações. A suposição de que as séries se tornam estacionárias após a aplicação de diferenças pode ser uma delas, principalmente para as séries econômicas brasileiras que têm quebras estruturais, sendo os testes usados para determinar a ordem de diferenciação sensíveis a estas quebras, embora exista uma vasta literatura econométrica sobre testes de raízes unitárias com quebras estruturais (ver Stock(1994) para uma resenha). Processos pouco complicados que envolvem ciclos ou sazonalidades têm funções de autocorrelações bastante complexas, dificultando a identificação do modelo ARIMA apropriado.

Enfim, há vantagens que aconselham a utilização do modelo estrutural, além dele possuir uma interpretação mais natural e fazer bastante sentido para séries econômicas.

\section{7 - Modelos estruturais multivariados}

Para os modelos estruturais multivariados, os componentes isolados do modelo univariado são substituídos por vetores de componentes, e os hiperparâmetros (variâncias dos estados) por matrizes de covariância. Modelos multivariados com perturbações mutuamente não correlacionadas em todos períodos são citados na literatura como seemingly unrelated time series equations (SUTSE).

A metodologia de ajuste permite que se construam modelos nos quais duas ou mais séries possuam componentes comuns. Assim, o nível e a taxa de inclinação da tendência, a sazonalidade, o ciclo e até mesmo o irregular, muito embora neste caso faça pouco sentido, podem ser comuns a duas ou mais séries. Um modelo multivariado pode, para determinado componente, conter uma ou mais de uma fonte de variação. Por exemplo, num modelo multivariado para quatro séries pode-se ter uma tendência comum para as quatro séries ou duas tendências comuns, uma para cada grupo de duas séries.

A ocorrência de fatores comuns está relacionada com a existência de pelo menos uma perturbação que é combinação linear de outras. Isto acarreta em restrições que são materializadas na matriz de covariância que neste caso terá posto reduzido. A 
decomposição de Cholesky da matriz de covariância fornece a matriz de carga (factor loading) que relaciona os componentes comuns do modelo.

Para os modelos sem variáveis explicativas não estacionárias, a presença de níveis ou tendências comuns implica co-integração das séries, indicando, no caso de séries integradas de ordem 1, que há combinações lineares das séries que são estacionárias e que estão associadas a um termo de longo prazo das séries.

Um modelo é dito um sistema homogêneo caso as matrizes de covariância das perturbações dos componentes sejam proporcionais. Neste caso, as restrições se dão entre as matrizes e não dentro das matrizes de covariância.

A tendência pode ter o nível ou a taxa de crescimento ou ambos comuns. Existe o modelo de tendência homogênea em que as correspondentes matrizes de covariância são proporcionais.

Os ciclos comuns são proporcionais entre si, mas, em geral, não se considera esta hipótese na estimação por razões de parcimônia. Inclusive, pelo mesmo motivo, admitese, quase sempre, ciclos similares, ou seja, um único ciclo para as diversas séries dependentes.

Geralmente quando se tem um fator comum, um componente apresenta alta correlação entre os estados associados das diversas séries. Contudo, a existência de correlações altas não implica fatores comuns.

Por exemplo, duas séries podem possuir sazonalidades estimadas correlacionadas mas covariância das perturbações baixa, indicando que as mudanças da sazonalidade não são comuns, ou, não possuem a mesma fonte. A correlação significante é determinada pelo padrão existente nas sazonalidades, numa espécie de regressão espúria.

Há, ainda, a possibilidade de se terem fatores comuns somente em freqüências específicas da sazonalidade, implicando co-integração sazonal em freqüências diferentes.

\section{8 - Variáveis independentes e intervenções}

A introdução de variáveis explicativas no modelo estrutural, causando um misto de análise de regressão e de série temporal, é permitida e não acrescenta dificuldades para sua estimação. Presenças das variáveis são aconselháveis quando trouxerem ganho na 
qualidade de ajuste ou de previsão do modelo, porém, deve-se estar ciente que as previsões desejadas para as séries dependentes estarão condicionadas a cenários definidos para as variáveis dependentes.

As variáveis são importantes para se observar como se comportam as séries dependentes sob cenários alternativos e para se buscar uma estabilidade dos parâmetros do modelo em séries que apresentam quebras estruturais.

Os estimadores dos parâmetros destas variáveis, que, em geral, são admitidos não variarem no tempo, podem ser interpretadas de maneira semelhante a do modelo de regressão padrão, possuindo assintoticamente distribuição normal quando não se conhece as perturbações dos componentes.

Em várias situações a inclusão de intervenções nos componentes são necessárias. Estas intervenções são aconselháveis nos períodos em que as séries apresentarem quebras estruturais ou outliers, que derivam de situações associadas às mudanças de regimes ou a qualquer evento específico. A estimação e avaliação dos parâmetros destas intervenções se dão do mesmo modo que as das variáveis explicativas.

No caso de um outlier, aditivo, a intervenção na equação do modelo é representada por uma variável dummy que tem valor 1 no período e 0 nos outros. Esta intervenção está associada a um valor extremo para o irregular da série em um dado instante do tempo.

Uma quebra estrutural no nível $\left(\mu_{\mathrm{t}}\right)$ da tendência está relacionada com uma alteração no patamar da série. A intervenção para esta característica pode ser representada por uma variável dummy na equação do modelo que tenha o valor 1 num período específico e após ele, e valor 0 antes. Ou equivalentemente por uma intervenção diretamente no nível da tendência. Sua necessidade pode ser diagnosticada por valor discrepante nas perturbações do nivel.

A inclinação $\left(\beta_{t}\right)$ da tendência pode apresentar quebra, modelada, por exemplo, por uma variável com valor 1 para o período seguinte ao ocorrido e sucessivamente valores $2,3,4, \ldots$ sucessivamente para os períodos seguintes. É detectada através de valores grandes nos resíduos da inclinação da tendência. 


\section{9 - Previsões}

As previsões, de modo geral, são obtidas a partir de extrapolações de um modelo estimado mediante a minimização de alguma função perda, por exemplo, o erro quadrático médio (EQM). É comum serem denotadas por $\hat{y}_{\mathrm{T}+\pi}$, onde $l$ é um inteiro positivo que representa a distância, número de passos, entre o último valor observado da série e o valor que se deseja prever.

Para um modelo de série temporal puro, isto é sem variáveis explicativas, as previsões são, em geral, obtidas através de uma função de previsão que extrapola as estimativas dos componentes para o último instante de tempo da amostra.

Desse modo, por exemplo, tanto para sazonalidade determinística como para estocástica, a função de previsão considera a sazonalidade futura com padrão constante, isto é a sazonalidade será constante, sendo igual à obtida para os últimos períodos da amostra.

Para os modelos estruturais com variáveis explicativas contemporâneas ou defasadas, é obrigatório para a obtenção da função de previsão que estejam disponíveis valores das variáveis independentes após o último período da amostra utilizada na estimação. Se estes valores futuros forem desconhecidos, eles podem ser previstos por algum modelo ou determinados de modo a refletirem cenários específicos.

Com as previsões sendo obtidas por um modelo estatístico, o erro quadrático médio (EQM), que é a esperança do quadrado do erro de previsão a um passo, pode ser calculado. O EQM é a função perda mais utilizada e é dado por

$$
\mathrm{E}\left(\mathrm{y}_{\mathrm{T}+1}-\hat{y}_{\mathrm{T}+1}\right)^{2}
$$

Intervalos de confiança para as previsões são construídos considerando a raiz do EQM (REQM) e supondo uma distribuição para os dados, o que quase invariavelmente quer dizer normal. Quanto mais o tempo da previsão se afasta do último valor disponível para a série, Ут, maior será o intervalo estimado, refletindo a crescente incerteza das previsões.

A previsão ótima, que minimiza o EQM, para $l$ passos a frente da última observação é o valor esperado de $\mathrm{y}_{\mathrm{T}+} /$ condicionado em todo conjunto de informações até o tempo $\mathrm{T}$, isto é, $\mathrm{Y}_{\mathrm{T}}=\left\{\mathrm{y}_{1}, \mathrm{y}_{2}, \ldots, \mathrm{y}_{\mathrm{T}}\right\}$, escrito como

$$
\tilde{y}_{\mathrm{T}+\ell \mathrm{T}}=\mathrm{E}\left(\mathrm{y}_{\mathrm{T}+d} \mathrm{Y}_{\mathrm{T}}\right), \quad \ell=1,2, \ldots
$$


O fato de (2.27) minimizar o EQM é verificado observando-se que para qualquer previsor, $\hat{y}_{T+\iota \pi}$, construído com base no conjunto de informação $Y_{T}$, o erro de previsão estimado pode ser dado por

$$
\mathrm{y}_{\mathrm{T}+\ell}-\hat{y}_{\mathrm{T}+\ell \pi}=\left[\mathrm{y}_{\mathrm{T}+\ell}-\mathrm{E}\left(\mathrm{y}_{\mathrm{T}+} d \mathrm{Y}_{\mathrm{T}}\right)\right]+\left[\mathrm{E}\left(\mathrm{y}_{\mathrm{T}+} d \mathrm{Y}_{\mathrm{T}}\right)-\hat{y}_{\mathrm{T}+\ell \mathrm{T}}\right]
$$

Como o último termo do lado direito da expressão (2.28) é fixo em $\mathrm{T}$, quando se eleva (2.28) ao quadrado e toma-se a esperança condicional em $Y_{T}$, o termo derivado do produto dos termos à direita na equação (2.28) é igual a zero e desaparece, tem-se então

$$
\operatorname{EQM}\left(\hat{y}_{\mathrm{T}+\ell \mathrm{T}}\right)=\operatorname{Var}\left(\mathrm{y}_{\mathrm{T}+} N_{\mathrm{T}}\right)+\left[\hat{y}_{\mathrm{T}+\ell \mathrm{T}}-\mathrm{E}\left(\mathrm{y}_{\mathrm{T}+} / Y_{\mathrm{T}}\right)\right]^{2}
$$

A variância condicional de $y_{T+\iota}$ não depende de $\hat{y}_{T+\iota r}$. Então, o EQM de um previsor que considera o conjunto de informação $Y_{T}$ é mínimo somente quando este previsor é igual à média condicional dada em (2.27). Por esta propriedade $E\left(y_{t_{+}} / Y_{T}\right)$ é dito o estimador erro quadrático médio mínimo (EQMM) para $\mathrm{y}_{\mathrm{T}+4}$

O filtro de Kalman, sob normalidade, dará como resultado estimativas ótimas para os hiperparâmetros e parâmetros. Sem normalidade, as estimativas do filtro serão as ótimas entre as lineares.

A estimação dos parâmetros é realizada maximizando-se a função de verossimilhança que é decomposta em função dos erros de previsão.

\section{3 - Filtro de Kalman e representação em espaço de estado}

\section{1 - Introdução}

A colocação de modelos de séries temporais na representação em espaço de estado cria possibilidade para a aplicação do filtro de Kalman, um algoritmo que fornece os erros de previsão a um passo à frente que são úteis para:

i) construção da verossimilhança;

ii) diagnóstico do modelo;

iii) extração de sinal, i.e., obtenção de estimativas para o vetor de estados das séries;

iv) previsões futuras. 


\section{2 - Representação em espaço de estado}

A principal característica da REE é relacionar linearmente variáveis observadas com outras variáveis, geralmente não observadas diretamente, que podem evoluir ao longo do tempo segundo leis específicas de formação. Os modelos estruturais para séries temporais são facilmente representados sob essa forma.

A REE é um sistema composto por duas equações que podem ser escritas de diversas maneiras. Uma dessas equações relaciona o vetor de medida $y_{t}$ (valores observados), de dimensão $N$, em cada tempo t, com o vetor de estado $\alpha_{t},(m \times 1)$, que representa as componentes não observadas, o vetor $d_{t,}(N \times 1)$, e o vetor de perturbações aleatórias $\varepsilon_{t}(\mathrm{~N} \times 1)$, conforme a seguinte equação

$$
y_{t}=z_{t} \alpha_{t}+d_{t}+\varepsilon_{t} \quad t=1,2, \ldots, T
$$

onde, $Z_{\mathrm{t}}(\mathrm{N} \times \mathrm{m})$ é uma matriz de sistema conhecida (não estocástica), que pode variar ao longo do tempo, $d_{t}$ são variáveis exógenas que podem influenciar as observações, por exemplo, dummies ou variáveis explicativas, e $\varepsilon_{t}$ um vetor de perturbaçōes serialmente não correlacionadas, com média zero e matriz de covariância $H_{t}$, ou seja, $E\left(\varepsilon_{t} \varepsilon_{\tau}^{\prime}\right)$ é igual a $H_{t}$ para $t=\tau$, e a 0 , caso contrário. A equação 3.1. a é conhecida como equação de medida (ou observacional).

A outra equação, chamada de equação de transição, mostra a evolução do vetor de estados, $\alpha_{\mathrm{t}}$, como um processo markoviano auto-regressivo de primeira ordem, relacionando-o com seu valor anterior, $\alpha_{+1}$, com um vetor $c_{t}$ de variáveis exógenas de dimensão $\mathrm{m}$, e com o vetor de distúrbios aleatórios $\eta_{\mathrm{t}}$ de dimensão g. Assim,

$$
\alpha_{t}=T_{t} \alpha_{t-1}+c_{t}+R_{t} \eta_{t} \quad t=1,2, \ldots, T
$$

onde $T_{t}(m \times m)$ é a matriz de transição, conhecida, dos coeficientes auto-regressivos, $R_{t}$ é uma matriz $(\mathrm{mxg})$ e $\eta_{\mathrm{t}}$ é um vetor de perturbações serialmente não correlacionadas com média igual a zero e matriz de covariância igual a $Q_{t}$.

Para complementar a especificação do modelo, supõe-se que o vetor de estado inicial $\alpha_{0}$ tem média zero e matriz de covariância $P_{0}$, e que as perturbaçōes $\varepsilon_{t}$ e $\eta_{t}$ são não correlacionadas entre si e também com o estado inicial em todos períodos, ou seja, $E\left(\varepsilon \eta^{\prime}{ }^{\prime}\right)=0, E\left(\varepsilon_{1} \alpha^{\prime}{ }_{0}\right)=0$ e $E\left(\eta_{1} \alpha_{0}^{\prime}{ }_{0}\right)=0$, para $s, t=1,2, \ldots, T$. 
O modelo descrito é uma representação geral e pode ser usado nos modelos estruturais. Neste caso, algumas das matrizes de representação podem ser invariantes no tempo e deste modo o índice temporal é desnecessário.

Como conseqüência das equações e das suposições, o sistema será linear, com os valores de $y_{t}$ podendo ser descritos em função somente das perturbações do sistema e do estado inicial.

Os modelos não têm uma representação em espaço de estado única, sendo considerada ideal a que minimiza a dimensão do vetor de estado. Essas representações podem contemplar modelos com variáveis explicativas e intervenções. Por exemplo, o vetor $d_{t}$ pode representar variáveis explicativas e/ou intervenções em pontos aberrantes com seus respectivos coeficientes e o vetor $c_{t}$ pode conter intervençöes nos estados (quebras estruturais).

Para os modelos sem ciclos e sem defasagens nas variáveis dependentes, como os que serão propostos neste estudo, os parâmetros dos modelos representando as variações dos componentes não observados estarão presentes nas matrizes $H_{t} \in Q_{t}$. Estes parâmetros desconhecidos são denominados hiperparâmetros, assim chamados para diferenciá-los dos parâmetros que os modelos possam possuir em decorrência da presença de variáveis explicativas e intervenções. Em geral, os hiperparâmetros são constantes. Conforme Lopes, Schmidt e Moreira (1996), os hiperparâmetros quantificam propriedades dos modelos que são constantes ao longo da amostra e que condicionam e estabelecem relações não lineares com os demais parâmetros do modelo.

\section{3 - Filtro de Kalman}

Ao se especificar um modelo na representação em espaço de estado é possível utilizar um algoritmo recursivo, filtro de Kalman, para os erros de previsão a um passo à frente e suas respectivas variâncias e como subproduto estimativas dos vetores de estado.

Em um modelo com um estado inicial especificado, o filtro de Kalman fornece, baseado em toda informação disponivel até e inclusive o instante t, i.e., $Y_{t}=\left[y_{1}, y_{2}, \ldots, y_{t}\right]$, o previsor linear ótimo para o vetor de estado no período $t$, assim considerado o que apresenta o erro quadrático médio mínimo. Se valer a suposição de distribuição normal 
para as perturbações e para o estado inicial, esse previsor será ótimo dentre todos e não só na classe dos lineares.

Então, seja $a_{t}$ o previsor linear ótimo de $\alpha_{t}$ considerando $Y_{t}$, isto é, $a_{t}=E\left(\alpha_{t} \mid Y_{t}\right)$ e seja $P_{t}$ a matriz $(m \times m)$ de covariância do erro de previsão associado, denominada matriz do erro quadrático médio de $\mathbf{a}_{\mathrm{t}}$, isto é,

$$
P_{t}=E\left[\left(\alpha_{t}-a_{t}\right)\left(\alpha_{t}-a_{t}\right)^{\prime}\right]
$$

Como conseqüência, a partir de um modelo sob a REE (sistema 3.1), admitindo-se que no momento $t$ sejam conhecidos $a_{t-1}$ e $\mathbf{P}_{t-1}$, tem-se que o previsor linear ótimo de $\alpha_{t}$ baseado em $\mathbf{a}_{t-1}$, considerando-se a equação de transição, será

$$
a_{t t t-1}=T_{t} a_{t-1}+c_{t}
$$

e a medida de dispersão associada a esta previsão é dada pela matriz de covariância

$$
P_{t \mid t-1}=T_{t} P_{t-1} T_{t}^{\prime}+R_{t} Q_{t} R_{t}^{\prime}
$$

As equaçöes 3.3 são as equações de previsão do filtro de Kalman, a partir delas e da equação de medida 3.1.a, pode-se obter o previsor de $\mathbf{y}_{\mathrm{t}}$, usando a informação até o instante $\mathrm{t}-1$, i.e.,

$$
\widetilde{y}_{t \mid t-1}=Z_{t} a_{t t \mid-1}+d_{t}
$$

por conseqüência, os erros de previsão ou as inovações, que representam a nova informação fornecida pela última observação, serão dados por

$$
v_{t}=y_{t}-\widetilde{y}_{t t-1}=Z_{t}\left(\alpha_{t}-a_{t t}-1\right)+\varepsilon_{t}
$$

Condicionado a $\mathbf{Y}_{t}, E\left[\mathbf{V}_{t}\right]$ é igual a zero e a matriz do EQM destas inovações será

$$
F_{t}=Z_{t} P_{t t-1} Z_{t}^{\prime}+H_{t}
$$

pois $E\left[v_{t} v_{t}^{\prime}\right]=E\left\{\left[Z_{t}\left(\alpha_{t}-a_{t t \mid-1}\right)+\varepsilon_{t}\right]\left[Z_{t}\left(\alpha_{t}-a_{t \mid t-1}\right)+\varepsilon_{t}\right]^{\prime}\right\}$

$$
\begin{aligned}
& =E\left\{Z_{t}\left(\alpha_{t}-a_{t t \mid-1}\right)\left(\alpha_{t}-a_{t \mid t-1}\right)^{\prime} Z_{t}^{\prime}+\varepsilon_{t} \varepsilon_{t}^{\prime}+Z_{t}\left(\alpha_{t}-a_{t t t-1}\right) \varepsilon_{t}^{\prime}+\varepsilon_{t}\left(\alpha_{t}-a_{t t-1}\right)^{\prime} Z_{t}^{\prime}\right\} \\
& =Z_{t} P_{t \mid t-1} Z_{t}^{\prime}+H_{t}
\end{aligned}
$$

já que as esperanças de $\left[\left(\alpha_{t}-a_{t \mid t-1}\right) \varepsilon^{\prime}\right]$ e de seu transposto são iguais a zero.

Com uma nova observação $y_{t}$, previsões atualizadas de $a_{t}$ e de $P_{t}$ para o estado contemporâneo podem ser obtidas pelas equações 


$$
a_{t}=a_{t t-1}+P_{t t-1} Z_{t}^{\prime} F_{t}^{-1}\left(y_{t}-Z_{t} a_{t t-1}-d_{t}\right)
$$

e

$$
P_{t}=P_{t \mid t-1}-P_{t \mid t-1} Z^{\prime} F_{t}^{-1} Z_{t} P_{t \mid t-1}
$$

Essas equações de atualização do filtro de Kalman, sob suposição de normalidade das perturbações $\varepsilon_{t}$ e $\eta_{t}$, e do vetor de estado inicial $\alpha_{0}$, neste caso com média $a_{0}$ e matriz de covariância $P_{0}, e$, ainda, de distribuições independentes entre si, podem ser derivadas repetindo-se o procedimento a seguir para se conhecer a distribuição de $\alpha_{1}$ condicionado em $\mathbf{y}_{1}$.

Escrevendo-se

$$
\begin{aligned}
& \alpha_{1}=\mathbf{a}_{1 \mid 0}+\left(\alpha_{1}-\mathbf{a}_{1 \mid 0}\right) \\
& \mathbf{y}_{1}=\mathbf{z}_{1} \mathbf{a}_{1 \mid 0}+\mathbf{d}_{1}+\mathbf{z}_{1}\left(\alpha_{1}-\mathbf{a}_{1 \mid 0}\right)+\varepsilon_{1}
\end{aligned}
$$

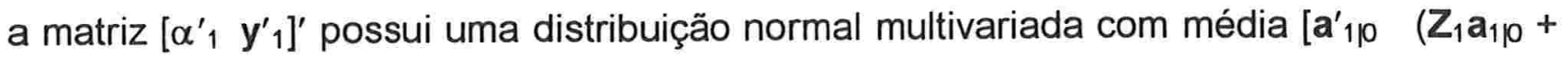
$\left.\left.d_{1}\right)^{\prime}\right]^{\prime}$ e matriz de covariância

$$
\left|\begin{array}{cc}
\mathbf{P}_{1 \mid 0} & \mathbf{P}_{1 \mid 0} \mathbf{Z}^{\prime} \\
\mathbf{Z}_{1} \mathbf{P}_{1 \mid 0} & \mathbf{Z}_{1} \mathbf{P}_{1 \mid 0} \mathbf{Z}^{\prime}{ }_{1}+\mathbf{H}_{1}
\end{array}\right|
$$

Segue-se por um lema aplicado à distribuição normal multivariada, ver, por exemplo, Harvey (1989), página 165, a distribuição de $\alpha_{1}$ condicionada em um determinado valor de $y_{1}$ é normal multivariada com média

$$
a_{1}=a_{1 \mid 0}+P_{1 \mid 0} Z_{1}^{\prime} F_{1}{ }^{-1}\left(y_{1}-Z_{1} a_{1 \mid 0}-d_{1}\right)
$$

e matriz de covariância igual a

$$
\mathbf{P}_{1}=\mathbf{P}_{1 \mid 0}-\mathbf{P}_{1 \mid 0} \mathbf{Z}^{\prime} \mathbf{F}_{1}{ }^{-1} \mathbf{Z}_{1} \mathbf{P}_{1 \mid 0} \quad \text { onde } \mathbf{F}_{1}=\mathbf{Z}_{1} \mathbf{P}_{1 \mid 0} \mathbf{Z}^{\prime}{ }_{1}+\mathbf{H}_{1} \text {. }
$$

Os cálculos das médias e matrizes de covariância dos estados, $\alpha_{t}$, condicionados em informações até e inclusive às suas ocorrências, efetuados para os diversos valores de $t$, resultam exatamente nas quantidades calculadas pelas equações de atualização do filtro de Kalman. Então, o filtro obtém a média e a matriz de covariância de $\alpha_{t}$ condicionado nas informações até e inclusive o instante t.

É possivel mostrar que o previsor $\mathbf{a}_{\mathrm{t}}$, supondo-se normalidade, é o previsor EQMM de $\alpha_{t}$ e que $P_{t}$ é EQM associado a $a_{t}$ sendo independente das observações. 
Sem normalidade, $a_{t}$ é o previsor que minimiza o erro quadrático médio dentro da classe dos lineares nas observações, sendo referido como previsor linear de erro quadrático médio mínimo de $\alpha_{t} ; P_{t}$ é EQM associado a $a_{t}$.

Essas conclusões valem também para $\mathbf{a}_{t \mid t-1}, P_{t \mid t-1}$ e $\widetilde{y}_{t \mid t-1}$, ou seja, eles são previsores de erro quadrático médio mínimo sob normalidade e no mínimo previsores lineares de erro quadrático médio mínimo sem normalidade.

Percebe-se por 3.7.a que o vetor de inovações tem grande importância na atualização de $a_{t}$, que é igual à previsão condicionada à informação disponível até o instante $\mathrm{t}-1$ acrescida de um termo diretamente associado ao erro de previsão. Assim, quanto maior (menor) o erro, maior (menor) a correção na previsão do vetor de estado $\alpha_{t}$ usando a informação até t. Se o erro for igual a 0 , a previsão atualizada é idêntica à previsão condicionada a $\mathbf{Y}_{t-1}$.

Com valores atualizados de $\mathbf{a}_{\mathrm{t}}$ e $\mathbf{P}_{\mathrm{t}}$ e com as equações de previsão 3.3 são obtidos

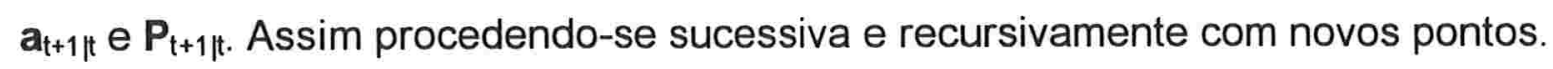

Desse modo, o filtro de Kalman é constituído pelos conjuntos de equações $3.3 \mathrm{e}$ 3.7. As equações podem ser rescritas, por exemplo, levando-se as informaçōes disponíveis em $t-1$ diretamente para $t+1$. Pelas substituições de 3.7.a e 3.7.b nas equações de previsão 3.3 resultam

$$
a_{t+1 \mid t}=\left(T_{t+1}-K_{t} Z_{t}\right) a_{t \mid t-1}+K_{t} y_{t}+\left(c_{t+1}-K_{t} d_{t}\right)
$$

onde $\mathrm{K}_{\mathrm{t}}$, chamado ganho do filtro, é definido por

$$
K_{t}=T_{t+1} P_{t \mid t-1} Z_{t}^{\prime} F_{t}^{-1}
$$

e

$$
P_{t+1 \mid t}=T_{t+1}\left(P_{t \mid t-1}-P_{t t \mid-1} Z_{t}^{\prime} F_{t}^{-1} Z_{t} P_{t \mid t-1}\right) T_{t+1}^{\prime}+R_{t+1} Q_{t+1} R_{t+1}^{\prime}
$$

conhecida como equação de Riccati.

No caso de modelos com matrizes de sistema invariantes no tempo e sob certas condições, ver Harvey (1989), páginas 115 a 119, a matriz de covariância $\mathbf{P}_{\mathbf{t + 1 | t}}$ a partir de algum momento pode ficar invariante no tempo, ou seja

$$
\mathbf{P}_{\mathrm{t}+1 \mid \mathrm{t}}=\mathbf{P}_{\mathrm{t|t-1}}=\overline{\mathbf{P}}
$$


Neste caso, diz-se que o filtro de Kalman atingiu o estado de equilíbrio, ocasionando um aumento da eficiência no tempo de cálculo do algoritmo. $O$ valor de $\bar{P}$ é obtido solucionando-se a equação de Ricatti que sob as condições estabelecidas será

$$
\overline{\mathbf{P}}-\mathrm{T} \overline{\mathbf{P}} \mathrm{T}^{\prime}+\mathrm{T} \overline{\mathrm{P}} \mathbf{Z}^{\prime} \mathbf{F}^{-1} Z \overline{\mathbf{P}} T^{\prime}-R Q R^{\prime}=0
$$

Em suma, a partir de valores para $\mathbf{a}_{t-1}$ e $\mathbf{P}_{t-1}$, o filtro é calculado recursivamente através da rotina:

1) conseguir $\mathbf{a}_{t t t-1}$ e $\mathbf{P}_{t t t-1}$ pelas equações de previsão (3.3);

2) conseguir $v_{t}$ (3.5) e $F_{t}(3.6)$;

3) com o valor observado seguinte da série, obter $\mathbf{a}_{t}$ e $\mathbf{P}_{t}$ pelas equações de atualização (3.7);

4) repetir até o último dado da amostra e para novos valores quando conhecidos.

Com os valores de $v_{t}$ e $F_{t}$, a função de verossimilhança decomposta em termos dos erros de previsão pode então ser construída. A maximização desta função por algum método numérico fornece os estimadores de máxima verossimilhança para os hiperparâmetros e para os coeficientes dos regressores.

Porém, uma questão anterior à estimação dos parâmetros através da função de verossimilhança é o conhecimento de $\mathrm{a}_{0}$ e $\mathrm{P}_{0}$, os valores iniciadores do filtro de Kalman, tendo em vista que são necessários pontos de partida para a média e para a matriz de covariância do vetor de estado para o filtro se iniciar.

\section{4 - Condições iniciais}

O valor inicial para $\alpha_{0}$ pode ser fixo e conhecido, ou, estocástico e desconhecido.

Quando o vetor de estado é composto por componentes estacionários, um procedimento ótimo para escolha dos valores iniciais é considerar a média e a matriz de covariância da distribuição não condicional - a priori - de $\alpha_{0}$.

Se, além da estacionariedade dos componentes do estado inicial, as matrizes para a equação de transição da representação em espaço de estado forem invariantes no tempo, a média e a matriz de covariância da distribuição de $\alpha_{0}$ são dados por:

$$
a_{0}=(I-T)^{-1} C
$$


e, sendo $P_{0}$ a solução direta de $P_{0}=T P_{0} T^{\prime}+R Q R^{\prime}$, por

$$
\operatorname{vec}\left(P_{0}\right)=[I-T \otimes T]^{-1} \operatorname{vec}\left(R Q R^{\prime}\right)
$$

onde $\otimes$ denota o produto de Kronecker e o operador vec(.) representa o vetor resultante da colocação uma em cima da outra das colunas de uma matriz.

Quando não há estacionariedade do vetor de estado, a solução preferida é assumir que $\alpha_{0}$ é uma variável com distribuição a priori difusa (vaga). Em geral, $\alpha_{0} \sim \mathrm{N}(0, \Lambda)$ com $\Lambda \rightarrow \infty$, ou equivalentemente $\Lambda^{-1} \rightarrow 0$.

Esta suposição é bastante razoável, pois significa admitir total desconhecimento do vetor de estado inicial.

Na prática, utiliza-se a aproximação $\Lambda=\mathbf{k l}$, com $\mathbf{k}$ um número grande, o que pode trazer uma certa instabilidade aos cálculos.

Este empecilho pode ser amenizado admitindo como covariância a solução $\bar{P}$ do estado de equilibrio. No procedimento de estimação, essa matriz de parâmetros invariantes no tempo pode ser concentrada fora da verossimilhança, cuja maximização se reduz, então, à minimização de $\mathbf{v}_{\mathbf{t}} \mathbf{v}_{\mathrm{t}}{ }^{\prime}$.

Uma abordagem mais geral para a estimação dos parâmetros da distribuição de $\alpha_{0}$, é a utilização de um filtro de Kalman difuso ou aumentado que busca valores iniciais para o filtro tradicional.

O filtro de Kalman difuso é o filtro usual acrescido de equações que tratam as situações difusas que surgem quando o estado inicial ou os parâmetros da regressão são desconhecidos e modelados como variáveis aleatórias com matriz de covariâncias grandes, que tendem ao infinito.

\section{5 - Filtro de Kalman difuso}

A aproximação descrita para o filtro de Kalman difuso é a adotada no programa STAMP (Structural Time Series Analyser, Modeller and Predictor), que está próxima da sugerida em de Jong (1991).

As vantagens do filtro aumentado são sua vasta utilidade, já que pode ser utilizado até com dados incompletos ou com modelos cujos parâmetros variam ao longo do tempo; o tratamento dado aos parâmetros dos regressores, que são excluídos do vetor de estado, evitando uma pior estimação para os valores iniciais. Enfim, é consenso que esta 
metodologia fornece resultados mais adequados sem despender maiores esforços, até mesmo o tempo computacional extra de cálculo é irrisório.

Para melhor compreensão é apresentada a representação em espaço de estado usada no STAMP, que é apropriada para o filtro de Kalman difuso. As equações do sistema da REE são dadas por

$$
\begin{aligned}
& y_{t}=Z_{t} \alpha_{t}+X_{t} b+G_{t} u_{t} \\
& \alpha_{t+1}=T_{t} \alpha_{t}+W_{t} b+H_{t} u_{t}
\end{aligned}
$$

valendo as seguintes suposições:

i) $\mathbf{u}_{\mathrm{t}} \sim \operatorname{NID}\left(0, \sigma^{2} \mathrm{I}\right)$;

ii) quando $\alpha_{0}=0$ tem-se $\alpha_{1}=W_{0} b+H_{0} u_{0}$;

iii) $\mathbf{b}=\mathbf{B} \delta$, onde $\delta \sim \mathrm{N}\left(\mu, \sigma^{2} \Lambda\right)$;

iv) $\delta$ e $u_{t}$ são não correlacionados;

v) $\mathbf{G}_{t}{ }^{\prime} \mathbf{H}_{t}=0$, implicando que $\mathbf{G}_{t} \mathbf{u}_{t} \in H_{t} \mathbf{u}_{t}$ ortogonais, distribuídos independentemente. As matrizes $Z_{t}$ e $T_{t}$ são fixas e em várias situações são invariantes no tempo, enquanto $\mathbf{X}_{\mathrm{t}}$ e $\mathbf{W}_{\mathrm{t}}$ são conhecidas. A matriz $\mathbf{X}_{\mathbf{t}}$ engloba as variáveis explicativas e intervenções para tratar pontos aberrantes, enquanto $\mathbf{W}_{t}$ incorpora as intervenções que estão relacionadas a quebras estruturais nas variáveis não observadas, i.e., o vetor de estado. As matrizes $H_{t} e$ $\mathrm{G}_{\mathrm{t}}$ contém os hiperparâmetros a serem estimados.

Essa representação tem aplicação no tratamento de modelos que possuam componentes não estacionários e coeficientes em b não conhecidos a priori.

A justificativa para se ter o vetor de parâmetros b nas duas equações do sistema é a abrangência possibilitada para o tratamento de diversos modelos. Vale notar que b define parcialmente o estado inicial.

O vetor $\delta$ do sistema é subdividido em duas partes, correspondentes aos efeitos dos regressores $(x)$ e aos efeitos iniciais (i), sendo representado por $\left(\delta_{\mathbf{x}}, \delta_{\mathrm{i}}\right)$. O mesmo ocorre com a matriz $\mathbf{B}$, isto é, $\mathbf{B}=\left(\mathbf{B}_{x}, \mathbf{B}_{\mathrm{i}}\right)$. Como conseqüência $\mathbf{b}=\mathbf{B}_{x} \delta_{x}+\mathbf{B}_{i} \delta_{i}$ e

$$
\begin{array}{lllll}
\mathbf{X}_{\mathrm{t}} \mathbf{b}=\mathbf{X}_{\mathrm{t}}^{*} \delta_{\mathrm{x}} & \text { com } & \mathbf{X}_{\mathrm{t}}^{*}=\mathbf{X}_{\mathrm{t}} \mathbf{B}_{\mathrm{x}} & \text { e } & \mathbf{X}_{\mathrm{t}} \mathbf{B}_{\mathrm{i}}=\mathbf{0} \\
\mathbf{W}_{\mathrm{t}} \mathbf{b}=\mathbf{W}_{\mathrm{t}}^{*} \delta_{\mathrm{x}} & \text { com } & \mathbf{W}_{\mathrm{t}}^{*}=\mathbf{W}_{\mathrm{t}} \mathbf{B}_{\mathrm{x}} & \text { e } & \mathbf{W}_{\mathrm{t}} \mathbf{B}_{\mathrm{i}}=\mathbf{0}
\end{array}
$$




$$
W_{0} b=W_{0}^{*} \delta_{i} \quad \text { com } \quad W_{0}^{*}=W_{0} B_{i} \quad \text { e } \quad W_{0} B_{x}=0 .
$$

O filtro de Kalman utilizado no STAMP também é um pouco diferente do descrito, ele calcula para o caso em que $\delta=0$, ou seja, quando da não existência de variáveis explicativas e de componentes não estacionárias

$$
\begin{aligned}
& \mathbf{a}_{t \mid t-1}=E\left(\alpha_{t} \mid Y_{t-1}, \delta=0\right) \\
& \left.\sigma^{2} P_{t \mid t-1}=E\left\{\left(\alpha_{t}-a_{t \mid t-1}\right)\left(\alpha_{t}-a_{t \mid t-1}\right)^{\prime} \mid Y_{t-1}, \delta=0\right\}\right)
\end{aligned}
$$

O conjunto de equações abaixo são fundamentais para a construção da função de verossimilhança:

$$
\begin{aligned}
& \mathbf{v}_{\mathrm{t}}=\mathbf{y}_{\mathrm{t}}-\mathbf{X}_{\mathrm{t}} \mathbf{b}-\mathbf{Z a}_{\mathrm{tt} t-1} \quad \mathrm{~F}_{\mathrm{t}}=\mathrm{ZP}_{\mathrm{tt|t-1}} \mathbf{Z}^{\prime}+\mathbf{G G}^{\prime} \\
& \mathrm{q}_{\mathrm{t}}=\mathrm{q}_{\mathrm{t}-1}+\mathbf{v}_{\mathrm{t}}^{\prime} \mathrm{F}_{\mathrm{t}}^{-1} \mathbf{v}_{\mathrm{t}} \quad \mathrm{K}_{\mathrm{t}}=\mathrm{TP}_{\mathrm{tt|}-1} \mathbf{Z}^{\prime} \mathbf{F}_{\mathrm{t}}^{-1} \\
& a_{t+1 \mid t}=T a_{t \mid t-1} T^{\prime}-W_{t} b+K_{t} V_{t} \quad P_{t+1 \mid t}=T P_{t \mid t-1} T^{\prime}-K_{t} F_{t} K_{t}^{\prime}+H H^{\prime}
\end{aligned}
$$

com $\mathbf{a}_{1 \mid 0}=\mathbf{W}_{0} \mathbf{b}, \mathbf{P}_{1 \mid 0}=\mathbf{H}_{0} H_{0}{ }^{\prime}$ e $q_{0}=0$; onde a matriz do erro quadrático médio do vetor de inovações $v_{t}$, é dada por $\sigma^{2} F_{t}$. A estimativa para $\sigma^{2}$ é dada por $\hat{\sigma}^{2}=q_{T} / N T$, onde $N$ é o número de variáveis independentes do modelo e $\mathrm{T}$ é o número de observações disponíveis. Para o caso especial de $y_{t}$ univariado têm-se os escalares $v_{t}$ e $\sigma^{2} f_{t}$ e o vetor $k_{t}$ em lugar de $\mathbf{K}_{\mathrm{t}}$.

Apesar de, no caso multivariado, a matriz $\mathbf{F}_{\mathbf{t}}$ precisar ser positiva definida e não singular, essa condição pode não ser cumprida desde o início do procedimento do filtro. Neste caso, o filtro é pré-inicializado pelas atualizações $a_{j+1 \mid 0}=T a_{j \mid 0}$ e $\mathbf{P}_{j+1 \mid 0}=T_{\mathrm{j} \mid 0} \mathbf{T}^{\prime}+\mathbf{H H}^{\prime}$, até que $F_{j}=Z P_{j} Z^{\prime}+G G^{\prime}$ seja positiva definida. Só então o filtro de Kalman é inicializado com $\mathbf{a}_{1 \mid 0}=a_{100}$ e $q_{0}=0$, onde i é o número de atualizações necessárias para se cumprir a condição desejada.

Quase sempre os modelos conterão variáveis explicativas elou componentes não estacionários e assim $\delta$ não será igual a zero, mas possuirá, por suposição, distribuição difusa. Condições iniciais difusas implicam que os valores iniciais são formados a partir dos valores observados. Neste caso, as equações do filtro de Kalman para $\mathbf{v}_{t}$ e $\mathbf{a}_{t t-1} \mathrm{e}$ para suas correspondentes matrizes de erros são substituídas, surgindo o filtro de Kalman aumentado. As informações obtidas pelo filtro de Kalman comum serão corrigidas pelos resultados do filtro de Kalman aumentado com as seguintes equações suplementares 


$$
V_{t}=-Z A_{t t-1}-X_{t} B
$$

$$
\begin{aligned}
& A_{t+1 \mid t}=T A_{t \mid t-1}+W_{t} B+K_{t} V_{t} \\
& \left(s_{t}, S_{t}\right)=\left(s_{t-1}, S_{t-1}\right)+V^{\prime} F_{t}^{-1}\left(V_{t}, V_{t}\right)
\end{aligned}
$$

para $t=1,2, \ldots, T$, com $\mathbf{A}_{1 \mid 0}=\mathbf{W}_{0} \mathbf{B}$. A matriz $\left(\mathbf{s}_{t}, \mathbf{S}_{\mathbf{t}}\right)$ contém quantidades importantes que aparecem na função de verossimilhança, com essas informações a previsão do vetor de estado a um passo e sua correspondente matriz de EQM serão

$$
\begin{aligned}
& \hat{a}_{t t-1}=a_{t t t-1}+A_{t t t-1} S_{t-1}{ }^{-1} s_{t-1}, \\
& \sigma^{2} \hat{\mathbf{P}}_{t \mid t-1}=\sigma^{2}\left(\mathbf{P}_{t \mid t-1}+A_{t t-1} S_{t-1}{ }^{-1} A_{t t t-1}^{\prime}\right),
\end{aligned}
$$

o erro de previsão a um passo e sua correspondente matriz de EQM possuirão estimadores de máxima verossimilhança, respectivamente, iguais a

$$
\begin{aligned}
& \hat{\mathbf{v}}_{\mathrm{t}}=\mathbf{V}_{\mathrm{t}}+\mathbf{V}_{\mathrm{t}} \mathbf{S}_{\mathrm{t}-1}{ }^{-1} \mathbf{S}_{\mathrm{t}-1} \\
& \sigma^{2} \hat{\boldsymbol{F}}_{\mathrm{t}}=\sigma^{2}\left(\mathbf{F}_{\mathrm{t}}+\mathbf{V}_{\mathrm{t}} \mathbf{S}_{\mathrm{t}-1}^{-1} \mathbf{V}_{t}^{\prime}\right)
\end{aligned}
$$

No filtro de Kalman difuso a estimativa para $\sigma^{2}$ é

$$
\hat{\sigma}^{2}=\hat{q}_{T} /(N T-d-k),
$$

onde $\hat{\mathrm{q}}_{\mathrm{T}}=\mathrm{q}_{\mathrm{T}}-\mathbf{s}_{\mathrm{T}} \mathbf{S}_{\mathrm{T}}{ }^{-1} \mathbf{S}_{\mathrm{T}}$. A estimativa pelo método dos mínimos quadrados generalizados de $\delta$ e de sua matriz de EQM, utilizada como estatística nos testes t de significância para os coeficientes presentes em $\delta$, são iguais a

$$
\begin{aligned}
& \hat{\delta}=\mathbf{S}_{\mathrm{T}}{ }^{-1} \mathbf{S}_{\mathrm{T}} \\
& \operatorname{EQM}(\hat{\delta})=\sigma^{2} \mathbf{S}_{\mathrm{T}}{ }^{-1}
\end{aligned}
$$

Para o caso em que no modelo não existam regressores a serem estimados relacionados a $X_{t}$ e com $W_{t}$ o filtro de Kalman aumentado é utilizado até no máximo o número de componentes não estacionários, usualmente o próprio número de componentes (d), quando deixará de ser usado e o filtro de Kalman comum passará a ser executado isoladamente. $O$ filtro aumentado se reduz ao filtro comum utilizando-se as equações 3.15 para $\mathrm{t}=\mathrm{d}$.

Já quando o modelo possui alguma variável nas matrizes $X_{t}$ e $W_{t}$ só é possivel uma redução ao filtro comum para as informações correspondentes aos efeitos iniciais $\left(\delta_{\mathrm{i}}\right)$. 0 
filtro aumentado continua sendo aplicado mas de forma simplificada, isto é, somente para a parte dos regressores, implicando um número menor de colunas nas matrizes utilizadas.

Esta redução parcial é operacionalizada particionando-se as matrizes $\delta, V_{t}, A_{t \mid t-1}, s_{t}$ e $S_{t}$ em duas, uma contendo informações sobre os regressores $(x)$ e outra sobre os estados iniciais (i), assim

$$
\begin{aligned}
& \delta=\left(\delta_{\mathrm{x}}, \delta_{\mathrm{i}}\right) \\
& A_{t \mid t-1}=\left(A_{x, t \mid t-1}, A_{i, t \mid t-1}\right), \quad V_{t}=\left(V_{x, t}, V_{i, t}\right) \\
& \mathbf{s}_{t}=\left(s_{x, t} s_{i, t}\right) \\
& S_{t}=\left|\begin{array}{ll}
S_{x x, t} & S_{i x, t}^{\prime} \\
S_{i x, t} & S_{i, t}
\end{array}\right|
\end{aligned}
$$

Desse modo, quando $\mathbf{S}_{\mathrm{ii}, \mathrm{t}}$ for invertível em $\mathrm{t}=\mathrm{d}$, o filtro difuso reduz-se parcialmente a

$$
\begin{aligned}
& \bar{A}_{t+1 \mid t}=A_{x, t+1 \mid t}+A_{i, t+1 \mid t} S_{i i, t}{ }^{-1} S_{i x, t} \\
& \bar{P}_{t+1 \mid t}=P_{t+1 \mid t}+A_{i, t+1 \mid t} S_{i i, t}{ }^{-1} S_{i, t+1 \mid t} \\
& \bar{q}_{t}=q_{t}-S_{i, t}^{\prime} S_{i i, t}{ }^{-1} S_{i, t} \\
& \overline{\mathbf{S}}_{t}=S_{x, t}-S_{i x, t}^{\prime} S_{i, t}{ }^{-1} S_{i, t} \\
& \overline{\mathbf{S}}_{t}=S_{x x, t}-S_{i x, t}^{\prime} S_{i, t}{ }^{-1} S_{i x, t}
\end{aligned}
$$

a matriz $B$ é substituída no filtro por $\bar{B}=B_{x}$.

Para uma descrição mais detalhada sobre o filtro difuso ver de Jong (1991), de Jong \& Chu-Chun-Lin (1994) e Koopman, S. J., Harvey, A. C., Doornik, J. A. \& Shephard, N. (1995).

Semelhantemente às partições anteriores, o estimador $\hat{\delta}$ é dividido em $\hat{\delta}_{x}$ e $\hat{\delta}_{\mathrm{i}}$, uma parte, de k elementos, relacionada com os regressores e outra, de d elementos, com os efeitos iniciais. $O$ vetor $\hat{\delta}_{x}$ dos regressores é estimado por

$$
\hat{\delta}_{\mathrm{x}}=\overline{\mathbf{S}}_{\mathrm{T}}^{-1} \overline{\mathbf{S}}_{\mathrm{T}}
$$

e sua matriz de erro quadrático médio por

$$
\operatorname{EQM}\left(\hat{\delta}_{\mathrm{x}}\right)=\hat{\sigma}^{2} \overline{\mathbf{S}}_{\mathrm{T}}^{-1}
$$




\section{6 - Resíduos}

É notório que os resíduos de um modelo possuem informações valiosas para uma análise para se verificar o poder preditivo, a qualidade do ajuste e o cumprimento das suposições assumidas. Quase sempre o interesse é na obtenção de resíduos padronizados, que são as diferenças entre os valores ajustados pelo modelo e os valores observados, ponderadas pelas suas variabilidades.

Existem diferentes resíduos associados aos modelos estruturais dependendo se são usadas estimativas suavizadas ou filtradas para obtê-los.

No caso univariado as inovações padronizadas são dadas pela razão

$$
\widetilde{v}_{t}=\hat{v}_{t} /\left(\hat{\sigma} \hat{f}_{t}^{1 / 2}\right), \quad t=d+1, \ldots, T
$$

onde os estimadores do numerador e do denominador são casos univariados de 3.16.

Para modelos com $\mathrm{k}=0$ e com d componentes não estacionários, as inovações padronizadas são obtidas através do filtro de Kalman, após a redução do filtro difuso que se dará para $\mathrm{t}>\mathrm{d}$.

Nos modelos multivariados esses resíduos são dados por

$$
\widetilde{v}_{j, t}=\hat{v}_{j, t} /\left(\hat{\sigma} \hat{F}_{j, t}^{1 / 2}\right), \quad t=d+1, \ldots, T
$$

onde $\hat{v}_{\mathrm{j}, \mathrm{t}}$ é o j-ésimo elemento do vetor $\hat{v}_{\mathrm{t}}$ e $\hat{\mathrm{F}}_{\mathrm{j}, \mathrm{t}}^{1 / 2}$ o elemento (j,j) da matriz $\hat{\mathrm{F}}_{\mathrm{t}}^{1 / 2}$.

As inovações padronizadas correspondem aos resíduos de mínimos quadrados generalizados e, em um modelo corretamente especificado, são aproximadamente normais identicamente distribuídos com média zero e matriz de covariância igual à matriz identidade.

Outros dois tipos de resíduos, independentes do valor de k, são os resíduos de mínimos quadrados generalizados, utilizados nos testes de normalidade, heterocedasticidade e correlação serial, e os resíduos recursivos generalizados, usados nos testes de previsão e nos diagnósticos. Ambos possuem a fórmula (3.20) das inovações padronizadas, contudo, as estimativas de $F_{t}$ e $\mathbf{v}_{t}$ são obtidas de formas distintas, caso $k=0$ os resultados são os mesmos.

Nos resíduos de mínimos quadrados generalizados, $\hat{\mathbf{v}}_{\mathrm{t}}$ e $\hat{\mathbf{F}}_{\mathrm{t}}$ se originam de um filtro aumentado em que $b$ é substituído por $B_{x} \hat{\delta}_{x}$ na REE. O cálculo se dá em duas 
etapas, primeiro obtêm-se $\hat{\delta}_{x}$ e $\hat{\sigma}$ por um filtro aumentado com $d+k$ colunas para $A_{t+1 \mid t}$, que pode se reduzir parcialmente em $t=d$. Depois, os valores de interesse são calculados recursivamente por um filtro com as informações da primeira rodada e com d colunas para $A_{t+1 \mid t}$, que pode se reduzir em $t=d$ para o filtro de Kalman comum. Para amostras pequenas estes resíduos não são independentemente distribuídos nem têm variância constante.

Nos resíduos recursivos generalizados $\left(w_{t}\right), \hat{v}_{t}$ e $\hat{F}_{t}$ vêm de um filtro aumentado com $d+k$ colunas para $A_{t+1 \mid t}$, que se reduz parcialmente em $t=d$, acompanhado das seguintes regressões recursivas para avaliação da inversa de $\mathbf{S}_{t}$

$$
\begin{array}{ll}
\hat{a}_{t \mid t-1}=a_{t \mid t-1}+A_{t \mid t-1} C_{t-1}, & \hat{P}_{t \mid t-1}=P_{t \mid t-1}+A_{t \mid t-1} C_{t-1} A_{t \mid t-1}^{\prime}, \\
\hat{v}_{t}=v_{t}+V_{t} S_{t-1}{ }^{-1} S_{t-1}, & \hat{F}_{t}=F_{t}+V_{t} C_{t-1} V_{t}^{\prime} \\
\mathbf{C}_{t}=C_{t-1}^{*}+K_{t}^{* \prime} \hat{v}_{t}, & \hat{F}_{t}^{-1} V_{t} C_{t-1} \\
\end{array}
$$

onde $\mathbf{C}_{\mathrm{t}}=\mathrm{S}_{\mathrm{t}}^{-1} \mathbf{S}_{\mathrm{t}}$ e $\mathbf{C}_{\mathrm{t}}=\mathrm{St}_{\mathrm{t}}^{-1}$. Estes resíduos são obtidos para $\mathrm{t}=\mathrm{d}+\mathrm{k}+1, \ldots, \mathrm{T}$.

Existem, ainda, os resíduos suavizados, que são estimativas do vetor de perturbações $u_{t}$ obtidas usando-se toda informação amostral.

As estimativas destes resíduos suavizados e da correspondente matriz de erro quadrático médio são geradoras de diversas estatísticas para melhor análise do modelo ajustado. Com base nos resíduos suavizados pode-se ter:

I. A estimativa suavizada para o vetor de estado, que considera toda informação da amostra;

II. Estimativas para os resíduos auxiliares (que são as perturbações associadas aos componentes não observados), e a partir destes, algumas estatísticas para se detectar pontos aberrantes da série e quebras estruturais dos componentes não observados;

III.Um algoritmo EM (alternativa à maximização numérica, geralmente utilizada na obtenção dos estimadores pelo método de máxima verossimilhança) para estimação dos hiperparâmetros do modelo em representação de espaço de 
estado, cujas estimativas, no STAMP, servirão de valores iniciais para a maximização numérica da função de verossimilhança nos modelos univariados;

IV.O cálculo do escore, a primeira derivada da verossimilhança em relação ao vetor de hiperparâmetros;

V. Os métodos para extração de sinal, ou seja, a obtenção dos componentes não observados da série, por exemplo, retirada da tendência e/ou da sazonalidade.

As equações para os resíduos suavizados mostradas a seguir são as descritas e provadas em Koopman (1993) para o caso especial de modelos invariantes no tempo e perturbações das equações de medida e de transição da REE não correlacionadas (HG' = 0), que, acrescidas das suposições de normalidade para o modelo, são as utilizadas no STAMP.

Quando $\delta=0$, os estimadores suavizados das perturbações $\mathrm{Hu}_{\mathrm{t}}$ e $\mathrm{Gu}_{\mathrm{t}}$ são definidos a partir das estimativas do vetor $\mathbf{u}_{\mathrm{t}}$ e de sua matriz de EQM, ou seja,

$$
E\left(\mathbf{u}_{t} \mid \mathbf{Y}_{T}, \delta=0\right)=\widetilde{\mathbf{u}}_{\mathrm{t}} \quad \text { e } \quad \operatorname{EQM}\left(\widetilde{\mathbf{u}}_{\mathrm{t}}\right)=\sigma^{2} \mathbf{C}_{\mathrm{t}} \quad \mathrm{t}=1,2, \ldots, \mathrm{T}
$$

Para se obter essas estimativas, é inicialmente rodado o filtro de Kalman para se conseguir as quantidades $\mathbf{v}_{\mathrm{t}}, \mathbf{F}_{\mathrm{t}}^{-1}$ e $\mathbf{K}_{\mathrm{t}}$, para $\mathbf{t}=1,2, \ldots, \mathrm{T}$, e em seguida são aplicadas, para $t=T, T-1, \ldots, 1$, as equações recursivas

$$
\begin{array}{ll}
\mathbf{e}_{\mathrm{t}}=\mathrm{F}_{\mathrm{t}}^{-1} \mathbf{v}_{\mathrm{t}}-\mathrm{K}_{\mathrm{t}}^{\prime} \mathbf{r}_{\mathrm{t}}, & \mathbf{r}_{\mathrm{t}-1}=\mathbf{Z}^{\prime} \mathbf{e}_{\mathrm{t}}+\mathrm{T}^{\prime} \mathbf{r}_{\mathrm{t}} \\
\mathbf{D}_{\mathrm{t}}=\mathrm{F}_{\mathrm{t}}^{-1}+\mathrm{K}_{\mathrm{t}}^{\prime} \mathbf{N}_{\mathrm{t}} \mathbf{K}_{\mathrm{t},} & \mathbf{N}_{\mathrm{t}-1}=\mathbf{Z}^{\prime} \mathrm{F}_{\mathrm{t}}^{-1} \mathbf{Z}+\mathrm{L}_{\mathrm{t}}^{\prime} \mathrm{N}_{\mathrm{t}} \mathrm{L}_{\mathrm{t}},
\end{array}
$$

onde $L_{t}=T-K_{t} Z$ e as recursões são inicializadas com $r_{T}=0$ e $N_{T}=0$.

Assim, $e_{t}$ e $r_{t}$ servirão, respectivamente, como base para as estimativas das perturbações da equação de medida e da equação de transição, que serão dadas por

$$
\mathrm{G}_{\mathrm{u}}=\mathrm{GG}^{\prime} \mathrm{e}_{\mathrm{t}} \quad \mathrm{e} \quad H \widetilde{\mathbf{u}}_{\mathrm{t}}=H H^{\prime} \mathrm{r}_{\mathrm{t}}
$$

e $D_{t}$ e $N_{t}$ para as estimativas das matrizes associadas de erro quadrático médio, dadas por

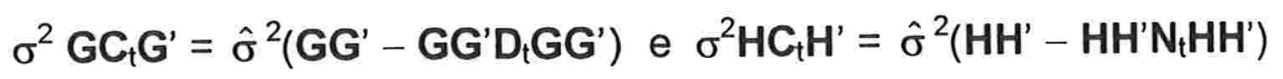

No caso de $\delta$ ser desconhecido, isto é, existirem efeitos iniciais e regressores com distribuição difusa, há aumento das recursões com as equações suplementares 


$$
E_{t}=F_{t}^{-1} V_{t}-K^{\prime} R_{t} \quad \text { e } \quad R_{t-1}=Z^{\prime} E_{t}+T^{\prime} R_{t}
$$

com $\mathbf{R}_{\mathbf{T}}=\mathbf{0}$ e $\mathbf{V}_{\mathrm{t}}$ definido como anteriormente no caso do filtro de Kalman aumentado.

Quando não há redução total do filtro aumentado, as estimativas do vetor de perturbações da equação de medida e de sua respectiva matriz de erro quadrático médio são dados conforme anteriormente, só que com $e_{t}$ e $D_{t}$ substituídos por:

$$
\hat{\mathbf{e}}_{\mathrm{t}}=\mathrm{e}_{\mathrm{t}}+\mathrm{E}_{\mathrm{t}} \tilde{\delta} \quad \hat{D}_{\mathrm{t}}=\mathrm{D}_{\mathrm{t}}-\mathrm{E}_{\mathrm{t}} \mathrm{S}^{-1} E_{\mathrm{t}}^{\prime}
$$

para $t=1,2, \ldots$, T. O mesmo acontecendo para o vetor de perturbações da equação de transição com $r_{\mathrm{t}}$ e $\mathrm{N}_{\mathrm{t}}$, substituídos por

$$
\hat{\mathbf{r}}=\mathbf{r}_{\mathrm{t}}+\mathbf{R}_{\mathrm{t}} \tilde{\delta} \quad \text { e } \quad \hat{\mathbf{N}}_{\mathrm{t}}=\mathbf{N}_{\mathrm{t}}-\mathbf{R}_{\mathrm{t}} \mathbf{S}^{-1} \mathbf{R}_{\mathrm{t}}^{\prime}
$$

onde $\widetilde{\delta}=\mathbf{S}_{\mathrm{T}}{ }^{-1} \mathbf{S}_{\mathrm{T}}$ e $\mathbf{S}=\mathbf{S}_{\mathrm{T}}$.

Quando há redução total do filtro aumentado em $\mathrm{t}=\mathrm{m}, \mathrm{T} \leq \mathrm{m} \leq \mathrm{d}$, o suavizador das perturbações simples pode ser utilizado para $t=T, T-1, \ldots, m+1$. Neste caso, para os outros valores de t a suavização não é direta, pois não há disponibilidade das matrizes $\mathbf{S}_{\mathrm{T}}$ e $\mathbf{R}_{\mathrm{m}}$. Um modo de se conseguir estas matrizes é sugerido em Chu-Chun-Lin \& de Jung (1993).

É importante considerar que as estimativas suavizadas dos resíduos são serialmente correlacionadas, mesmo em modelos especificados corretamente, ver Koopman (1993).

A padronização das estimativas dos resíduos suavizados fornece os resíduos auxiliares, que são importantes na detecção de quebras estruturais ou pontos aberrantes nos componentes não observados, com as mais comuns sendo alterações no nível. Como estes resíduos são serialmente correlacionados, testes para verificação da suposição de normalidade necessitam de ajustes, ver Harvey \& Koopman (1992).

As informações dos resíduos suavizados e dos erros de previsão a um passo, com suas matrizes de EQM, servirão para a estimação por máxima verossimilhança dos parâmetros do modelo.

Enquanto o filtro de Kalman fornece estimativas para o vetor de estado $\alpha_{t}$ condicionado na informação até o instante $t$, a suavização fornece estimativas para $o$ estado $\alpha_{1}$ considerando também um conhecimento futuro, quase sempre toda a amostra 
disponível. Então, por considerar mais informação em seu cálculo, é provável que o suavizador possua uma matriz de EQM com elementos, em geral, menores do que os derivados de um filtro que só considera informações passadas e contemporânea.

Um exemplo de suavizador é um algoritmo para trás que se inicia com as últimas estimativas do vetor de estado e de seu EQM resultantes do filtro de Kalman, isto é, a e $\mathbf{P}_{\mathrm{T}}$, e que a partir destes busca estimativas de $\mathbf{a}_{\mathrm{t} \mid \mathrm{T}}$ e $\mathbf{P}_{\mathrm{t} \mid \mathrm{T}}$. As equações deste algoritmo são

$$
a_{t \mid T}=a_{t}+P^{*}\left(a_{t+1 \mid T}-T_{t+1} a_{t}-c_{t+1}\right) \quad \text { e } \quad P_{t \mid T}=P_{t}+P_{t}^{*}\left(P_{t+1 \mid T}-P_{t+1 \mid t}\right) P^{* \prime}{ }_{t}
$$

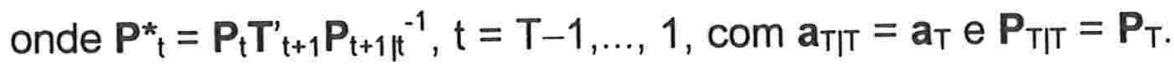

Outro suavizador do vetor de estado, o utilizado no STAMP e descrito em Koopman (1993), considera que somente o estimador dos componentes é relevante, não tendo preocupação em obter as matrizes de EQM associadas. Este suavizador é conseguido da seguinte maneira:

I. o filtro de Kalman é rodado e armazena-se $\mathbf{v}_{t}, F_{t}^{-1}$ e $K_{t}$, para $t=1,2, \ldots, T$;

II. as estimativas dos resíduos suavizados $\mathrm{Hu}_{\mathrm{t}}$ são derivadas através da aplicação do algoritmo descrito anteriormente, para $t=T, T-1, \ldots, 1$;

III.os componentes suavizados são obtidos a partir do valor inicial $\widetilde{\alpha}_{1}=\hat{a}_{10}+$ $\hat{\mathbf{P}}_{1 \mid 0}\left(\mathbf{r}_{0}+\mathbf{R}_{0} \widetilde{\delta}\right)$ através da equação recursiva $\tilde{\alpha}_{t+1}=\mathbf{T} \widetilde{\alpha}_{t}+\mathbf{W}^{*} \widetilde{\delta}_{x}+\mathbf{H} \widetilde{\mathbf{u}}_{t}$, para $t$ $=1,2, \ldots, \mathrm{T}$.

Uma vantagem desta formulação é sua eficiência computacional, em grande parte, decorrente da falta de cálculos para as matrizes de erro.

O vetor $\hat{\delta}_{x}$ e a estimativa do estado no último período disponível, $\hat{a}_{T \mid T}$ possuem toda informação necessária para a obtenção de previsões. Este estado é estimado por

$$
\hat{\mathbf{a}}_{T \mid T}=\hat{\mathbf{a}}_{T \mid T-1}+\hat{\mathbf{P}}_{T \mid T-1} \mathbf{Z}_{T}^{\prime} \hat{\mathbf{F}}_{T}^{-1} \hat{\mathbf{v}}_{T}
$$

e sua matriz de erro quadrático médio por

$$
\hat{\sigma}^{2} \hat{\mathbf{P}}_{\mathrm{TTT}}=\hat{\sigma}^{2}\left(\hat{\mathbf{P}}_{\mathrm{TTT}-1}+\hat{\mathbf{P}}_{\mathrm{TTT}-1} \mathbf{Z}_{\mathrm{T}}^{\prime} \hat{\mathbf{F}}_{\mathrm{T}}^{-1} \mathbf{Z}_{\mathrm{T}} \hat{\mathbf{P}}_{\mathrm{TTT}-1}\right),
$$

com os elementos da diagonal principal desta matriz sendo usados na formação dos erros padrões e dos testes de significância de â T|T. 
Então, com as estimativas do último estado e dos coeficientes regressores, as previsões dos estados que minimizam o $\mathrm{EQM}$, para /passos, com $\ell=1,2, \ldots, \mathrm{L}$, são dadas recursivamente por

$$
\hat{\mathbf{a}}_{\mathrm{T}+_{\ell} \mid \mathrm{T}}=\mathrm{T} \hat{\mathbf{a}}_{\mathrm{T}+\ell-1 \mid \mathrm{T}}+\mathrm{W}^{*} \mathrm{~T}_{\ell} \widetilde{\delta}_{\mathrm{x}}
$$

e sua matriz de erro quadrático médio

$$
\hat{\sigma}^{2} \hat{\mathbf{P}}_{\mathrm{T}+_{\ell} \mid \mathrm{T}}=\hat{\sigma}^{2}\left(\mathrm{~T} \hat{\mathbf{P}}_{\mathrm{T}+\ell-1 \mid \mathrm{T}^{\prime}}+\mathrm{HH}^{\prime}\right)
$$

Como conseqüência, as previsões ótimas para a própria série e a respectiva matriz de covariância, que será utilizada na construção de intervalos de confiança no caso de modelos com suposição de normalidade, são, respectivamente, dadas por

$$
\begin{aligned}
& \hat{\mathbf{y}}_{\mathrm{T}_{\ell} \mid \mathrm{T}}=\mathbf{Z} \hat{\mathbf{a}}_{\mathrm{T}_{\ell} \mid \mathrm{T}}+\mathbf{X}^{*}{ }_{\mathrm{T}+/} \widetilde{\boldsymbol{\delta}}_{\mathrm{x}} \\
& \hat{\sigma}^{2} \hat{\mathbf{F}}_{\mathrm{T}_{\ell} \mid \mathrm{T}}=\hat{\sigma}^{2}\left(\mathbf{Z} \hat{\mathbf{P}}_{\mathrm{T}_{+\ell} \mid \mathrm{T}} \mathbf{Z}^{\prime}+\mathrm{GG}^{\prime}\right)
\end{aligned}
$$

Os resíduos para as previsões futuras podem ser avaliados quando do conhecimento de novos valores para a série original. Eles serão dados diretamente pela diferença entre 0 valor real observado $y_{t}$ e sua previsão $\hat{y}_{T+\ell \mid T}$. Suas matrizes de covariância são as

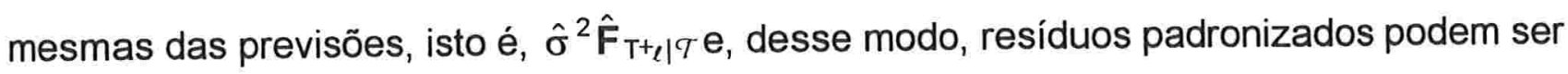
calculados.

\section{4 - Estimação dos hiperparâmetros}

\section{1 - Introdução}

As suposições mais comuns admitidas na estimação do vetor de hiperparâmetros são que o modelo estrutural é invariante no tempo e que as perturbações e o estado inicial possuem distribuição normal independentes entre si.

Com os modelos estruturais representados pela REE, os hiperparâmetros, vetor $\theta$ no caso univariado e matriz $\theta$ no multivariado, serão estimados via maximização da função de verossimilhança obtida através do filtro de Kalman.

A metodologia para a estimação dos parâmetros de um modelo estrutural que será descrita fornece estimadores de máxima verossimilhança decorrentes de abordagem no domínio do tempo. Não serão vistos aqui modelos que contenham ciclos e defasagens da 
própria variável dependente, estes casos e a estimação no domínio da freqüência são dados em Harvey (1989).

Após a estimação do vetor de hiperparâmetros, as estimativas resultantes serão utilizadas para uma nova aplicação do filtro de Kalman, sendo esses novos resultados os que servirão para realização de análise, diagnóstico e para obtenção de previsões e de estimativas dos estados.

O método padrão de estimação através da maximização da função de verossimilhança tem como suposição que as variáveis são independentes e identicamente distribuidas. Desse modo, a função densidade de probabilidade conjunta pode ser escrita por um produtório das distribuições marginais. Mas quando as variáveis são dependentes pode-se escrever a densidade conjunta como produto de densidades condicionais no passado. Agora, para uma dada amostra esta função depende dos parâmetros desconhecidos e é a verossimilhança do modelo.

\section{2 - Função de verossimilhança}

Como para séries temporais, a suposição de independência das variáveis não é válida, mas a função de densidade conjunta pode ser escrita em função das distribuições de probabilidade das variáveis condicionadas em seus valores passados,

$$
\mathrm{L}(\mathbf{y} ; \theta)=\prod_{t=1}^{T} \mathrm{p}\left(\mathbf{y}_{\mathbf{t}} \mid \mathbf{Y}_{\mathbf{t}-1}\right)
$$

onde $p\left(y_{t} \mid Y_{t-1}\right)$ denota a distribuição de $y_{t}$ condicionada na informação disponível até o período $t-1$, isto é, $Y_{t-1}=\left\{y_{t-1}, y_{t-2}, \ldots, y_{1}\right\}$.

A média da distribuição condicional de $\mathbf{y}_{\mathrm{t}}$ é dada pela esperança de $\mathbf{y}_{\mathrm{t}}$ condicionado nos valores passados. A diferença entre $y_{t}$ e esta esperança condicional, o erro de previsão $v_{t}$, possui matriz de erro quadrático médio, $F_{t}$, igual à variância condicional de $y_{t} \mid Y_{t-1}$. Estes fatos são relevantes no caso em que a distribuição das variáveis é normal, principalmente porque a distribuição de uma variável normal condicionada em variáveis distribuídas normalmente é também normal.

Desse modo, a distribuição conjunta pode ser decomposta em termos dos erros de previsão. Então, considerando o estado inicial do modelo conhecido $(\delta=0)$ e dada uma 
amostra tem-se que esta função depende dos parâmetros e seu logaritmo pode ser expresso em termos dos erros de previsão. Sob a suposição de normalidade tem-se

$$
\log L(\theta)=-(\mathrm{NT} / 2) \log 2 \pi-(1 / 2) \sum_{t=1}^{T} \log \left|\mathbf{F}_{\mathrm{t}}\right|-(1 / 2) \sum_{t=1}^{T} \mathbf{v}_{\mathrm{t}}{ }_{\mathrm{t}} \mathbf{F}^{-1} \mathbf{v}_{\mathrm{t}}
$$

que é a decomposição da função em termos dos erros de previsão.

Então, a aplicação do filtro de Kalman gera o vetor de inovações $v_{t}$, e a matriz $F_{t}$ que são funções das variâncias das perturbações, hiperparâmetros, a serem estimados.

Para os modelos univariados, $\mathbf{v}_{\mathbf{t}}$ e $\mathbf{F}_{\mathbf{t}}$ são substituídos, respectivamente, pelos escalares $v_{t}$ e $f_{t}$. Também, para estes modelos, há a possibilidade de um parâmetro, $\sigma^{\star 2}$, ser concentrado fora da função de verossimilhança mediante uma reparametrização que reparte o vetor de parâmetros, $\theta$, em duas partes, ou seja, $\theta=\left(\theta^{*}, \sigma^{*^{2}}\right)^{\prime}$. Sendo a matriz $\mathbf{P}_{0}$ também dada em função de $\sigma^{* 2}$, o filtro de Kalman é rodado independentemente desta quantia. Verifica-se que os erros de previsão continuam os mesmos obtidos sem a concentração do parâmetro, mas suas correspondentes matrizes de erro serão dadas por $\sigma^{\star 2} \mathrm{f}_{\mathrm{t}}$. Neste caso, o logaritmo da função de verossimilhança, sem o termo constante, que será omitido também nas próximas funções, é

$$
\log L\left(\theta^{*}, \sigma^{* 2}\right)=-(T / 2) \log \sigma^{* 2}-(1 / 2) \sum_{t=1}^{T} \log f_{t}-(1 / 2) \sigma^{* 2} \sum_{t=1}^{T} v_{t}^{2} / f_{t}
$$

Como $v_{t}$ e $f_{t}$ não dependem de $\sigma^{* 2}$, derivando-se 4.1 com relação a este parâmetro e igualando-se o resultado a zero tem-se um estimador condicionado num determinado valor de $\theta^{*}$ que é dado por

$$
\widetilde{\sigma}^{* 2}\left(\theta^{\star}\right)=(1 / T) \sum_{t=1}^{T}\left(v_{t}^{2} / f_{t}\right)
$$

Substituindo-se 4.2 em 4.1, tem-se o logaritmo da função de verossimilhança concentrada em $\sigma^{\star 2}$, cujo núcleo é

$$
\log \mathrm{L}_{c}\left(\theta^{*}\right)=-(1 / 2) \sum_{t=1}^{T} \log f_{t}-(T / 2) \log \widetilde{\sigma}^{{ }^{2}}\left(\theta^{\star}\right) \quad 4.3
$$

O parâmetro concentrado fora da verossimilhança é usualmente a maior variância associada às perturbações, as estimativas das outras variâncias são dadas em função deste parâmetro, como um quociente, a razão q. 
Quando os efeitos iniciais não são estacionários, $\delta$ tem distribuição difusa, utiliza-se uma função de verossimilhança difusa que na notação adotada no STAMP tem logaritmo dado por

$$
\log L\left(\theta^{*}\right)=-\left(T^{\star} / 2\right) \log \sigma^{2}-(1 / 2) \sum_{t=1}^{T} \log f_{t}-(1 / 2) \log \left|S_{T}\right|-(1 / 2) \sigma^{-2} \hat{q}_{T}
$$

com a matriz $\mathrm{S}_{\mathrm{T}}$ dada por 3.14.c; $\mathrm{T}^{*}=\mathrm{T}-\mathrm{k}-\mathrm{d}$, sendo $\mathrm{k}$ correspondente aos parâmetros regressores e d aos efeitos iniciais não estacionários; e $\hat{q}_{\mathrm{T}} .=q_{\mathrm{T}}-\mathbf{s}_{\mathrm{T}} \mathbf{S}_{\mathrm{T}}{ }^{-1} \mathbf{s}_{\mathrm{T}}$.

Quando o filtro de Kalman aumentado se reduz ao no filtro comum, a matriz $\mathbf{S}_{\mathrm{T}}$ é substituída na verossimilhança pela matriz $\mathbf{S}^{*}=\mathbf{S}_{\mathrm{T}}$. Quando a redução é total em $t=m, m$ restrito a $T \leq m \leq d$, e $k=0$, tem-se que $\left|S^{*}\right|=\left|S_{m}\right|$. Se $K>0$ e a redução for parcial $\left|S^{*}\right|=$ $\left|\mathbf{S}_{\mathrm{ii}, \mathrm{m}} \| \overline{\mathbf{S}}_{\mathrm{T}}\right|$, com essas quantidades como já definidas.

Ao se concentrar este parâmetro a verossimilhança concentrada passa a ser escrita da seguinte forma:

$$
\log L_{c}\left(\theta^{*}\right)=-\left(T^{*} / 2\right) \log \hat{\sigma}^{2}-(1 / 2) \sum_{t=1}^{T} \log f_{t}-(1 / 2) \log \left|\mathbf{S}^{*}\right|
$$

onde $\hat{\sigma}^{2}=\hat{q}_{T} /(N T-d-k)$.

Harvey (1993), página 93, comenta sobre a superioridade dos estimadores decorrentes da maximização da função de verossimilhança difusa sobre os advindos de verossimilhança de um modelo com estados iniciais fixos que necessitam ser estimados, concluindo que a distribuição difusa para os estados iniciais, que implica eles serem formados pelas próprias observações da série, é mais adequada do que considerá-los fixos e concentrá-los fora da verossimilhança.

No caso multivariado, os estimadores das matrizes que expressam as variabilidades e seus erros associados também são obtidos por meio de uma verossimilhança difusa, porém neste caso não há concentração de nenhum hiperparâmetro, esta função é dada por

$$
\log L_{c}\left(\theta^{*}\right)=-(1 / 2) \sum_{t=1}^{T} \log F_{t}-(1 / 2) \log \left|S^{*}\right|-\hat{q}_{T} / 2
$$

com $\mathrm{S}^{\star}$ e $\hat{q}_{\mathrm{T}}$ sendo como já descrito. 


\section{3 - Método numérico para maximização da verossimilhança}

As condições de primeira ordem na maximização da função de verossimilhança para os modelos estruturais fornece quase sempre um sistema não linear nos parâmetros a serem estimados, com exceção dos valores concentrados fora da função, não tendo solução analítica. Este fato demanda um procedimento de maximização iterativo. Assim, a partir de estimativas iniciais para os parâmetros, novas estimativas são conseguidas iterativamente, somando-se um incremento aos valores anteriores até que haja convergência da função de verossimilhança e/ou das próprias estimativas e/ou das derivadas, neste caso para zero.

Outro ponto de destaque na estimação dos hiperparâmetros de um modelo estrutural é que seus valores são necessariamente não negativos, implicando que o procedimento de maximização da verossimilhança deve conter restriçöes.

Dentre as diversas opções de procedimento para a maximização ou minimização de funçőes destacam-se os métodos numéricos que, relativamente, apresentam baixo custo computacional e operacional. Para maior conhecimento do tema ver capítulo 4 de Harvey (1990).

No programa STAMP, ver capítulo 14 de Koopman, Harvey, Doornik and Shephard (1995), a otimização é realizada através do método de atualização quasi-Newton Broyden-Fletcher-Goldfarb-Shanno (BFGS), que sumariamente consiste em maximizar o núcleo do logaritmo da verossimilhança $\log L(\theta)$, considerando como equação de atualização para as estimativas dos parâmetros

$$
\theta_{\mathrm{i}+1}=\theta_{\mathrm{i}}+\mathrm{s}_{\mathrm{i}} \delta_{\mathrm{i}}
$$

onde $\theta_{i+1}$ é uma nova estimativa para $\theta$, dado uma estimativa $\theta_{i}, s_{i}$ é um escalar e $\delta_{i}$ é um vetor de busca direcional dado em função dos vetores de escore e da matriz hessiana, que são respectivamente as primeiras e segundas derivadas da função de verossimilhança em relação aos parâmetros a serem estimados.

Quando as estimativas finais são obtidas, há a classificação da convergência alcançada em quatro categorias (muito forte, forte, fraca e muito fraca) conforme critérios de convergência para a verossimilhança, o gradiente (escore) e as estimativas dos parâmetros. 
Para modelos univariados, o programa aplica a partir de valores iniciais, determinados a priori, uma pré-rotina de estimação, com no máximo cinco passos, para obter o hiperparâmetro a ser inicialmente concentrado fora da verossimilhança (aquele que tiver o maior valor) e os valores iniciais dos hiperparâmetros para o procedimento de estimação principal (BFGS).

Nos modelos multivariados, valores iniciais a priori são impostos para as matrizes de covariância das perturbações e estimados a princípio a partir de cinco passos do algoritmo EM, à semelhança do descrito em Koopman (1993). Com estas pré-estimativas, dá-se início ao procedimento principal da estimação.

As matrizes de covariância são agrupadas numa única matriz, na qual se aplica a decomposição de Cholesky, separando-se uma parte correspondente às cargas ou fatores, que é utilizada nos casos em que existe componentes comuns nas séries, e outra parte associada a quocientes de parâmetros (transformados para se contemplar as restrições necessárias, como os hiperparâmetros serem não negativos).

Tanto nos modelos univariados como nos multivariados, quando a estimativa de um hiperparâmetro está próxima de sua região de fronteira de definição, indicando que a variabilidade do componente associado é baixa, ele é fixado na sua fronteira, i.e., em zero, permitindo que os outros sejam estimados regularmente com maior rapidez.

Finalmente, com estimativas dos parâmetros e com valores de uma nova rodada do filtro de Kalman pode-se, com estatísticas derivadas destes valores, analisar o ajuste e as previsões do modelo através de testes específicos.

\section{5 - Testes de especificação e falta de especificação}

A verificação do cumprimento das suposições de um modelo, a avaliação de suas qualidades de ajuste e de previsão, a comparação com modelos concorrentes e a análise da significância das estimativas dos parâmetros de interesse são realizadas mediante utilização de testes estatísticos que comprovam ou refutam hipóteses pré-estabelecidas.

Grande parte dos testes estatísticos são funções dos resíduos, que são as inovações, ou erros de previsão a um ou mais passos. Assim, correlação serial nas inovações indica que o modelo não está capturando com competência a dinâmica da série. De maneira geral, se os resíduos possuem algum padrão, há problemas. 
A seguir são apresentados testes utilizados na análise dos modelos no programa STAMP, descritos em Koopman, Harvey, Doornik e Shephard (1995) e também em Harvey (1989).

As suposições do modelo estrutural são, em geral, verificadas através de testes para a série original e para os resíduos do modelo ajustado.

Para se testar a normalidade é utilizado o teste de Bowman-Shenton (BS) baseado em estimativas para o terceiro e o quarto momentos das inovações do modelo.

Assim, a assimetria e curtoses são definidas respectivamente por $\beta_{1}{ }^{1 / 2}=\left(\mu_{3}\right) /\left(\mu_{2}{ }^{3 / 2}\right)$ e $\beta_{2}=\mu_{4} / \mu_{2}{ }^{2}$, onde $\mu_{i}=E[y-\mu]^{i}$ e os valores amostrais $m_{i}=(1 / T)\left(\sum_{t=1}^{T}\left(y_{t}-\bar{y}\right)^{i}\right)$. Estimativas para $\beta_{1}^{1 / 2}$ e $\beta_{2}$, que em variáveis com distribuição normal têm valores, respectivamente, centrados em 0 e 3 , são dadas por $b_{1}{ }^{1 / 2}=\left(m_{3}\right) /\left(m_{2}{ }^{3 / 2}\right)$ e $b_{2}=m_{4} / m_{2}{ }^{2}$. Estas estimativas são assintoticamente normais (AN) para modelos corretamente especificados, com

$$
\mathrm{b}_{1}{ }^{1 / 2} \sim \mathrm{AN}(0,6 / \mathrm{T}) \text { e } \mathrm{b}_{2} \sim \mathrm{AN}(3,24 / \mathrm{T})
$$

Então, com s $=(T / 6) b_{1}$ e $k=(T / 24)\left(b_{2}-3\right)^{2}$, o teste BS é dado pela estatística $N_{B S}=s+k$, que tem, sob hipótese de normalidade dos dados, distribuição, já $\chi_{2}^{2}$ que $s$ e $k$ são independentes e têm distribuição $\chi_{1}^{2}$.

Deve-se atentar que o teste BS pode, para amostras pequenas, não fornecer resultados adequados, principalmente, porque a convergência de $b_{2}$ é muita lenta.

Para o caso de pequenas amostras, o manual do STAMP indica o uso do teste de Doornik-Hansen $(\mathrm{DH})$, para se testar normalidade. $E$ citado que neste teste, $b_{2}$, condicionado $a b_{2}>1+b_{1}$, tem distribuição gama e $b_{1}{ }^{1 / 2}$ tem distribuição aproximada pelo sistema $\mathrm{S}_{\mathrm{u}}$ de Johnson.

Como os testes para normalidade são bastante influenciados pela presença de valores extremos, deve-se, quando da rejeição da hipótese de distribuição normal, testar a presença de valores extremos através dos resíduos auxiliares.

A avaliação de variância constante da série é feita comparando-se a variabilidade do primeiro terço de observações da série com a do último terço. A estatística é dada pela razão entre as somas dos quadrados das inovações do primeiro terço e da último terço da série, assim, valores afastados de 1 para este quociente indicam falta de volatilidade 
constante. A estatística de teste tem distribuição F com h graus de liberdade tanto para 0 numerador quanto para o denominador, onde $h=T / 3$.

Para a verificação de estrutura ou correlação nos resíduos, pode ser utilizada como indicativo a estatística de Durbin-Watson (DW $\left.=\sum_{t=2+d}^{T}\left(\widetilde{V}_{t}-\widetilde{V}_{t-1}\right)^{2} / \sum_{t=1+d}^{T} \widetilde{V}_{t}^{2}\right)$, construída em função das inovações padronizadas e, em um modelo corretamente especificado, distribuída aproximadamente como uma $\mathrm{N}(2,4 / \mathrm{T})$.

A independência serial dos resíduos pode ser avaliada pela estatística $Q$ de BoxLjung, dada por

$$
Q(P, d)=T(T+2) \sum_{j=1}^{P}(T-j)^{-1} r^{2}(j)
$$

com $d=P-n+1, n$ o número de hiperparâmetros ou, para modelos multivariados, o número de matrizes de covariância, sendo $\mathrm{P}$, em geral, aproximadamente $\sqrt{T}$. Sob a hipótese de que o modelo está corretamente especificado, $Q$ tem aproximadamente distribuição $\chi_{d}^{2}$. Deve-se atentar que ajustes precisam ser efetuados caso exista alguma defasagem de série dependente no modelo.

As estimativas do vetor de estado final, dos coeficientes associados aos regressores, intervenções e variáveis explicativas são usados para testar, por exemplo, suas significâncias, através de testes t-Student.

Os níveis descritivos para os testes $\mathrm{t}$ de significância apresentados pelo STAMP são baseados na distribuição normal.

As matrizes de hiperparâmetros fornecem subsídio para avaliação dos componentes de cada série isoladamente e da existência de componentes comuns. Se um componente tiver hiperparâmetro estimado próximo de zero, deve-se torná-lo determinístico e aí verificar sua importância, por exemplo, através do teste de significância dos componentes para o período final da amostra. Neste caso, a não significância deste componente indica que ele pode ser retirado, ou seja, a presença do componente determinístico não se justifica. A presença de componentes comuns é verificada através da das covariâncias na matriz de hiperparâmetros, elas espelham as ligações, correlações entre componentes.

Algumas vezes, a dúvida se o componente é ou não importante é decidida através da análise do ajuste e da previsão dos modelos possíveis, que são, o modelo com 
componente estocástica, o com determinístico ou o sem componente, usando-se algum critério de informação para seleção ou teste de falha de previsão quando o critério de seleção for via previsão, embora última abordagem implique em data-mining.

A significância do ciclo pode ser avaliada através do percentual que ele representa na tendência, isto é, sua importância relativa. Valores baixos indicam que o ciclo não é necessário no modelo. Também podem ser avaliados através de testes, porém somente quando não existe o componente irregular no modelo.

Para verificação da qualidade do ajuste e comparação entre modelos, são vários os testes estatísticos disponíveis. As inovações e os resíduos de mínimos quadrados generalizados são usados, respectivamente, para modelos sem e com variáveis explicativas.

Uma das principais medidas é a variância do erro de previsão (VEP) ou, no caso multivariado, a diagonal da matriz de covariância do erro de previsão. Estas quantidades correspondem à variância do erro de previsão a um passo no estado de equilíbrio; que, caso não seja atingido, é substituído pela VEP finita de algum período próximo ao final da amostra, em geral o último.

Pode-se também avaliar o erro padrão, que corresponde à raiz quadrada da VEP. Outra medida é o desvio médio absoluto das inovações

$$
D M=\left(\tilde{\sigma}^{2} /(T-d)\right) \sum_{t=d+1}^{T}\left|v_{t}\right|
$$

O erro relativo é fornecido para modelos em log sendo igual a 100 DM.

Um ajuste satisfatório pode ser indicado pelos coeficientes de determinação. 0 coeficiente de determinação $\mathrm{R}^{2}$ para o modelo estrutural é definido como

$$
R^{2}=1-\left\{(T-d) \tilde{\sigma}^{2} / \sum_{t=1}^{T}\left(y_{t}-\bar{y}\right)^{2}\right\}
$$

onde $\bar{y}$ é a média amostral da série e $\widetilde{\sigma}^{2}$.a VEP. Para séries multivariadas, $y_{t}$ é uma das séries e $\widetilde{\sigma}^{2}$ é o elemento da diagonal principal da matriz de covariância do erro de previsão correspondente. Sua utilização só deve se dar quando as séries não possuem padrões cíclicos ou tendências, ou seja, caso exista estacionariedade.

Para séries que possuam tendência marcante, é aconselhável comparar a VEP com a variância da primeira diferença, $\Delta y_{t}=y_{t}-y_{t-1}$, ou seja, 


$$
R_{D}^{2}=1-\left\{(T-d) \widetilde{\sigma}^{2} / \sum_{t=2}^{T}\left(\Delta y_{t}-\overline{\Delta y}\right)^{2}\right\}
$$

Onde $\bar{\Delta} \mathrm{y}$ é a média amostral de $\Delta \mathrm{y}_{\mathrm{t}}$. Para o caso de valor negativo do coeficiente temse que o ajuste é pior do que um passeio aleatório com correnteza.

Caso existam tendência e sazonalidade no modelo, a comparação é feita com um passeio aleatório com correnteza e sazonalidade fixa,

$$
R^{2}{ }_{S}=1-\left\{(T-d) \tilde{\sigma}^{2} / S Q D M S\right\}
$$

onde a soma de quadrados SQDMS tem origem na diferença entre a média sazonal e $\Delta y_{t}$

Os critérios de informação AIC e BIC são utilizados na comparação de modelos concorrentes, mesmo com número de parâmetros diferentes, já que consideram esta diferença em seus cálculos e além disto podem ser usados mesmo para modelos não encaixados.

A inclusão de componentes comuns nos modelos se dá mormente avaliando-se a melhoria no ajuste e na capacidade preditiva que ela ocasiona. Em modelos de previsão, a introdução de componentes comuns estará condicionada principalmente à melhora do poder preditivo.

Os resíduos auxiliares servem para se identificar candidatos a pontos de quebras estruturais ou pontos extremos nos componentes tendência e irregular, respectivamente. Esses pontos estão relacionados a instantes de tempo em que movimentos fora do padrão da série são observados. Os resíduos são autocorrelacionados, mas há possibilidade de se trabalhar com estatísticas corrigidas.

Dois ou mais modelos podem ser comparados em função das qualidades de ajuste e/ou de previsão. Quando se deseja prever é mais sensato considerar prioritariamente a capacidade preditiva, porém, sem se desprezar a qualidade de ajuste.

Assim, quando o objetivo for previsão, após a verificação das significâncias dos coeficientes e hiperparâmetros dos modelos, deve-se avaliar sistemicamente, olhando-se mais atentamente para os indicadores de previsão, porém os resultados do ajuste têm que ser aceitáveis para se ter as melhores previsões possíveis. 
Para os testes de previsão, há duas classificações. Quanto ao período e quanto ao número de passos futuros, avaliados, respectivamente, para previsões realizadas dentro ou fora da amostra, e a um ou a mais de um passo. Deve-se priorizar testes a um passo, pois na estimação foi usada função perda que considera o erro de previsão a um passo.

Testes preditivos pós-amostra validam a capacidade preditiva do modelo e só podem ser utilizados caso tenham sido guardados períodos posteriores ao último utilizado na estimação. Já os testes dentro da amostra são utilizados independentemente de separação de observações.

Quando há variável explicativa e/ou intervenção no modelo, os testes a um passo dentro da amostra usam os resíduos recursivos generalizados $\left(W_{t}\right)$. O teste é o de Chow

$$
\text { Chow }=\left\{\left(\mathrm{T}-b \mathrm{~d}^{*}\right) / \zeta\right\} \sum_{t=T-1+1}^{T} \mathrm{w}^{2} t / \sum_{t=d^{*}+1}^{T-1} \mathrm{w}^{2} \mathrm{t}
$$

onde $\mathrm{d}^{*}=\mathrm{d}+\mathrm{k}$, $\mathrm{k}$ o número de variáveis explicativas do modelo, $\mathrm{w}_{\mathrm{t}}=0$ nos períodos em que houver intervenção e a estatística é distribuída aproximadamente como uma $F\left(\measuredangle T-\measuredangle d^{*}\right)$.

Para testes de falha de previsão (tfp) a um passo pós-amostra, os coeficientes das variáveis explicativas e intervenções são tomados como os valores estimados no final da amostra e o teste, que considera os resíduos padronizados $\widetilde{v}_{t}$, é dado por

$$
t f p=\sum_{j=1}^{L} \widetilde{v}_{T+j}^{2}
$$

onde $L$ é o número de períodos fora da amostra utilizada na estimação. A estatística é aproximadamente distribuída como $\chi_{\mathrm{L}}^{2}$.

Pode-se, ainda, nestes testes do poder preditivo, checar informações através de somas acumuladas (CUSUM) dos erros de previsão. Os gráficos CUSUM espelham eventuais mudanças de nível das inovações ou resíduos analisados e podem, ainda, avaliar alterações na variância quando for usada a soma acumulada dos quadrados. As bandas serão baseadas em nível de significância de $10 \%$. 


\section{6 - Aplicações a séries de agregados monetários brasileiros}

\section{1 - Introdução}

Para ilustrar a metodologia do modelo estrutural na obtenção de previsões serão utilizadas séries de agregados monetários da economia brasileira.

Pretende-se obter previsões dos saldos médios mensais da base monetária (BM), do papel moeda em poder do público (PMPP) e do depósito a vista (DV). Saldo médio mensal equivale à média aritmética dos saldos efetivos dos dias úteis do mês.

A variável PMPP representa o total de dinheiro físico que se encontra efetivamente em circulação e em poder do público. Isto é, todo o dinheiro de liquidez imediata para qualquer pessoa, física ou jurídica.

O conceito de base monetária está associado ao passivo monetário das autoridades monetárias do país. A BM brasileira é constituída por três parcelas: o PMPP, o total de encaixes bancários depositados pelas instituições financeiras junto ao Banco Central (Bacen) e o total de reservas bancárias também depositadas pelas instituições junto ao Bacen, que são formadas unicamente pelos depósitos compulsórios sobre os depósitos a vista.

Os depósitos a vista são os valores depositados nas contas correntes da totalidade de pessoas, físicas ou jurídicas, nas instituições financeiras do país.

Essas variáveis são expressas em padrões monetários e portanto sofreram as alterações de moeda ocorridas no Brasil nos últimos anos. Assim, para uma análise efetiva dos dados, elas são transformadas para uma mesma moeda, o Real (R\$).

A inflação brasileira é outro fator que mascara os dados, tendo provocado, ao longo do tempo, perdas expressivas no valor da moeda. Em muitos casos, até mesmo valores defasados por poucos meses são incomparáveis.

Para contornar essa perda do poder aquisitivo da moeda, os valores das séries são trazidos a valores de outubro de 1996 pela inflação, de modo que quaisquer dois valores possam ser comparáveis e os componentes avaliados.

Como medida da inflação brasileira é utilizado o Índice Geral de Preços Disponibilidade Interna (IGP-DI). Este índice é composto pela média ponderada do Índice de Preços ao Atacado, do Índice de Preço ao Consumidor e do Índice Nacional da 
Construção Civil, calculados pela Fundação Getúlio Vargas, com pesos de 0,6, 0,3 e 0,1 respectivamente.

A estratégia para obtenção das previsões será considerar dois modelos. O primeiro, univariado, tratará da base monetária média. O segundo modelo, bivariado, terá os saldos médios de depósitos a vista e de papel moeda em poder do público.

O fator condicionante da utilização de dois modelos é o tamanho das amostras. Enquanto a base monetária média possui dados desde janeiro de 1980, as outras duas variáveis só começaram a ser disponibilizadas pelo Banco Central a partir de janeiro de 1992.

O prazo de interesse para as previsões é de até seis meses, com ênfase no mês seguinte à última observação.

\section{2 - Modelo estrutural univariado para a base monetária.}

\subsection{1 - Análise da série base monetária}

O comportamento da base monetária está relacionado com algumas variáveis, entre as mais convencionalmente citadas estão as taxas de inflação e de juros nominais ou reais. A relação com essas taxas é inversa, no sentido que quando as taxas de inflação ou de juros crescem, os valores da base decrescem e vice-versa. Isto, principalmente porque uma grande parte da BM é dada pelo PMPP, e em períodos de altas taxas de inflação ou de juros os agentes realocam o dinheiro em seu poder para ativos financeiros indexados, para evitar perda de poder aquisitivo da moeda, contraindo a base. E em períodos de baixas taxas de inflação ou de juros os agentes tendem a possuir maior quantidade de moeda em seu poder já que a perda de poder aquisitivo é reduzida, expandindo a BM.

O gráfico 6.2.1.1 apresenta a série histórica da base monetária média mensal para o período de janeiro de 1980 a outubro de 1996. Os dados foram retirados de Boletins do Banco Central do Brasil e encontram-se no apêndice, a valores de outubro de 1996, atualizados pelo IGP-DI, e sob um mesmo padrão monetário, o Real - R\$. 
Base monetária média mensal, a preços constantes de out/96.

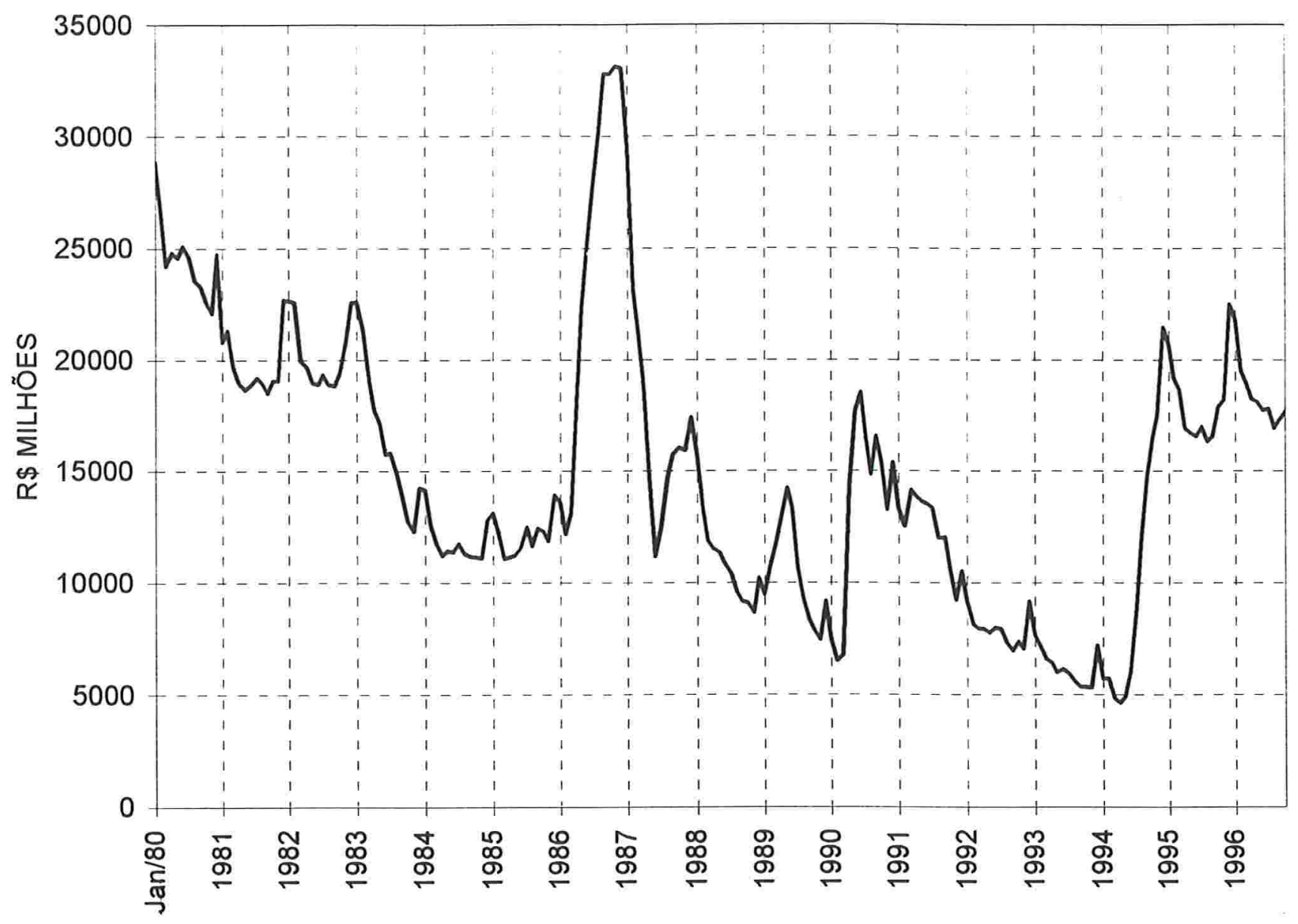

Visualmente, o comportamento da BM média não se mostra plenamente regular ao longo da amostra, o que é justificado pelos períodos de turbulência econômica e pelas tentativas de estabilização que o país atravessou.

Nas épocas dos planos econômicos, a série tem padrão muito semelhante: no início, quando as taxas de inflação e juros nominais recuavam, existia uma elevação no nível da BM, porém, com o fracasso da estabilização, aumento das taxas, o nível da base retornava ou passava os patamares anteriores aos planos.

O grande pico, presente no ano de 1986, é a quebra estrutural mais marcante. Provavelmente porque está associado a um plano econômico, o plano Cruzado de março de 1986, que obteve grande confiança em seu possível sucesso por parte da população.

A lista de planos econômicos que afetaram a economia brasileira no período sob análise é composta pelo plano Cruzado, março de 1986; Cruzado II, novembro de 1986; 
Bresser, junho de 1987; Verão, janeiro de 1989; Collor, março de 1990; Collor II, março de 1991; e Real, junho de 1994.

Com o plano Real, o comportamento da base foi somente em parte semelhante ao observado em outros planos de estabilização da economia, dado que houve um aumento em seu nível e não houve até final de 1996 a volta aos níveis anteriores ao plano.

O gráfico 6.2.1.1 mostra a existência de padrão sazonal na série. Há indicação que no início e final de cada ano os saldos são superiores aos meses intermediários. O efeito mais marcante acontece no mês de dezembro que apresenta nítida e freqüentemente saldos maiores que os outros meses.

Também observa-se que não existe tendência de crescimento ou decrescimento constante ao longo da amostra. As tendências variam em consonância com as implantações e os fracassos dos planos econômicos. A partir de 1995, a taxa de crescimento da série encontra-se próxima de zero.

A série original, bem como a logaritmada, pode ser considerada integrada de primeira ordem, I(1), para os niveis de coeficiente de confiança usuais de $1 \%$ e $5 \%$, segundo o teste de raiz unitária realizado no PcGive. Os resultados podem ser vistos nas tabelas 6.2.1.1 e 6.2.1.2. O teste utilizado é o de Dickey-Fuller aumentado e inclui constante e termos sazonais no modelo para o período amostral de maio/1981 até outubro/1996 e os valores críticos correspondentes a $5 \%$ e a $1 \%$ são iguais, respectivamente, a -2.877 e -3.467 . 
TABELA 6.2.1.1

Testes de raiz unitária Dickey-Fuller aumentado: BM original e sua primeira diferença.

\begin{tabular}{|c|c|c|c|c|c|}
\hline VARIÁVEL & t-ADF & $\sigma$-LAG & LAG & t-LAG & P-VALUE \\
\hline $\mathrm{BM}$ & -2.13 & 1144.4 & 8 & -0.34 & 0.732 \\
\hline $\mathrm{BM}$ & -2.22 & 1141.3 & 7 & -2.12 & 0.036 \\
\hline BM & -2.64 & 1153.2 & 6 & -0.71 & 0.482 \\
\hline BM & -2.85 & 1151.5 & 5 & -0.72 & 0.470 \\
\hline BM & $-3.10^{*}$ & 1149.8 & 4 & 0.79 & 0.432 \\
\hline BM & $-3.00^{*}$ & 1148.5 & 3 & -0.01 & 0.993 \\
\hline BM & $-3.10^{*}$ & 1145.2 & 2 & 0.33 & 0.744 \\
\hline BM & $-3.11^{*}$ & 1142.2 & 1 & 9.81 & 0.000 \\
\hline BM & -1.65 & 1422.5 & 0 & & \\
\hline DBM & $-5.67^{\star \star}$ & 1157.9 & 8 & 0.78 & 0.436 \\
\hline DBM & $-5.87^{\star \star}$ & 1156.5 & 7 & 0.67 & 0.506 \\
\hline DBM & $-6.19^{\star \star}$ & 1154.6 & 6 & 2.55 & 0.012 \\
\hline DBM & $-5.55^{\star \star}$ & 1173.4 & 5 & 1.26 & 0.210 \\
\hline DBM & $-5.48^{\star \star}$ & 1175.5 & 4 & 1.38 & 0.170 \\
\hline DBM & $-5.34^{* \star}$ & 1178.5 & 3 & -0.14 & 0.886 \\
\hline DBM & $-5.92^{\star \star}$ & 1175.2 & 2 & 0.71 & 0.478 \\
\hline DBM & $-6.22^{* *}$ & 1173.5 & 1 & 0.36 & 0.719 \\
\hline DBM & $-6.83^{\star \star}$ & 1170.5 & 0 & & \\
\hline
\end{tabular}

Nota: (i) t-ADF corresponde à estatística t da variável em nível;

(ii) $\sigma$-LAG corresponde ao desvio padrão residual quando se utiliza o número de defasagens dado pela coluna seguinte;

(iii LAG é o número de defasagens utilizado;

(iv) t-LAG é a estatística t da defasagem;

(v) P-VALUE é o nível descritivo de (iv).

TABELA 6.2.1.2

Testes de raiz unitária Dickey-Fuller aumentado: BM logaritmada e sua primeira diferença.

\begin{tabular}{|c|c|c|c|c|c|}
\hline VARIÁVEL & t-ADF & $\sigma$-LAG & LAG & t-LAG & P-VALUE \\
\hline BM & -2.10 & 0.093 & 8 & 0.11 & 0.915 \\
\hline BM & -2.11 & 0.093 & 7 & -2.15 & 0.033 \\
\hline BM & -2.54 & 0.094 & 6 & 0.05 & 0.957 \\
\hline BM & -2.58 & 0.094 & 5 & -0.09 & 0.931 \\
\hline BM & -2.65 & 0.093 & 4 & 1.39 & 0.165 \\
\hline BM & -2.44 & 0.094 & 3 & -1.27 & 0.205 \\
\hline BM & -2.76 & 0.094 & 2 & 0.60 & 0.549 \\
\hline BM & -2.70 & 0.094 & 1 & 7.19 & 0.000 \\
\hline BM & -1.67 & 0.106 & 0 & & \\
\hline DBM & $-5.26^{\star \star}$ & 0.094 & 8 & 0.74 & 0.461 \\
\hline DBM & $-5.40^{\star \star}$ & 0.094 & 7 & 0.21 & 0.834 \\
\hline DBM & $-5.84^{* \star}$ & 0.094 & 6 & 2.57 & 0.011 \\
\hline DBM & $-5.17^{\text {** }}$ & 0.095 & 5 & 0.43 & 0.667 \\
\hline DBM & $-5.44^{\star \star}$ & 0.095 & 4 & 0.59 & 0.559 \\
\hline DBM & $-5.68^{\star \star}$ & 0.095 & 3 & -0.92 & 0.357 \\
\hline DBM & $-6.90^{\star \star}$ & 0.095 & 2 & 1.79 & 0.075 \\
\hline DBM & $-6.81^{\text {** }}$ & 0.096 & 1 & -0.07 & 0.948 \\
\hline DBM & $-8.03^{\star \star}$ & 0.095 & 0 & & \\
\hline
\end{tabular}


Então, com o teste de raiz unitária Dickey-Fuller aumentado considerado como indicativo, pois há várias quebras estruturais na BM que podem provocar anomalias, há indicação que a ordem de integração da BM - tanto original como transformada - é menor do que 2 o teste aponta BM como I(1) mas não como I(2), pois sua primeira diferença é estacionária).

A conclusão é que a presença de tendência com taxa de crescimento diferente de zero no modelo pode ser descartada. Assim, justifica-se sua ausência nos modelos a serem ajustados para a BM. Porém, o fator definitivo na decisão de excluir a taxa de crescimento foi devido às piores previsões apresentadas pelos modelos que a incluíram.

A falta de tendência marcante na série recente e as acentuadas oscilações na inclinação durante a amostra toda contribuem para a ausência de taxa de crescimento estatisticamente significativa nos modelos a serem estimados.

Apesar da série aparentemente não apresentar componente cíclica, pode haver algum pseudo-ciclo nos dados, o que não é raro em séries econômicas. Assim, será testado a existência desse componente no modelo final.

\subsection{2 - Especificação e estimação do modelo estrutural para a base monetária}

Então, a busca de um modelo estrutural adequado para previsão da BM média mensal partirá de um modelo com nível local, sazonalidade e componente irregular, todos estocásticos.

Considerando que a série possui diversas quebras estruturais, um modelo univariado puro, sem variáveis explicativas, pode não possuir parâmetros estáveis ao longo do tempo, refletindo esta instabilidade nas previsões. Desse modo, é aconselhável a introdução no modelo de ao menos uma variável explicativa. A presença de uma variável serve também para se avaliar comportamentos da BM sob possiveis cenários alternativos.

Optou-se por incluir apenas uma variável independente considerando que o objetivo é prever e que as previsões para a BM dependerão de valores futuros das variáveis explicativas presentes no modelo. 
Um índice inflacionário é uma variável adequada como explicativa para auxiliar na modelagem da BM tendo em vista seu significativo coeficiente de correlação linear e sua facilidade de obtenção.

Tendo em vista que os componentes não observados do modelo estrutural são apresentados na forma aditiva e que para a base monetária, ou variáveis econômicas, esses componentes são, em geral, mais realisticamente combinados na forma multiplicativa, a BM, em Real R\$, a valores de outubro de 1996 (corrigida pelo IGP-DI) será transformada pela função logaritmo.

A taxa de inflação será o IGP-DI, sua série histórica encontra-se no apêndice. A série da variação mensal em percentagem será convertida em fatores e em seguida será transformada pela função logaritmo. Isto é, os valores das percentagens da variação mensal serão divididos por cem, em seguida somados a um, e por fim serão tomados os logaritmos desses valores. As variações mensais do índice de preços não são logaritmadas diretamente pois existem no período alguns poucos valores em que a inflação mensal foi negativa.

GRÁFICO 6.2.2.1

Base monetária média mensal e IGP-DI transformados.

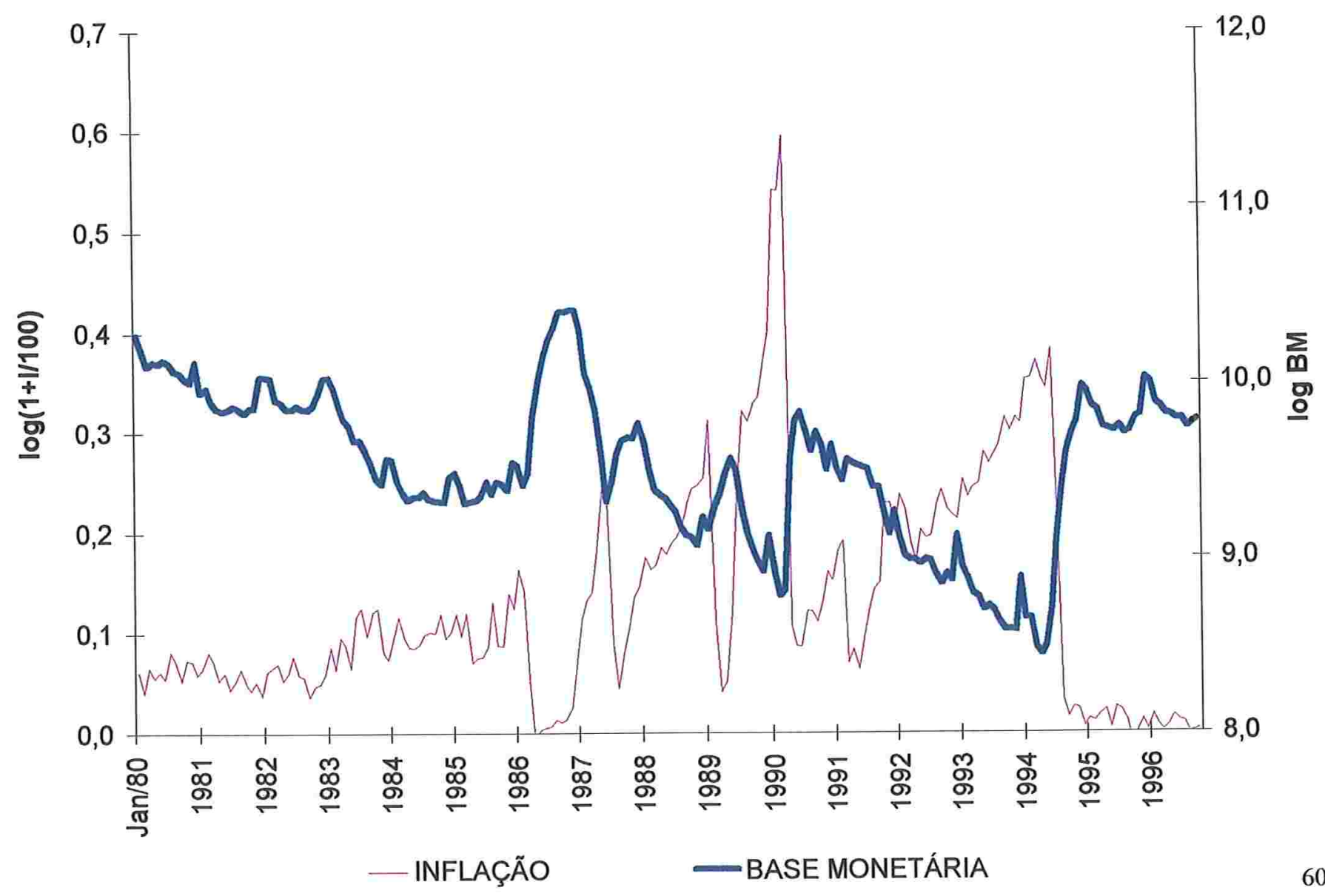


Pelo gráfico, que apresenta as séries transformadas da BM média mensal e da inflação, percebe-se claramente a relação inversa entre as variáveis.

Enfim, será inicialmente estimado um modelo para o logaritmo da BM que contém os componentes estocásticos nível, sazonalidade e irregular, além da variável explicativa transformada da inflação do mês e de suas defasagens até ordem quatro. ${ }^{1}$

O período amostral será de janeiro de 1980 a março de 1996, deixando-se as sete observações de abril a outubro de 1996 para validação do modelo e para a comparação do poder preditivo de modelos concorrentes.

A presença da inflação contemporânea no modelo deve-se à superioridade de ajuste e de capacidade preditiva que ele possui quando comparado com modelos estimados sem a presença da inflação do mês.

Então o modelo 1 pode ser escrito na seguinte forma:

$$
B M_{t}=\mu_{t}+\gamma_{t}+\delta_{0} l_{t}+\delta_{1} l_{t-1}+\delta_{2} l_{t-2}+\delta_{3} l_{t-3}+\left.\delta_{4}\right|_{t-4}+\varepsilon_{t}
$$

onde, $\mu_{t}=\mu_{t-1}+\eta_{t}, \quad$ e $\quad \sum_{j=1}^{s-1} \gamma_{t-j}=\varpi_{t}$

O componente estocástico sazonal é da forma dummy porque o modelo final com essa forma apresentou melhor poder preditivo do que o modelo com a forma trigonométrica.

A estimação e toda análise da modelagem é realizada no programa STAMP. Sua referência é Koopman, Harvey, Doornik and Shephard (1995).

A convergência na estimação dos parâmetros do modelo 1 é, como desejável, classificada na melhor categoria utilizada no STAMP, isto é, muito forte; de acordo com seu o critério de convergência padrão. Os próximos modelos para o ajuste da base monetária que serão descritos também possuem esta importante característica, que deixará de ser mencionada.

As estimativas para os coeficientes das variáveis explicativas e seus níveis descritivos são apresentadas na tabela 6.2.2.1. Pode-se notar que os valores para os coeficientes de $\mathrm{I}_{\mathrm{t}-3}$ e $\mathrm{I}_{\mathrm{t}-4}$ não se mostram importantes para o modelo ajustado. Os valores

\footnotetext{
1 Este lag foi escolhido imaginando-se que as ausências das defasagens de ordens superiores a 4 para a inflação não seriam prejudiciais na escolha de um modelo para se prever a BM média, principalmente considerando a relativa estabilidade posterior a julho de 1994. Esta escolha mostrou-se acertada pois, no modelo final, em testes para a inflação desde a defasagem de ordem 13, somente as três primeiras e a contemporânea mostraram-se significativamente diferentes de zero.
} 
das estatísticas para eles são indicações que não se rejeitam as hipóteses nulas de que os coeficientes dessas defasagens são estatisticamente iguais a zero.

TABELA 6.2.2.1

Estimativas para os coeficientes das variáveis explicativas (modelo 1).

\begin{tabular}{|c|c|c|c|c|}
\hline VARIÁVEL & COEFICIENTE & REQM & T-VALUE & P-VALUE \\
\hline $\mathrm{I}_{\mathrm{t}}$ & -1.4509 & 0.0992 & -14.623 & {$[0.0000]^{* *}$} \\
$\mathrm{I}_{\mathrm{t}-1}$ & -0.5418 & 0.0991 & -5.467 & {$[0.0000]^{* *}$} \\
$\mathrm{I}_{\mathrm{t}-2}$ & -0.3710 & 0.0979 & -3.791 & {$[0.0002]^{* *}$} \\
$\mathrm{I}_{\mathrm{t}-3}$ & -0.1192 & 0.0992 & -1.202 & {$[0.2311]$} \\
$\mathrm{I}_{\mathrm{t}-4}$ & -0.1127 & 0.0989 & -1.139 & {$[0.2560]$} \\
\hline
\end{tabular}

Nota: (i) REQM significa raiz do erro quadrático médio;

(ii) t-value, estatística t do coeficiente

(iii) p-value, nivel descritivo.

Os sinais negativos dos coeficientes estimados são compatíveis com o esperado, confirmando a relação inversa entre a BM e a inflação. A significância das defasagens diminui com o tempo, isto é, quanto mais afastada do período contemporâneo menos importante é a variável para explicar a BM média.

Os valores estimados para os hiperparâmetros dos componentes não observados estão na tabela 6.2.2.2.

O hiperparâmetro da sazonalidade é próximo de zero; valor igual a zero indica que a sazonalidade é determinística ou caso os efeitos sazonais sejam iguais a zero que a sazonalidade não existe. Para a BM valeria a primeira hipótese, pois é notória a existência de padrão sazonal nos dados. Além disso o nível descritivo do teste de qui-quadrado para a hipótese de falta de sazonalidade no último período do vetor de espaço de estados é igual a 0.0000 , sendo altamente significativo, ou seja, há rejeição da hipótese de não existência de fatores sazonais

O fato do nível ser o componente que possui a maior variabilidade ao longo do período é uma constante em todos modelos estimados implicando que este componente é o responsável pela variabilidade da série.

TABELA 6.2.2.2

Estimativas dos hiperparâmetros (modelo 1).

\begin{tabular}{|l|c|c|}
\hline Componente & Desvio Padrão & Razão q \\
\hline Irregular & 0.0000 & 0.0000 \\
Nivel & 0.0659 & 1.0000 \\
Sazonalidade & 0.0027 & 0.0413 \\
\hline
\end{tabular}


Embora o modelo 1 não esteja bem ajustado à $\mathrm{BM}$, contendo, inclusive, variáveis não significativas, a inspeção dos resíduos auxiliares do nível é sugestiva, podendo antecipar a necessidade de introdução de intervenções no nível. Ao mesmo tempo, essas indicações de intervenções podem ter suas presenças confirmadas caso tenham ocorrido nos conhecidos períodos de quebras estruturais associadas aos planos econômicos.

TABELA 6.2.2.3

Maiores valores dos resíduos do nível (modelo
\begin{tabular}{|c|c|c|}
\hline PERÍODO & VALOR & P-VALUE \\
\hline 1981.1 & -2.352 & {$[0.0098]^{* *}$} \\
1986.4 & 3.107 & {$[0.001]^{* *}$} \\
1986.5 & 2.507 & {$[0.0065]^{* *}$} \\
1987.6 & -4.027 & {$[0.0000]^{* *}$} \\
1989.5 & 2.516 & {$[0.0063]^{* *}$} \\
1990.3 & 3.636 & {$[0.0002]^{* *}$} \\
1990.6 & -3.373 & {$[0.0004]^{* *}$} \\
1990.7 & -3.068 & {$[0.0012]^{* *}$} \\
1990.8 & -2.426 & {$[0.0081]^{* *}$} \\
1994.6 & 3.832 & {$[0.0001]^{* *}$} \\
1994.7 & 2.484 & {$[0.0069]^{* *}$} \\
\hline
\end{tabular}

Assim, um novo modelo será estimado retirando-se a quarta defasagem da variável transformada da inflação - $I_{t-4}$ - e incluindo-se intervenções no nível da série que estão associadas a nítidos pontos de quebra estrutural da série, a maioria períodos iniciais de planos econômicos, quando as mudanças do nível do saldo médio da base monetária foram mais drásticas. Os pontos com esses maiores resíduos do nível, conforme tabela 6.2.2.3, são: 1986/4, 1987/6, 1990/3, 1990/6, 1990/7, 1994/6 ².

Então, o novo modelo é descrito conforme a equação

$$
\mathrm{BM}_{\mathrm{t}}=\mu_{\mathrm{t}}+\gamma_{\mathrm{t}}+\delta_{0} \mathrm{l}_{\mathrm{t}}+\delta_{1} \mathrm{I}_{\mathrm{t}-1}+\delta_{2} \mathrm{I}_{\mathrm{t}-2}+\delta_{3} \mathrm{l}_{\mathrm{t}-3}+\sum_{i=1}^{6} \lambda_{i} \mathrm{~W}_{\mathrm{i}, \mathrm{t}}+\varepsilon_{\mathrm{t}}
$$

onde $\lambda_{i}$ são os parâmetros desconhecidos das intervenções $w_{i, t}$ que são variáveis pulso que assumem valores zero antes do período determinado como intervenção e um no próprio período e nos seguintes, indicando uma mudança de nível da série. Os componentes não observados são idênticos às do modelo anterior.

Nesse modelo 2, as estimativas dos hiperparâmetros, conforme tabela 6.2.2.4, indicam uma maior variabilidade para a sazonalidade e uma menor para o nível, quando

\footnotetext{
${ }^{2}$ Embora existam outros instantes de tempo com valores acima dos valores críticos usuais, optou-se por incluir, inicialmente, os instantes com valores superiores a 3. Como será visto mais a frente, algumas intervenções não incluidas neste modelo serão necessárias.
} 
comparados com os respectivos valores obtidos para o modelo 1 . O hiperparâmetro do irregular apresenta valor idêntico ao anterior, sendo novamente na estimação mantido como restrito.

TABELA 6.2.2.4

Estimativas dos hiperparâmetros do modelo 2.

\begin{tabular}{|l|c|c|}
\hline Componente & Desvio Padrão & Razão q \\
\hline Irregular & 0.0000 & 0.0000 \\
Nível & 0.0489 & 1.0000 \\
Sazonalidade & 0.0050 & 0.1017 \\
\hline
\end{tabular}

As estimativas dos coeficientes das variáveis independentes e das intervenções, tabela 6.2.2.5, indicam que todos coeficientes são significativos.

TABELA 6.2.2.5

Estimativas para os coeficientes das variáveis explicativas e intervenções (modelo 2).

\begin{tabular}{|c|c|c|c|c|}
\hline VARIÁVEL & COEFICIENTE & REQM & T-VALUE & P-VALUE \\
\hline$I_{t}$ & -1.5361 & 0.0754 & -20.361 & {$[0.0000]$ ** } \\
\hline$I_{t-1}$ & -0.4605 & 0.0751 & -6.130 & {$[0.0000]^{* *}$} \\
\hline $\mathrm{I}_{\mathrm{t}-2}$ & -0.6787 & 0.1074 & -6.318 & {$[0.0000]^{* *}$} \\
\hline$I_{t-3}$ & -0.3917 & 0.1075 & -3.645 & {$[0.0003]^{* \star}$} \\
\hline LvI 1986.4 & 0.2230 & 0.0523 & 4.261 & {$[0.0000]^{* *}$} \\
\hline Lvl 1987.6 & -0.2635 & 0.0526 & -5.008 & {$[0.0000]^{\star \star}$} \\
\hline Lvl 1990.3 & 0.2935 & 0.0534 & 5.498 & {$[0.0000]^{* *}$} \\
\hline Lvl 1990.6 & -0.2995 & 0.0754 & -3.973 & {$[0.0001]^{\star *}$} \\
\hline Lvl 1990.7 & -0.2919 & 0.0731 & -3.992 & {$[0.0001]^{* *}$} \\
\hline Lvl 1994.6 & 0.2488 & 0.0535 & 4.654 & {$[0.0000]^{* *}$} \\
\hline
\end{tabular}

Porém, ainda existem resíduos auxiliares destoantes no nível da série, tabela 6.2.2.6. Esses pontos mal ajustados, indicam que novas intervenções devem melhorar o ajuste e a capacidade preditiva do modelo 2. Esses períodos estão, à exceção de janeiro de 1981, relacionados a épocas de planos econômicos.

TABELA 6.2.2.6

Maiores valores dos resíduos do nível (modelo 2).

\begin{tabular}{|c|r|c|}
\hline PERIODO & VALOR & P-VALUE \\
\hline 1981.1 & -3.1934 & {$[0.0008]^{* *}$} \\
1986.5 & 2.8935 & {$[0.0021]^{* *}$} \\
1990.4 & 2.8993 & {$[0.0021]^{\star *}$} \\
1994.7 & 2.3473 & {$[0.0100]^{* *}$} \\
\hline
\end{tabular}

Pelo exposto, outro modelo será estimado. Ele não possuirá o componente irregular ${ }^{3}$ mas, além das variáveis explicativas e intervenções do modelo 2, mais quatro intervenções no

\footnotetext{
${ }^{3}$ Caso o modelo a ser descrito possuisse o irregular, não haveria alteraçōes nas estatísticas em geral, inclusive verossimilhança e testes de previsão. Só os critérios AIC e BIC seriam diferentes, justificando o uso do modelo 3 sem irregular.
} 
nível dos períodos 1981/1,1986/5, 1990/4 e 1994/7. O modelo é escrito da seguinte forma:

$$
\mathrm{BM}_{\mathrm{t}}=\mu_{\mathrm{t}}+\gamma_{\mathrm{t}}+\delta_{0} \mathrm{l}_{\mathrm{t}}+\delta_{1} \mathrm{l}_{\mathrm{t}-1}+\delta_{2} \mathrm{l}_{\mathrm{t}-2}+\delta_{3} \mathrm{l}_{\mathrm{t}-3}+\sum_{i=1}^{10} \lambda_{\mathrm{i}} \mathrm{W}_{\mathrm{i}, \mathrm{t}}
$$

Os valores dos novos hiperparâmetros estimados, tabela 6.2.2.7, quando comparados com os valores estimados no modelo 2 , apresentam novos aumento de variabilidade no caso da sazonalidade e diminuição no caso do nível. Ressalte-se que a variabilidade do nível ainda é mais expressiva do que a da sazonalidade.

\section{TABELA 6.2.2.7}

Estimativas dos hiperparâmetros (modelo 3).

\begin{tabular}{|l|c|c|}
\hline Componente & Desvio Padrão & Razão q \\
\hline Nível & 0.0432 & 1.0000 \\
Sazonalidade & 0.0052 & 0.1210 \\
\hline
\end{tabular}

A tendência suavizada combinada com as variáveis explicativas, ilustrada no gráfico 6.2.2.2, dá uma noção da qualidade do ajuste do modelo.

\section{GRÁFICO 6.2.2.2}

Componente tendência combinada com variáveis explicativas (modelo 3).

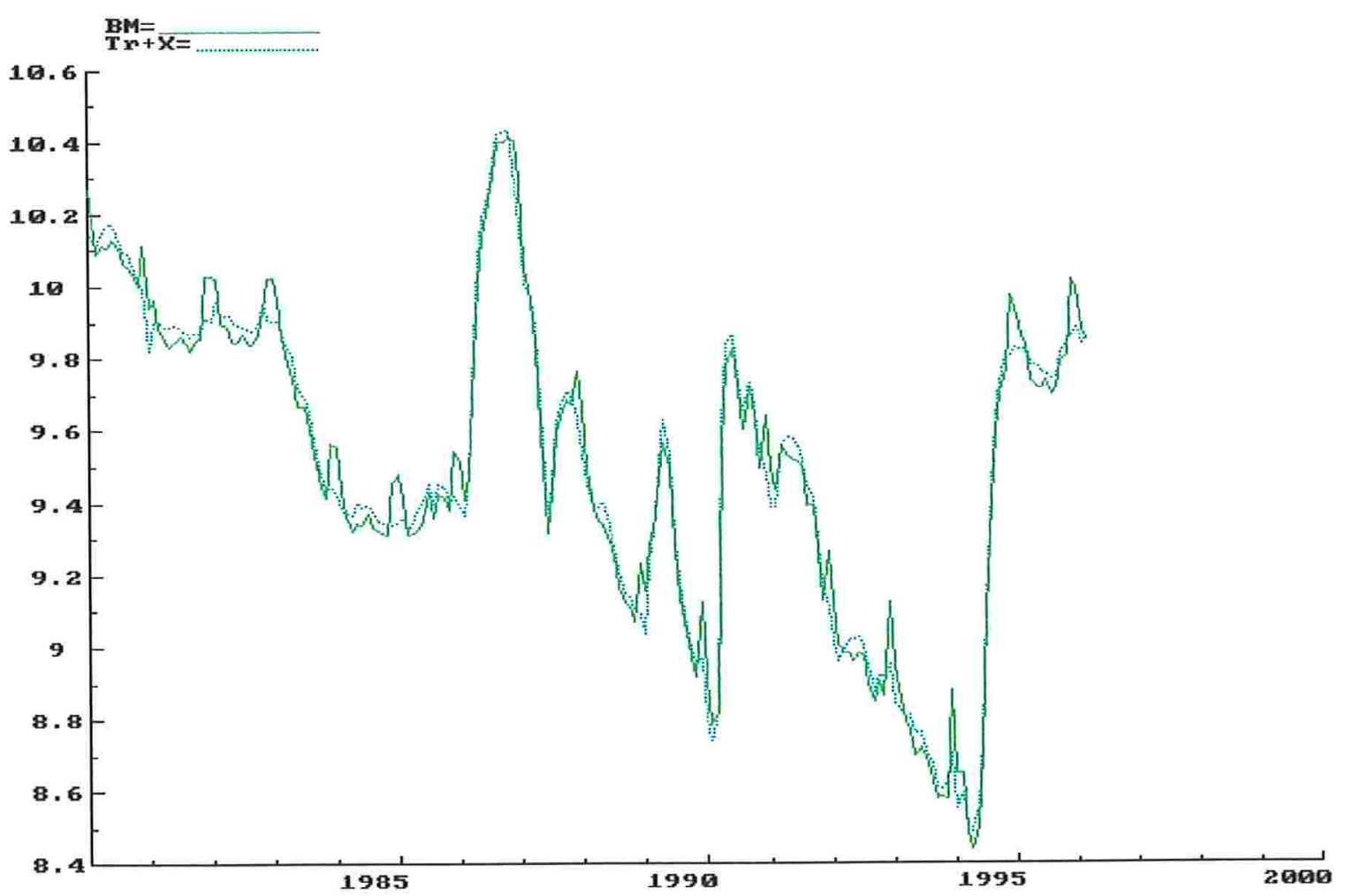


As estimativas da sazonalidade e de seus fatores mensais ao longo da amostra para a série original são apresentadas no gráfico 6.2.2.3. Ao longo da amostra os fatores sazonais mensais não variam muito, porém os efeitos mais significativos são os que mais se alteram. Na tabela 6.2.2.8 encontram-se, também para a série original, os fatores mensais de proporcionalidade estimados para o último período da amostra. As contribuições individuais são mais intensas para os meses de dezembro, janeiro e maio. As estimativas para o último período mostram que a base monetária encontra-se, em média, $17.54 \%$ maior no mês de dezembro, $11.52 \%$ maior no mês de janeiro e $5.62 \%$ menor em maio.

GRÁFICO 6.2.2.3

Sazonalidade e fatores ao longo da amostra para a série original (modelo 3 ).
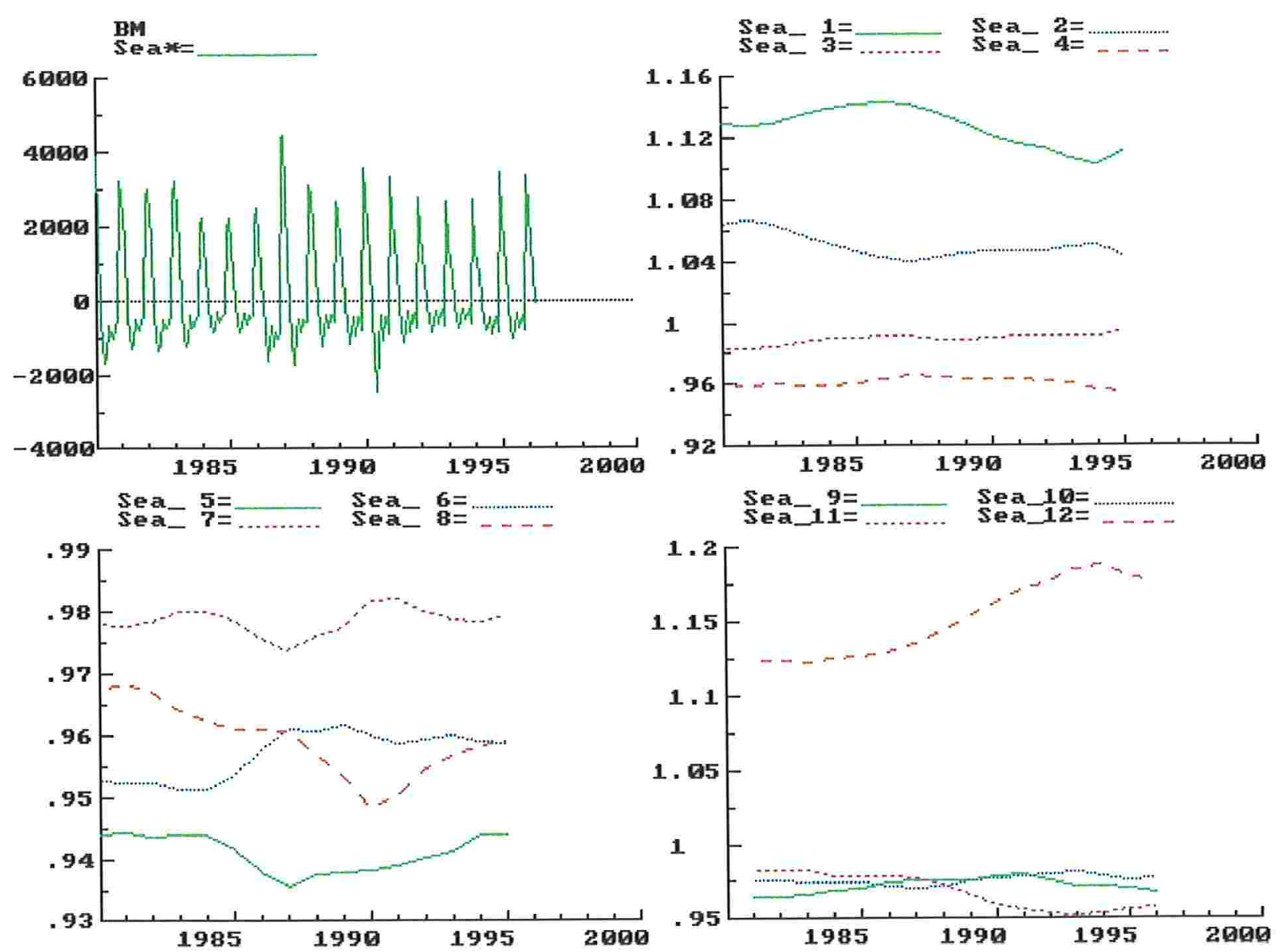
TABELA 6.2.2.8

Estatísticas para a sazonalidade do último período da amostra (modelo 3).

\begin{tabular}{|c|c|c|}
\hline & FATOR DE & \\
PERIODO & PROPORCIONALIDADE & PERCENTAGEM \\
\hline JAN & 1.115 & 11.52 \\
FEV & 1.040 & 4.05 \\
MAR & 0.997 & -0.30 \\
ABR & 0.955 & -4.47 \\
MAI & 0.944 & -5.62 \\
JUN & 0.958 & -4.15 \\
JUL & 0.979 & -2.08 \\
AGO & 0.959 & -4.13 \\
SET & 0.968 & -3.23 \\
OUT & 0.978 & -2.25 \\
NOV & 0.958 & -4.17 \\
DEZ & 1.175 & 17.54 \\
\hline
\end{tabular}

TABELA 6.2.2.9

Coeficientes estimados para o último vetor de espaços de estados (modelo 3 ).

\begin{tabular}{|c|c|c|c|l|}
\hline VARIÁVEL & COEFICIENTE & REQM & T-VALUE & P-VALUE \\
\hline Nível & 9.8713 & 0.0161 & 613.79 & {$[0.0000]^{* *}$} \\
sea 1 & -0.0030 & 0.0163 & -0.185 & {$[0.8535]^{*}$} \\
sea 2 & 0.0397 & 0.0154 & 2.577 & {$[0.0108]^{*}$} \\
sea 3 & 0.1090 & 0.0153 & 7.107 & {$[0.0000]^{* \star}$} \\
sea 4 & 0.1617 & 0.0151 & 10.738 & {$[0.0000]^{* *}$} \\
sea 5 & -0.0426 & 0.0151 & -2.812 & {$[0.0055]^{* *}$} \\
sea 6 & -0.0227 & 0.0152 & -1.498 & {$[0.1359]^{*}$} \\
sea 7 & -0.0328 & 0.0152 & -2.156 & {$[0.0324]^{*}$} \\
sea 8 & -0.0422 & 0.0154 & -2.733 & {$[0.0069]^{* *}$} \\
sea 9 & -0.0211 & 0.0157 & -1.337 & {$[0.1828]^{* *}$} \\
sea 10 & -0.0424 & 0.0162 & -2.610 & {$[0.0098]^{* *}$} \\
sea 11 & -0.0578 & 0.0158 & -3.649 & {$[0.0003]^{* *}$} \\
\hline
\end{tabular}

Além do nível, existem seis fatores sazonais altamente significativos no último período da amostra conforme tabela 6.2.2.9.

As estimativas para os coeficientes das variáveis explicativas e das intervenções são todos significativamente diferentes de zero. 
TABELA 6.2.2.10

Estatísticas para os coeficientes das variáveis explicativas e intervenções (modelo 3 ).

\begin{tabular}{|c|c|c|c|c|}
\hline VARIÁVEL & COEFICIENTE & REQM & T-VALUE & P-VALUE \\
\hline$I_{t}$ & -1.2082 & 0.1008 & -11.986 & {$[0.0000]^{* *}$} \\
\hline$I_{t-1}$ & -0.5399 & 0.0693 & -7.790 & {$[0.0000]^{* *}$} \\
\hline$I_{t-2}$ & -0.5952 & 0.0975 & -6.102 & {$[0.0000]^{* *}$} \\
\hline$I_{t-3}$ & -0.4308 & 0.0970 & -4.441 & {$[0.0000]^{* *}$} \\
\hline Lvl 1981.1 & -0.1701 & 0.0484 & -3.511 & {$[0.0006]^{* *}$} \\
\hline Lvl 1986.4 & 0.2339 & 0.0470 & 4.982 & {$[0.0000]^{\star *}$} \\
\hline LvI 1986.5 & 0.1534 & 0.0472 & 3.253 & {$[0.0014]^{\star *}$} \\
\hline LvI 1987.6 & -0.2583 & 0.0471 & -5.481 & {$[0.0000]^{\star \star}$} \\
\hline Lvl 1990.3 & 0.2569 & 0.0482 & 5.327 & {$[0.0000]^{\star *}$} \\
\hline Lvl 1990.4 & 0.2711 & 0.0690 & 3.927 & {$[0.0001]^{* *}$} \\
\hline Lvl 1990.6 & -0.2558 & 0.0681 & -3.757 & {$[0.0002]^{* *}$} \\
\hline LVl 1990.7 & -0.3145 & 0.0662 & -4.748 & {$[0.0000]^{\star *}$} \\
\hline Lvl 1994.6 & 0.2346 & 0.0480 & 4.887 & {$[0.0000]^{\star *}$} \\
\hline Lvl 1994.7 & 0.1792 & 0.0510 & 3.516 & {$[0.0006]^{\star *}$} \\
\hline
\end{tabular}

Quanto à qualidade de ajuste, o modelo 3 estimado fornece as estatísticas da tabela 6.2.2.11. Pode-se dizer que a especificação do modelo é apropriada.

Essa tabela 6.2.2.11 também fornece os resultados para o modelo 2. Comparandose os resultados o modelo 3 é escolhido segundo critérios de informação.

Comentando-se exclusivamente os resultados do modelo 3 , percebe-se que a variância dos erros de previsão (VEP), que é a média dos erros ao quadrado, o erro padrão e o desvio médio dos erros de previsão para a série transformada apresentam valores pequenos. O erro relativo é razoável, pois indica que o erro médio de previsão para as previsões a um passo é de aproximadamente $0,15 \%$. A estimativa da razão $2 \mathrm{VEP} / \pi \mathrm{DM}^{2}$ é igual a 1.1761, ela não se encontra afastada do valor ideal 1.

Os coeficientes de determinação apresentam valores superiores a $80 \%$ em suas três versões. 
TABELA 6.2.2.11

Estatísticas de qualidade de ajuste (modelos 2 e 3).

\begin{tabular}{|c|c|c|}
\hline \multirow[b]{2}{*}{ ESTATÍSTICAS } & \multicolumn{2}{|c|}{ ESTIMATIVAS } \\
\hline & MODELO 2 & MODELO 3 \\
\hline Log-Verossimilhança & 496.039 & 502.866 \\
\hline Variância dos erros de previsão (VEP) & 0.0026 & 0.0021 \\
\hline Erro Padrão & 0.0509 & 0.0453 \\
\hline Desvio médio dos erros de previsão (DM) & 0.0019 & 0.0015 \\
\hline $2 \mathrm{VEP} / \pi \mathrm{DM}^{2}$ & 1.1549 & 1.1761 \\
\hline Erro relativo (100 $\times$ DM) & 0.1926 & 0.1512 \\
\hline Normalidade & $2.775[0.2497]$ & $0.774[0.6792]$ \\
\hline$H(61)$ & $1.228[0.2124]$ & $1.761[0.0144]^{*}$ \\
\hline$r(1)$ & 0.0340 & 0.0323 \\
\hline$r(12)$ & 0.0683 & 0.1270 \\
\hline DW & 1.911 & 1.914 \\
\hline $\mathrm{Q}(12,10)$ (modelo 2$)$ e $\mathrm{Q}(12,11)$ (modelo 3) & $13.29[0.2079]$ & $14.08[0.2286]$ \\
\hline Coeficiente de determinação & 0.9869 & 0.9896 \\
\hline baseado em diferenças & 0.8161 & 0.8543 \\
\hline baseado em dif. torno da média saz. RS $^{2}$ & 0.7505 & 0.8023 \\
\hline Critério de Informação de Akaike & -5.7085 & -5.9104 \\
\hline de Schwartz (Bayes) & -5.3056 & -5.4572 \\
\hline
\end{tabular}

As estimativas para os resíduos do modelo ajustado mostram-se, adequadas, no sentido de não indicarem falta do cumprimento das suposições de normalidade, homocedasticidade e ausência de autocorrelação serial.

Os resíduos do modelo podem ser observados no gráfico 6.2.2.4 e na tabela 6.2.2.12. A estrutura dos resíduos não apresenta correlação significativa a níveis usuais, as estatísticas (teste Box-Ljung) sobre as estimativas de suas autocorrelações sugerem falta de padrão de dependência entre eles, corroborando o resultado do teste DW (1.914). A suposição de normalidade dos resíduos não é rejeitada pelos testes BS e DH com níveis descritivos iguais a 0.6792 e 0.5527 , respectivamente. A falta de padrão sistemático dos resíduos é também indicada pelo gráfico da soma acumulada (CUSUM) dos resíduos padronizados que não atinge as linhas de fronteira baseadas em um nível de significância de $10 \%$. 
GRÁFICO 6.2.2.4

Comportamento dos resíduos do modelo 3.
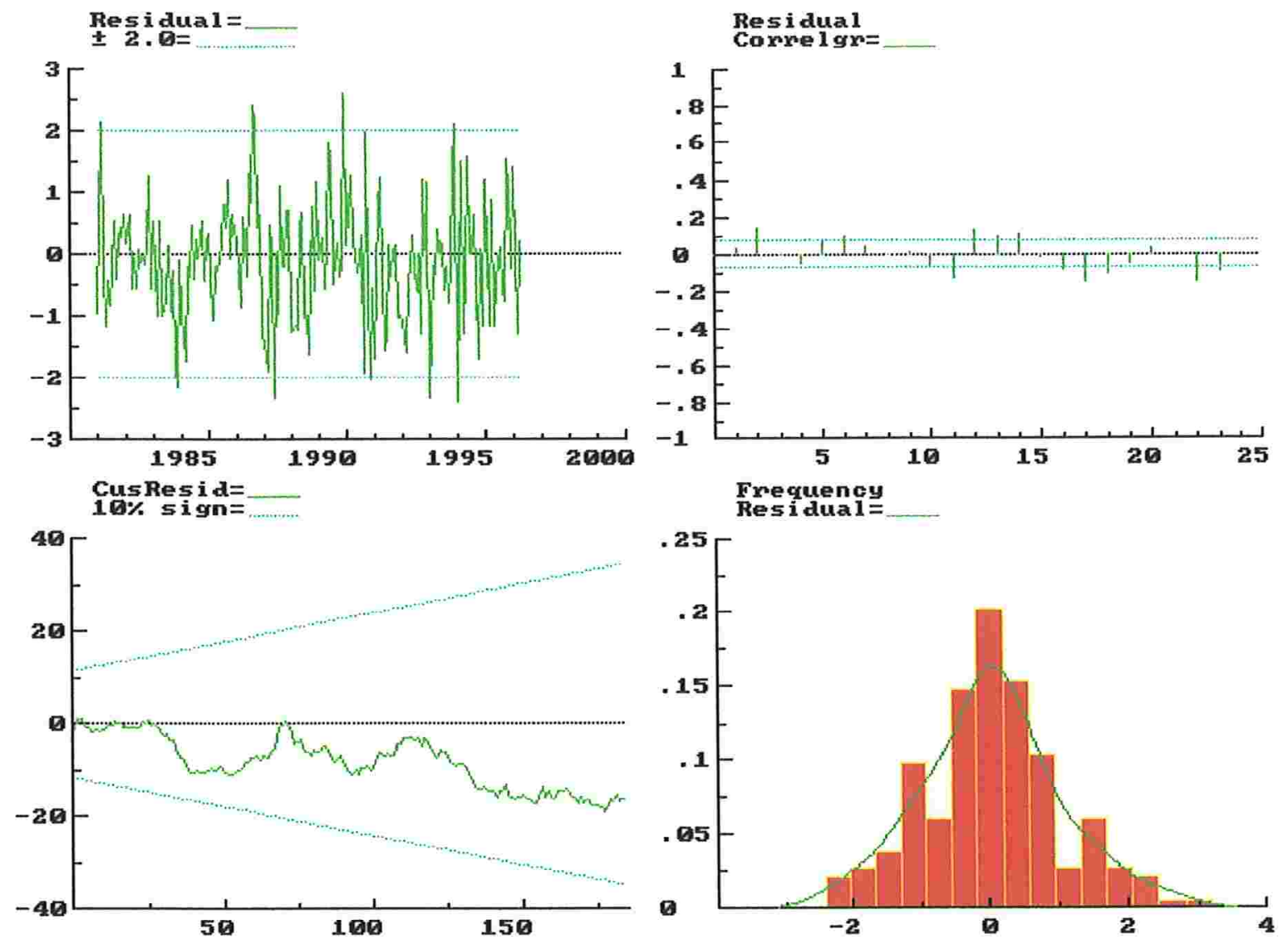

TABELA 6.2.2.12

Correlações seriais e estatísticas para os resíduos (modelo 3).

\begin{tabular}{|c|c|c|c|c|}
\hline LAG & $\begin{array}{c}\text { GRAUS DE } \\
\text { LIBERDADE }\end{array}$ & $\begin{array}{c}\text { AUTOCOR- } \\
\text { RELAÇÃO }\end{array}$ & $\begin{array}{c}\text { TESTE BOX- } \\
\text { LJUNG }\end{array}$ & $\begin{array}{c}\text { NÍVEL } \\
\text { DESCRITIVO }\end{array}$ \\
\hline 1 & 0 & 0.0322 & - & - \\
2 & 1 & 0.1350 & 3.6043 & {$[0.0576]$} \\
3 & 2 & -0.0098 & 3.6224 & {$[0.1635]$} \\
4 & 3 & -0.0475 & 4.0485 & {$[0.2563]$} \\
5 & 4 & 0.0563 & 4.6514 & {$[0.3250]$} \\
6 & 5 & 0.0919 & 6.2667 & {$[0.2811]$} \\
7 & 6 & 0.0338 & 6.4868 & {$[0.3709]$} \\
8 & 7 & -0.0028 & 6.4883 & {$[0.4840]$} \\
9 & 8 & 0.0048 & 6.4928 & {$[0.5922]$} \\
10 & 9 & -0.0746 & 7.5814 & {$[0.5768]$} \\
11 & 10 & -0.1297 & 10.8924 & {$[0.3660]$} \\
12 & 11 & 0.1270 & 14.0831 & {$[0.2284]$} \\
13 & 12 & 0.0933 & 15.8148 & {$[0.1999]$} \\
14 & 13 & 0.1041 & 17.9860 & {$[0.1581]$} \\
15 & 14 & -0.0165 & 18.0411 & {$[0.2049]$} \\
16 & 15 & -0.0866 & 19.5606 & {$[0.1894]$} \\
17 & 16 & -0.1515 & 24.2428 & {$[0.0843]$} \\
18 & 17 & -0.1014 & 26.3541 & {$[0.0682]$} \\
\hline
\end{tabular}


Nas autocorrelações estimadas para os resíduos do modelo 3 existem valores superiores ao intervalo de confiança (desvio assintótico), que é igual a $1 / \sqrt{n}$ (0.0718), embora pelo teste de Box-Ljung não há rejeição da aleatoriedade dos mesmos.

Os maiores valores para os resíduos auxiliares estimados para o nível encontramse na tabela 6.2.2.13, percebe-se que ainda persistem alguns períodos não ajustados, o que daria margem para a possibilidade de se melhorar o ajuste desse modelo 3 através da introdução de intervenções. Porém, face à quantidade de intervenções no modelo, às suas boas qualidades de ajuste e de previsão, como será visto adiante, optou-se por não introduzir outras intervenções.

Para a distribuição dos resíduos do nível, a hipótese de normalidade não é rejeitada pelos testes BS e DH para níveis de significância inferiores a cerca de $25 \%$.

TABELA 6.2.2.13

Maiores valores dos resíduos do nível (modelo 3 ).

\begin{tabular}{|c|c|c|}
\hline PERIODO & VALOR & P-VALUE \\
\hline 1981.2 & 2.4504 & {$[0.0076]^{\star \star}$} \\
1986.8 & 2.4781 & {$[0.0070]^{\star \star}$} \\
1987.5 & -2.6017 & {$[0.0050]^{\star *}$} \\
1994.1 & -2.7505 & {$[0.0033]^{\star \star}$} \\
\hline
\end{tabular}

\subsection{3 - Poder preditivo do modelo para base monetária}

Como o objetivo é de se obter previsões para a BM mensal média, prever bem é a condição mais importante em um modelo. O modelo 3 realiza previsões com qualidade considerável para o período analisado.

A capacidade preditiva será avaliada predominantemente considerando previsões a um passo mas também serão feitas previsões a mais de um passo como subsídio à análise. Na tentativa de validar o modelo estimado, serão avaliadas as previsões para os sete últimos valores observados não considerados na estimação.

O gráfico 6.2.3.1 apresenta previsões a um passo, realizadas pelo modelo 3, para os sete meses não usados na estimação considerando a inflação realmente observada no período. Percebe-se que dos sete meses, pelo menos três são previstos com erros pequenos e os outros quatro possuem erros aceitáveis, pois ficam dentro dos intervalos de confiança com coeficiente de $50 \%$. A qualidade das previsões também pode ser 
comprovada pelo gráfico da soma acumulada, cujas linhas de fronteira em nenhum momento são cruzadas.

GRÁFICO 6.2.3.1
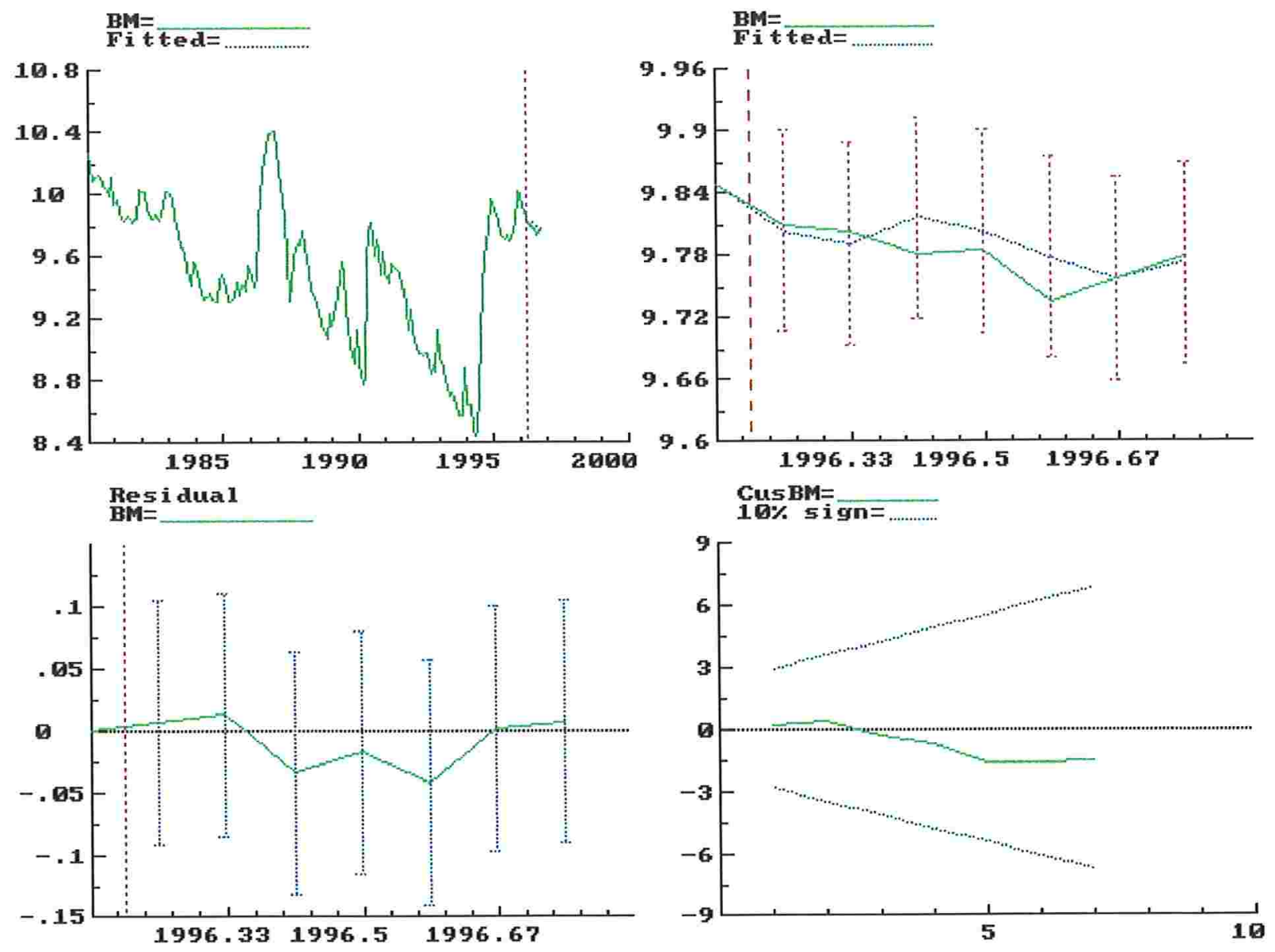

Previsões a um passo para 7 meses fora da amostra para BM transformada (modelo 3).

Quando as previsões são realizadas somente com as informações disponíveis até março de 1996, também tomando-se os valores realmente observados para a inflação, o modelo 3 possui uma capacidade preditiva aceitável para a série transformada, conforme gráfico 6.2.3.2. Os três primeiros meses são previstos com bom grau de acerto, nos outros quatro os erros são razoáveis, pois permanecem dentro dos intervalos de confiança com coeficiente de $68 \%$ e não apresentam crescimento significativo ao longo do tempo. $\mathrm{O}$ modelo é validado.

Ocorre piora de qualidade preditiva quando se passa para previsão a vários passos, neste caso as últimas cinco previsões são todas acima dos valores observados. Também é de se esperar, com o passar do tempo, uma piora nas previsões a mais de um 
passo pois novas informações não são utilizadas. Nota-se que nas previsões a um passo, os três períodos intermediários apresentaram valores previstos superiores aos observados, tal fato pode ser creditado a eventual diminuição no nível da série original ou padrão não absorvido pelo modelo ou simplesmente ao acaso.

\section{GRÁFICO 6.2.3.2}

Previsões vários passos para 7 meses fora da amostra para BM transformada (modelo 3).

Fit $\overline{\text { ted }}=$

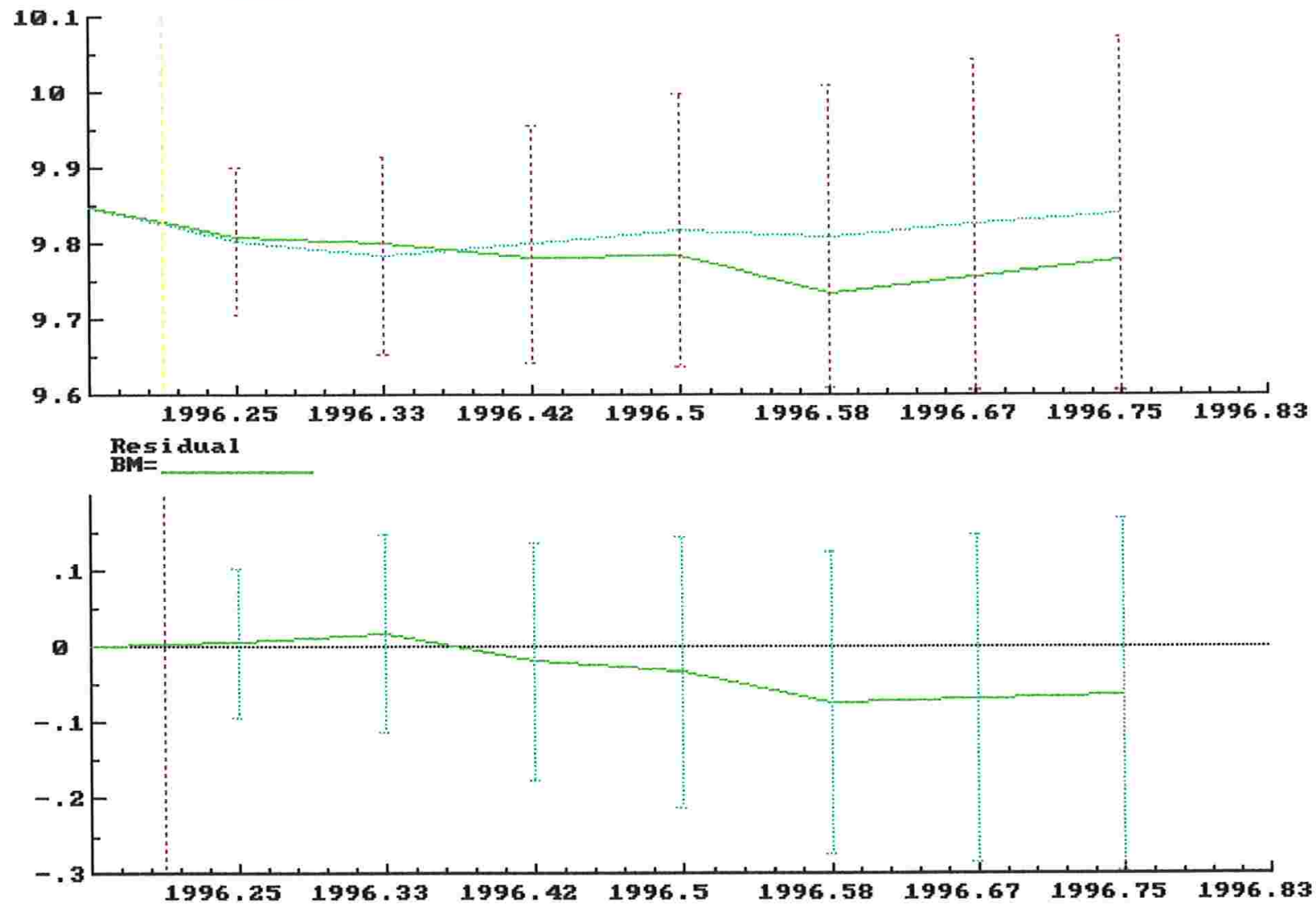

Os valores previstos a um e a vários passos acompanhados de seus erros encontram-se para a série em logaritmo na tabela 6.2.3.1 e para a série original na tabela 6.2.3.2. Para a série transformada os erros percentuais (percentagem do erro em relação ao valor observado) estão todos no intervalo $[-1.0,1.0]$. Para a série original os erros percentuais mais significativos são $-4.45 \%$ e $-8.16 \%$ para respectivamente as previsões a um e a mais de um passo, sendo a maioria dos erros bem inferior a esses valores.

Vale mencionar que as previsões para a série original não são obtidas diretamente via exponencialização das previsões para a série transformada pois essa transformação 
direta produz estimações viesadas. De acordo com as propriedades da distribuição lognormal, as previsões são obtidas exponencializando a soma da previsão da série transformada com a metade da variância dessa previsão - Harvey (1989), página 223 -, esta, estimada pelo REQM ao quadrado.

TABELA 6.2.3.1

Previsões e seus erros relativos para a série transformada (modelo 3 ).

\begin{tabular}{|c|c|c|c|c|c|c|c|}
\hline \multirow[b]{2}{*}{ PERÍODO } & \multirow[b]{2}{*}{$\begin{array}{c}\text { VALOR } \\
\text { OBS. }\end{array}$} & \multicolumn{3}{|c|}{ PREVISÄO A UM PASSO } & \multicolumn{3}{|c|}{ PREVISẢO A VÁRIOS PASSOS } \\
\hline & & VALOR & $\begin{array}{c}\text { ERRO } \\
\text { OBS. }\end{array}$ & $\begin{array}{c}\text { ERRO } \\
\%\end{array}$ & VALOR & $\begin{array}{c}\text { ERRO } \\
\text { OBS. }\end{array}$ & $\begin{array}{c}\text { ERRO } \\
\%\end{array}$ \\
\hline$a b r / 96$ & 9.8098 & 9.8038 & 0.0060 & 0.06 & 9.8038 & 0.0060 & 0.06 \\
\hline mai/96 & 9.8024 & 9.7903 & 0.0121 & 0.12 & 9.7850 & 0.0174 & 0.18 \\
\hline jun/96 & 9.7814 & 9.8162 & -0.0348 & -0.36 & 9.8001 & -0.0187 & -0.19 \\
\hline jul/96 & 9.7848 & 9.8030 & -0.0182 & -0.19 & 9.8176 & -0.0328 & -0.34 \\
\hline ago/96 & 9.7354 & 9.7777 & -0.0423 & -0.43 & 9.8088 & -0.0734 & -0.75 \\
\hline set/96 & 9.7574 & 9.7564 & 0.0010 & 0.01 & 9.8252 & -0.0678 & -0.69 \\
\hline out/96 & 9.7787 & 9.7723 & 0.0064 & 0.07 & 9.8405 & -0.0618 & -0.63 \\
\hline
\end{tabular}

Nota: (i) Valor obs. - valor observado;

(ii) Previsão a um passo - previsão considerando informação até o período anterior ao previsto;

(iii) Erro obs. - diferença entre observado e previsto;

(iv) Erro \% - percentual do erro quanto ao valor observado.

TABELA 6.2.3.2

Previsões e seus erros para a série original (modelo 3 ).

\begin{tabular}{|c|c|c|c|c|c|c|c|}
\hline \multirow[b]{2}{*}{ PFRÍODO } & \multirow[b]{2}{*}{$\begin{array}{c}\text { VALOR } \\
\text { OBS. }\end{array}$} & \multicolumn{3}{|c|}{ PREVISÃO A UM PASSO } & \multicolumn{3}{|c|}{ PREVISÃO A VÁRIOS PASSOS } \\
\hline & & VALOR & $\begin{array}{c}\text { ERRO } \\
\text { OBS. }\end{array}$ & $\begin{array}{c}\text { ERRO } \\
\%\end{array}$ & VALOR & $\begin{array}{l}\text { ERRO } \\
\text { OBS. }\end{array}$ & $\begin{array}{c}\text { ERRO } \\
\%\end{array}$ \\
\hline & 18211 & 18123 & 88 & 0.48 & 18123 & 88 & 0.48 \\
\hline 196 & 18077 & 17881 & 196 & 1.08 & 17803 & 274 & 1.52 \\
\hline jun/96 & 17701 & 18350 & -649 & -3.67 & 18091 & -390 & -2.20 \\
\hline & 17 & 18109 & -348 & -1.96 & 18429 & -668 & -3.76 \\
\hline ago/96 & 16905 & 17658 & -753 & -4.45 & 18285 & -1380 & -8.16 \\
\hline & 17 & 17284 & -3 & -0.02 & 18603 & -1322 & -7.65 \\
\hline out/96 & 17653 & 17561 & 92 & 0.52 & 18908 & -1255 & -7.1 \\
\hline
\end{tabular}

Os resultados dos testes sobre a capacidade preditiva dos modelos 2 e 3 para previsões a um passo confirmam suas qualidades, os testes não rejeitam a consistência das previsões dos modelos, tabela 6.2.3.3. Por esse critério pode-se dizer que os dois modelos possuem praticamente o mesmo poder preditivo. 
Assim, neste caso, a escolha de um dos dois modelos para se realizar previsões pode avaliar a qualidade das previsões a mais de um passo e a qualidade de ajuste. Nos dois casos há ligeira superioridade do modelo 3.

TABELA 6.2.3.3

Avaliação do poder preditivo dos modelos (7 valores externos).

\begin{tabular}{|l|l|c|c|}
\hline TIPO DA PREVISẢO & ESTATISTTCATESTE & MODELO 2 & MODELO 3 \\
\hline UM PASSO & Nível descritivo do teste falha preditiva & {$[0.9870]$} & {$[0.9825]$} \\
\hline VÁRIOS PASSOS & Soma dos erros absolutos de previsão & 3.2024 & 2.8821 \\
\hline VÁRIOS PASSOS & Soma dos erros quadrados de previsão & 2.0488 & 1.4871 \\
\hline
\end{tabular}

Tentou-se melhorar o modelo 3 introduzindo-se um ciclo, mas o teste para verificar a existência deste componente apresentou nível descritivo igual a $5.75 \%$, respectivamente, não rejeitando com certo rigor a hipótese de falta de ciclo.

\subsection{4 - Modelo para prever a base monetária}

O modelo 3 é o escolhido por fornecer as previsões mais adequadas para a BM média mensal. Desse modo, ele é reestimado para o período jan/80 a out/96 - modelo 4.

Este modelo 4 mantém as qualidades de ajuste e de previsão do modelo 3 , os meses introduzidos não se comportam como pontos de quebra estrutural. Os hiperparâmetros estimados estão na tabela 6.2.4.1. A equação do novo modelo com os valores estimados para os coeficientes e seus respectivos desvios são apresentadas a seguir.

TABELA 6.2.4.1

Estimativas dos hiperparâmetros (modelo 4).

\begin{tabular}{|l|c|c|}
\hline Componente & Desvio Padrão & Razão q \\
\hline Nivel & 0.0425 & 1.0000 \\
Sazonalidade & 0.0051 & 0.1201 \\
\hline
\end{tabular}

$$
\begin{aligned}
& \hat{\mathrm{BM}_{\mathrm{t}}}=\tilde{\mu_{\mathrm{t}}}+\tilde{\gamma_{\mathrm{t}}}-1.2073 \mathrm{I}_{\mathrm{t}}-0.5400 \mathrm{I}_{\mathrm{t}-1}-0.5904 \mathrm{I}_{\mathrm{t}-2}-0.4365 \mathrm{I}_{\mathrm{t}-3}-0.1705 \mathrm{w}_{1, \mathrm{t}}+0.2333 \mathrm{~W}_{2, \mathrm{t}}+ \\
& \begin{array}{llllll}
(0.0991) & (0.0681) & (0.0957) & (0.0951) & (0.0477) & (0.0462)
\end{array} \\
& 0.1536 w_{3, t}-0.2570 w_{4, t}+0.2561 w_{5, t}+0.2711 w_{6, t}-0.2513 w_{7, t}-0.3160 w_{8, t}+ \\
& \begin{array}{llllll}
(0.0464) & (0.0463) & (0.0475) & (0.0679) & (0.0668) & (0.0651)
\end{array} \\
& 0.2391 w_{9, t}+0.1786 w_{10, t} \\
& \text { (modelo 4) } \\
& \text { (0.0466) (0.0496) }
\end{aligned}
$$


onde $\mathrm{w}_{\mathrm{i}, \mathrm{t}}$ são as mesmas intervenções dummies no nível do modelo 3 , em ordem cronológica para $i=1,2, \ldots, 10$, isto é, $i=1$ corresponde à intervenção em 1981/1, i=2 em 1986/4 e assim por diante.

As estatísticas sobre o ajuste do modelo 4 são bastante próximas das obtidas pelo modelo 3, conforme tabela 6.2.4.2, o mesmo valendo para os coeficientes das variáveis explicativas e intervenções, tabela 6.2.4.3.

TABELA 6.2.4.2

Estatísticas de qualidade de ajuste (modelos 3 e 4).

\begin{tabular}{|c|c|c|c|}
\hline \multirow{2}{*}{\multicolumn{2}{|c|}{ ESTATÍSTICAS }} & \multicolumn{2}{|c|}{ ESTIMATIVAS } \\
\hline & & MODELO 3 & MODELO 4 \\
\hline Log-Verossimilhança & & 502.866 & 526.763 \\
\hline Variância dos erros de previsão (VEP & & 0.0021 & 0.0020 \\
\hline Erro Padrão & & 0.0453 & 0.0447 \\
\hline Desvio médio dos erros de previsão ( $D$ & & 0.0015 & 0.0015 \\
\hline $2 \mathrm{VEP} / \pi \mathrm{DM}^{2}$ & & 1.1761 & 1.1846 \\
\hline Erro relativo $(100 \times \mathrm{DM})$ & & 0.1512 & 0.1467 \\
\hline Normalidade & & $0.774[0.6792]$ & $1.177[0.5552]$ \\
\hline $\mathrm{H}(61)$ (modelo 3) e H(63) (modelo 4 & & $1.761[0.0144]^{*}$ & $1.582[0.0355]^{*}$ \\
\hline$r(1)$ & & 0.0323 & 0.0316 \\
\hline$r(12)$ & & 0.1270 & 0.1279 \\
\hline DW & & 1.914 & 1.913 \\
\hline $\mathrm{Q}(12,11)$ & & $14.08[0.2286]$ & 14.19 [0.2224] \\
\hline Coeficiente de determinação & $\mathrm{R}^{2}$ & 0.9896 & 0.9896 \\
\hline baseado em diferenças & $\mathrm{RD}^{2}$ & 0.8543 & 0.8533 \\
\hline baseado em dif. em torno média saz. & $\mathrm{RS}^{2}$ & 0.8023 & 0.8015 \\
\hline Critério de Informação de Akaike & AIC & -5.9104 & -5.9468 \\
\hline de Schwartz (Bayes) & $\mathrm{BIC}$ & -5.4572 & -5.5046 \\
\hline
\end{tabular}

TABELA 6.2.4.3

Estatísticas dos coeficientes das variáveis explicativas e intervenções (modelo 4).

\begin{tabular}{|c|c|c|c|c|}
\hline VARIÁVEL & COEFICIENTE & REQM & T-VALUE & P-VALUE \\
\hline $\mathrm{I}_{\mathrm{t}}$ & -1.2073 & 0.0991 & -12.1850 & {$[0.0000]^{\star *}$} \\
\hline$I_{t-1}$ & -0.5400 & 0.0681 & -7.9296 & {$[0.0000]^{\star \star}$} \\
\hline$I_{t-2}$ & -0.5904 & 0.0957 & -6.1676 & {$[0.0000]^{\star *}$} \\
\hline$I_{t-3}$ & -0.4365 & 0.0951 & -4.5897 & {$[0.0000]^{\star *}$} \\
\hline Lvl 1981.1 & -0.1705 & 0.0477 & -3.5761 & {$[0.0004]^{\star *}$} \\
\hline Lvl 1986.4 & 0.2333 & 0.0462 & 5.0496 & {$[0.0000]^{* *}$} \\
\hline Lvl 1986.5 & 0.1536 & 0.0464 & 3.3085 & {$[0.0011]^{\star *}$} \\
\hline LVl 1987.6 & -0.2570 & 0.0463 & -5.5458 & {$[0.0000]^{\star *}$} \\
\hline Lvl 1990.3 & 0.2561 & 0.0475 & 5.3960 & {$[0.0000]^{\star \star}$} \\
\hline Lvl 1990.4 & 0.2711 & 0.0679 & 3.9920 & {$[0.0001]^{\star *}$} \\
\hline Lvl 1990.6 & -0.2513 & 0.0668 & -3.7593 & {$[0.0002]^{\star *}$} \\
\hline Lvl 1990.7 & -0.3160 & 0.0651 & -4.8578 & {$[0.0000]^{\star *}$} \\
\hline Lvl 19 & 0.2391 & 0.0466 & 5.1269 & {$[0.0000]^{\star \star}$} \\
\hline Lvl 1994.7 & 0.1786 & 0.0496 & 3.6025 & {$[0.0004]^{\star \star}$} \\
\hline
\end{tabular}


As estimativas para os coeficientes do componente nivel e dos fatores sazonais para o último período da amostra são fornecidos na tabela 6.2.4.4. Esses valores em conjunto com os coeficientes estimados para as variáveis explicativas e as intervenções contém toda informação para obtenção das previsões.

TABELA 6.2.4.4

Estatísticas para os componentes no último período da amostra (modelo 4).

\begin{tabular}{|c|c|c|c|l|}
\hline VARIÁVEL & COEFICIENTE & REQM & T-VALUE & P-VALUE \\
\hline NIVEL & 9.8095 & 0.0156 & 628.4400 & {$[0.0000]^{* *}$} \\
SEA1 & -0.0227 & 0.0156 & -1.4582 & {$[0.1464]^{*}$} \\
SEA2 & -0.0338 & 0.0148 & -2.2825 & {$[0.0236]^{*}$} \\
SEA3 & -0.0477 & 0.0149 & -3.1929 & {$[0.0016]^{* *}$} \\
SEA4 & -0.0190 & 0.0151 & -1.2586 & {$[0.2097]$} \\
SEA5 & -0.0443 & 0.0153 & -2.8905 & {$[0.0043]^{* *}$} \\
SEA6 & -0.0518 & 0.0152 & -3.4151 & {$[0.0008]^{* *}$} \\
SEA7 & -0.0449 & 0.0152 & -2.9605 & {$[0.0035]^{* *}$} \\
SEA8 & -0.0030 & 0.0151 & -0.1988 & {$[0.8426]^{*}$} \\
SEA9 & 0.0403 & 0.0151 & 2.6685 & {$[0.0083]^{* *}$} \\
SEA10 & 0.1090 & 0.0150 & 7.2492 & {$[0.0000]^{* *}$} \\
SEA11 & 0.1613 & 0.0148 & 10.9260 & {$[0.0000]^{* *}$} \\
\hline
\end{tabular}

Os testes sobre o poder preditivo do modelo são agora realizados para os 6 últimos valores internos da amostra, o nível descritivo do teste indica uma boa capacidade preditiva do modelo.

TABELA 6.2.4.5

Avaliação do poder preditivo: 6 valores internos (modelo 4).

\begin{tabular}{|l|c|}
\hline UM PASSO & \\
\hline nível descritivo do teste Chow & {$[0.9446]$} \\
\hline VÁRIOS PASSOS & \\
\hline soma dos erros absolutos de previsão & 3.3811 \\
Soma dos erros quadrados de previsão & 2.1855 \\
\hline
\end{tabular}

\section{3 - Modelo estrutural multivariado para depósito a vista e papel moeda em poder do público}

\subsection{1 - Análise das séries papel moeda em poder do público e depósito a vista}

As séries depósito a vista e papel moeda em poder do público têm características comuns à base monetária, entre as quais: mais de um padrão monetário, perda de poder aquisitivo de seu valor nominal ao longo do tempo, presença de sazonalidade e correlação não desprezível com taxas de inflação e de juros. 
O período amostral para essas variáveis, de janeiro de 1992 até outubro de 1996, só contém um plano econômico, o Real, em junho de 1994. O gráfico 6.3.1.1 ilustra as séries atualizadas, isto é, sob um mesmo padrão monetário, o Real (R\$), e corrigidas pelo IGP-DI para valores de outubro de 1996.

Aparentemente, as duas séries não têm comportamentos muito díspares. Elas apresentam duas partes distintas quanto à tendência, com a quebra estrutural ocorrendo em julho de 1994. A partir desta data o nível abandona a tendência de queda. Contudo, após a quebra, o PMPP tem tendência de crescimento mais significativa do que o DV, que parece estar variando próximo de um nível, com taxa de crescimento inexpressiva.

Quanto às sazonalidades, destacam-se os marcantes efeitos de alta, correspondentes aos meses de dezembro e janeiro; e com menor intensidade, os de baixa representados, em sua maioria, pelos meses centrais do ano. A presença de ciclo nos dados é descartada já que sua inclusão no modelo final não se mostra importante.

GRÁFICO 6.3.1.1

DV e PMPP a preços de outubro de 1996.

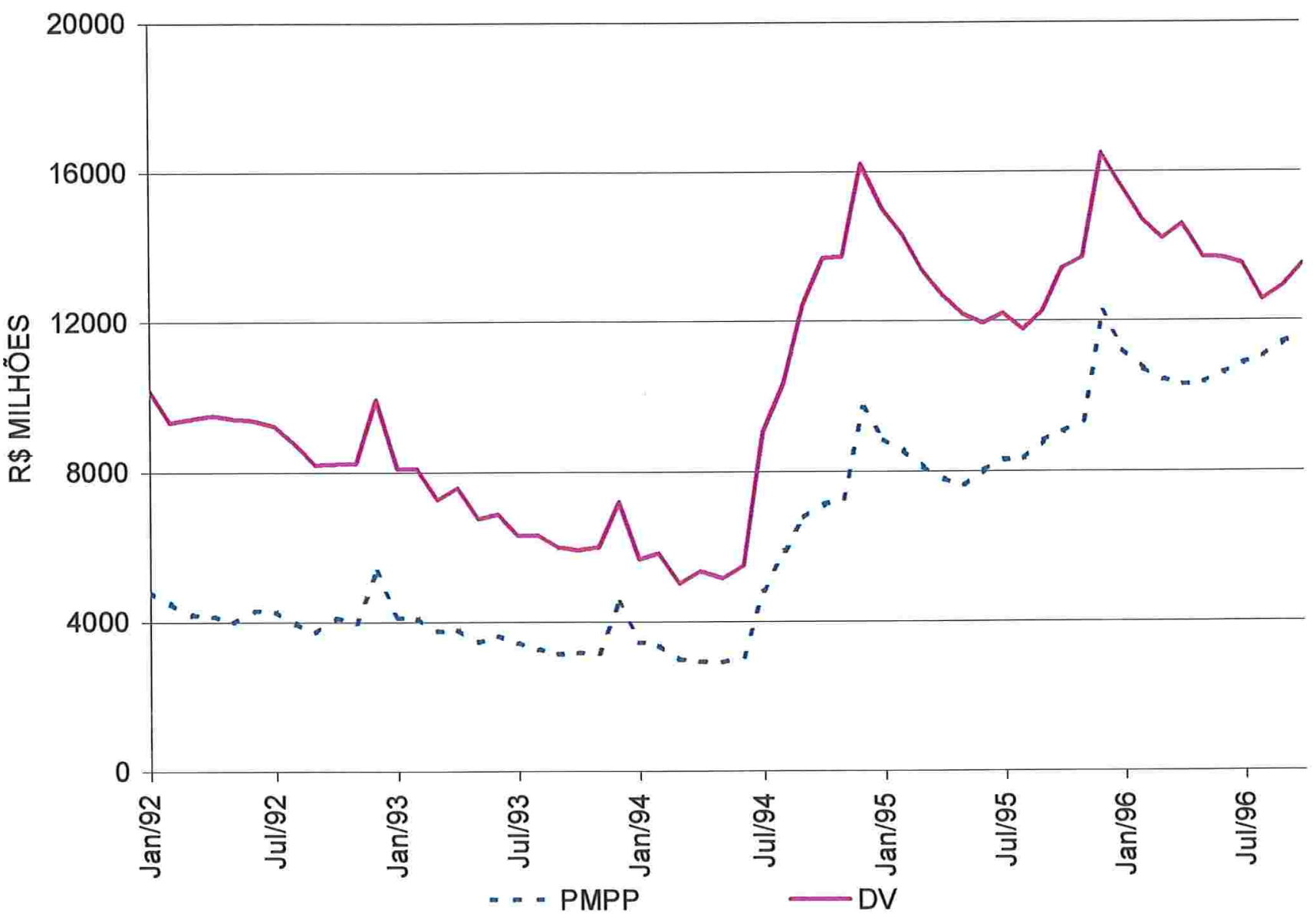




\subsection{2 - Especificação e estimação do modelo bivariado papel moeda em poder do público e depósito a vista.}

Os modelos que serão ajustados contam com uma variável explicativa, com o objetivo de buscar uma maior estabilidade dos parâmetros e para observar os comportamentos das variáveis dependentes sob determinado cenário dessa variável. As variáveis mais comuns e adequadas para se inserir isoladamente em um modelo para previsão das variáveis PMPP e DV são a taxa de inflação ou a taxa de juro nominal devido às relações destas variáveis.

A variável explicativa escolhida é a taxa de inflação (I), IGP-DI, a mesma do modelo univariado. Esta variável mostrou-se adequada porque o modelo final possui, no geral, ajuste e capacidade preditiva conjunta aceitáveis tanto para DV como para PMPP.

Foram realizadas transformações nas variáveis à semelhança das utilizadas no modelo da BM, ou seja, os valores originais foram colocados num mesmo padrão monetário e transformados a valores constantes de outubro de 1996 pelo IGP-DI e então transformados pela função logaritmo. Para a taxa de inflação foi tomado a transformação do logaritmo de um mais a taxa dividida por cem. Por convenção, as séries transformadas ou não estão denominada pela mesma siglas. Assim, DV, PMPP, e I podem fazer referência tanto às séries originais como às séries transformadas, bastando ter em mente que nos ajustes dos modelos foram utilizadas as variáveis transformadas.

Os coeficientes de correlação linear entre as primeiras diferenças das variáveis dependentes, DV e PMPP, e da independente, I, todas transformadas, encontram-se na tabela 6.3.2.1. As correlações são negativas. As séries transformadas encontram-se no apêndice e no gráfico 6.3.2.1 a seguir.

TABELA 6.3.2.1

Coeficientes de correlação linear entre as primeiras diferenças das variáveis transformadas dependentes com inflação.

\begin{tabular}{|l|c|}
\hline VARIÁVEL & 1 \\
\hline DV & -0.6216 \\
PMPP & -0.5903 \\
\hline
\end{tabular}




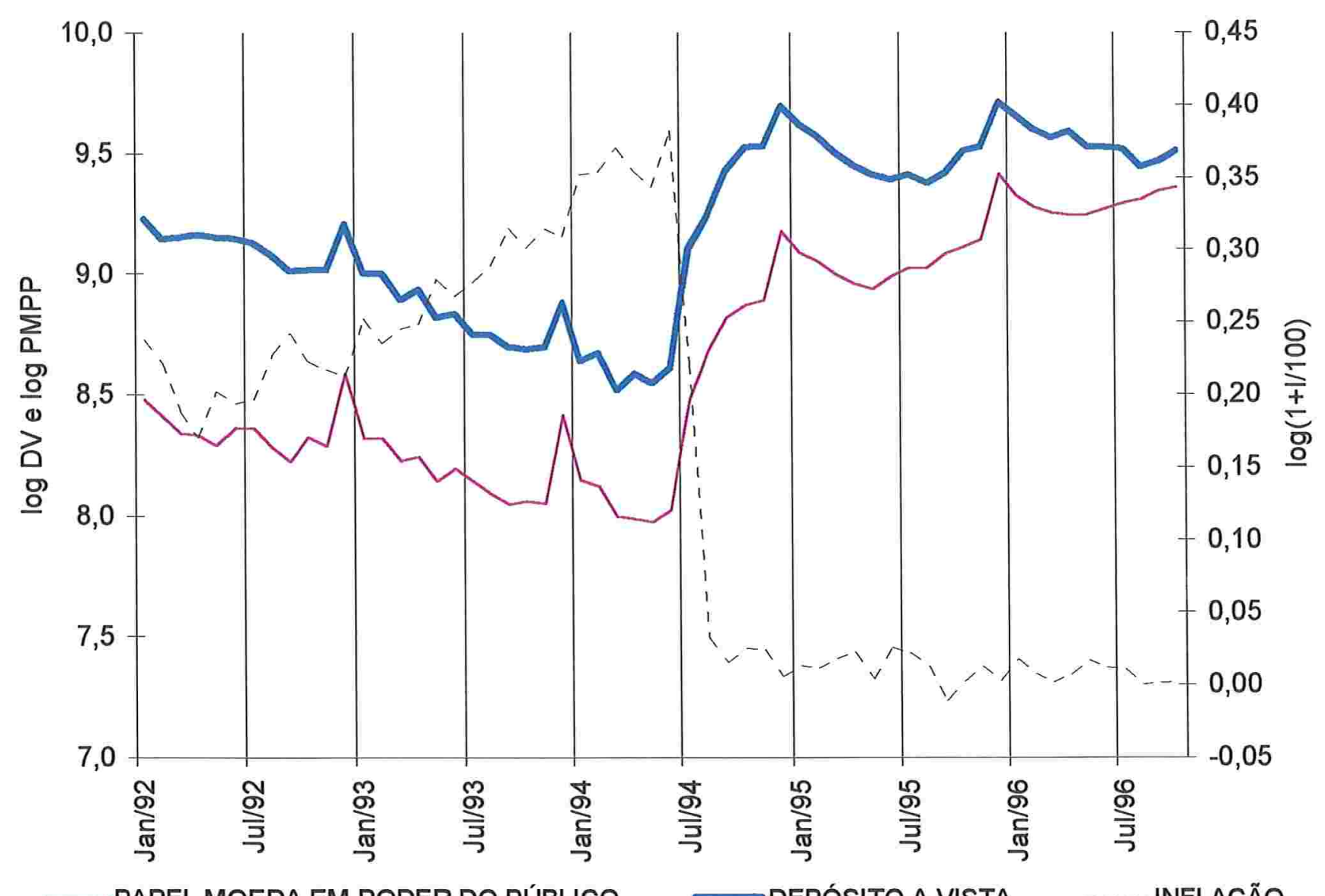

Percebe-se, pelo gráfico, a correlação inversa entre as variáveis dependentes DV e PMPP e a inflação, principalmente no período anterior a meados de 1994, quando se observa o início de estabilização econômica alcançada com o plano Real.

A introdução da taxa de inflação contemporânea nos modelos é realizada considerando principalmente o aumento de poder preditivo que sua utilização ocasiona.

Quanto à estacionariedade das séries, os resultados com o teste Dickey-Fuller aumentado que inclui constante e termos sazonais estão na tabela 6.3..2.2 para as variáveis transformadas. Novamente visto como indicativo, agora com maior cuidado devido ao reduzido número de anos da amostra, o teste sugere, para coeficientes de confiança usuais, que as variáveis possuem ordem de integração superior a 1, já que não há rejeição de raiz unitária, ou falta de estacionariedade, para as diferenças das duas variáveis. Os resultados para as variáveis originais são muito próximos aos descritos sendo as conclusões idênticas e não serão mostrados. 
TABELA 6.3.2.2

Testes raiz unitária Dickey-Fuller aumentado: PMPP logaritmado e sua primeira diferença.

\begin{tabular}{|c|c|c|c|c|c|}
\hline VARIÁVEL & t-ADF & $\sigma$-LAG & LAG & t-LAG & P-VALUE \\
\hline PMPP & -0.87 & 0.088 & 8 & 0.695 & 0.4931 \\
\hline PMPP & -0.73 & 0.087 & 7 & 0.097 & 0.9237 \\
\hline PMPP & -0.74 & 0.086 & 6 & 0.234 & 0.8165 \\
\hline PMPP & -0.71 & 0.085 & 5 & 0.262 & 0.7952 \\
\hline PMPP & -0.68 & 0.083 & 4 & 0.769 & 0.4477 \\
\hline PMPP & -0.51 & 0.083 & 3 & -1.055 & 0.2989 \\
\hline PMPP & -0.78 & 0.083 & 2 & 1.692 & 0.0999 \\
\hline PMPP & -0.44 & 0.085 & 1 & 1.676 & 0.1027 \\
\hline PMPP & -0.16 & 0.087 & 0 & & \\
\hline DPMPP & -1.67 & 0.088 & 8 & 0.863 & 0.3957 \\
\hline DPMPP & -1.50 & 0.087 & 7 & -0.605 & 0.5501 \\
\hline DPMPP & -1.80 & 0.086 & 6 & 0.157 & 0.8766 \\
\hline DPMPP & -1.87 & 0.085 & 5 & -0.092 & 0.9272 \\
\hline DPMPP & -2.06 & 0.083 & 4 & -0.096 & 0.9238 \\
\hline DPMPP & -2.30 & 0.082 & 3 & -0.447 & 0.6580 \\
\hline DPMPP & -2.79 & 0.081 & 2 & 1.085 & 0.2860 \\
\hline DPMPP & -2.57 & 0.081 & 1 & -1.810 & 0.0791 \\
\hline DPMPP & $-4.41^{\star \star}$ & 0.084 & 0 & & \\
\hline
\end{tabular}

TABELA 6.3.2.3

Testes raiz unitária Dickey-Fuller aumentado: DV logaritmado e sua primeira diferença.

\begin{tabular}{|c|c|c|c|c|c|}
\hline VARIÁVEL & t-ADF & $\sigma$-LAG & LAG & t-LAG & P-VALUE \\
\hline DV & -1.10 & 0.092 & 8 & 0.630 & 0.5335 \\
\hline DV & -0.98 & 0.091 & 7 & -0.718 & 0.4786 \\
\hline DV & -1.24 & 0.090 & 6 & 0.795 & 0.4330 \\
\hline DV & -1.08 & 0.089 & 5 & 0.299 & 0.7667 \\
\hline DV & -1.05 & 0.088 & 4 & -0.653 & 0.5182 \\
\hline DV & -1.33 & 0.087 & 3 & 0.189 & 0.8514 \\
\hline DV & -1.34 & 0.086 & 2 & 2.194 & 0.0281 \\
\hline DV & -0.89 & 0.091 & 1 & 2.031 & 0.0499 \\
\hline DV & -0.59 & 0.095 & 0 & & \\
\hline DDV & -2.01 & 0.094 & 8 & 0.836 & 0.4103 \\
\hline DDV & -1.85 & 0.094 & 7 & -0.366 & 0.7170 \\
\hline DDV & -2.17 & 0.092 & 6 & 1.012 & 0.3198 \\
\hline DDV & -1.95 & 0.092 & 5 & -0.476 & 0.6373 \\
\hline DDV & -2.33 & 0.091 & 4 & -0.032 & 0.9746 \\
\hline DDV & -2.59 & 0.090 & 3 & 1.002 & 0.3238 \\
\hline DDV & -2.39 & 0.090 & 2 & 0.188 & 0.8523 \\
\hline DDV & -2.54 & 0.088 & 1 & -2.028 & 0.0505 \\
\hline DDV & $-4.37^{\text {** }}$ & 0.092 & 0 & & \\
\hline
\end{tabular}


Desse modo, em consonância com o que foi avaliado, será estimado inicialmente. o modelo estrutural básico, formado pelos componentes estocásticos tendência - nível e taxa de crescimento -, sazonal e irregular, acrescido da variável inflação contemporânea e quatro defasagens, principalmente porque nos últimos tempos, com a estabilização da economia, a inflação deixou de possuir a importância que tinha períodos anteriores. A sazonalidade será estimada pelo método trigonométrico e serão incluídos todos os fatores mensais, a utilização deste método em quase nada se diferencia quanto às conclusões da utilização do método de variáveis dummies. Então, a equação deste modelo I será:

$Y_{t}=\mu_{t}+\gamma_{t}+\delta_{0} I_{t}+\delta_{1} l_{t-1}+\delta_{2} I_{t-2}+\delta_{3} l_{t-3}+\delta_{4} l_{t-4}+\varepsilon_{t}$

(Modelo I)

onde,

$Y_{t}=\left[\begin{array}{lll}P_{M P P} & D V_{t}\end{array}\right]^{\prime}, \mu_{t}=\left[\mu_{t, P M P P} \mu_{t, D V}\right]^{\prime}, \gamma_{t}=\left[\gamma_{t, \text { PMPP }} \gamma_{t, D V}\right]^{\prime}, \varepsilon_{t}=\left[\varepsilon_{t, P M P P} \varepsilon_{t, D V}\right]^{\prime}$,

$\delta_{\mathbf{i}}=\left(\delta_{\mathrm{i}, \mathrm{PMPP}} \delta_{\mathrm{i}, \mathrm{DV}}\right)^{\prime}$, para $\mathrm{i}=0,1,2,3$ e 4 ,

$\mu_{t}=\mu_{t-1}+\beta_{t-1}+\eta_{t}, \quad \eta_{t} \sim \operatorname{NID}\left(0, \Sigma_{\eta}\right)$

$\beta_{t}=\beta_{t-1}+\zeta_{t}, \quad \zeta_{t} \sim \operatorname{NID}(0, \Sigma \zeta)$

$\gamma_{\mathrm{t}}=\sum_{j=1}^{[s / 2]} \gamma_{\mathrm{j}, \mathrm{t}}$,

sendo $\gamma_{\mathrm{j}, \mathrm{t}}$ a sazonalidade trigonométrica 2.17 com $\varpi_{\mathrm{t}} \sim \mathrm{NID}\left(\mathbf{0}, \Sigma_{\varpi}\right), \varpi_{\mathrm{t}}^{*} \sim \mathrm{NID}\left(\mathbf{0}, \Sigma_{\varpi}\right)$, $\varepsilon_{\mathrm{t}} \sim \operatorname{NID}\left(0, \Sigma_{\varepsilon}\right), \Sigma_{\eta}, \Sigma_{\zeta}, \Sigma_{\varpi}, \Sigma_{\varepsilon}$ matrizes de covariância $2 \times 2$ e $\eta_{\mathrm{t}}, \zeta_{\mathrm{t}}, \varpi_{\mathrm{t}}$ e $\varepsilon_{\mathrm{t}}$ mutuamente não correlacionados em todos períodos.

O modelo I é estimado apresentando convergência muito forte. Essa fundamental característica é observada em todos modelos descritos adiante e deixará de ser citada.

As estimativas para os hiperparâmetros estão na tabela 6.3.2.4. Para o componente sazonal, percebe-se que seus valores não são expressivos - para o PMPP o hiperparâmetro estimado é igual a zero - indicando que elas podem ser consideradas determinísticas. 
TABELA 6.3.2.4

Estimativas dos hiperparâmetros (modelo I).

\begin{tabular}{|l|c|c|c|c|}
\hline \multirow{2}{*}{ COMPONENTE } & \multicolumn{2}{|c|}{ DV } & \multicolumn{2}{c|}{ PMPP } \\
\cline { 2 - 5 } & Desvio Padrão & Razão q & Desvio Padrão & Razão q \\
\hline Irregular & 0.0261 & $(1.0000)$ & 0.0316 & $(1.0000)$ \\
Nível & 0.0310 & $(1.1863)$ & 0.0056 & $(0.1758)$ \\
Taxa de crescimento & 0.0008 & $(0.0316)$ & 0.0022 & $(0.0681)$ \\
Sazonalidade & 0.0022 & $(0.0858)$ & 0.0000 & $(0.0000)$ \\
\hline
\end{tabular}

\section{GRÁFICO 6.3.2.2}

Componente sazonal e seus fatores mensais para o PMPP (modelol).

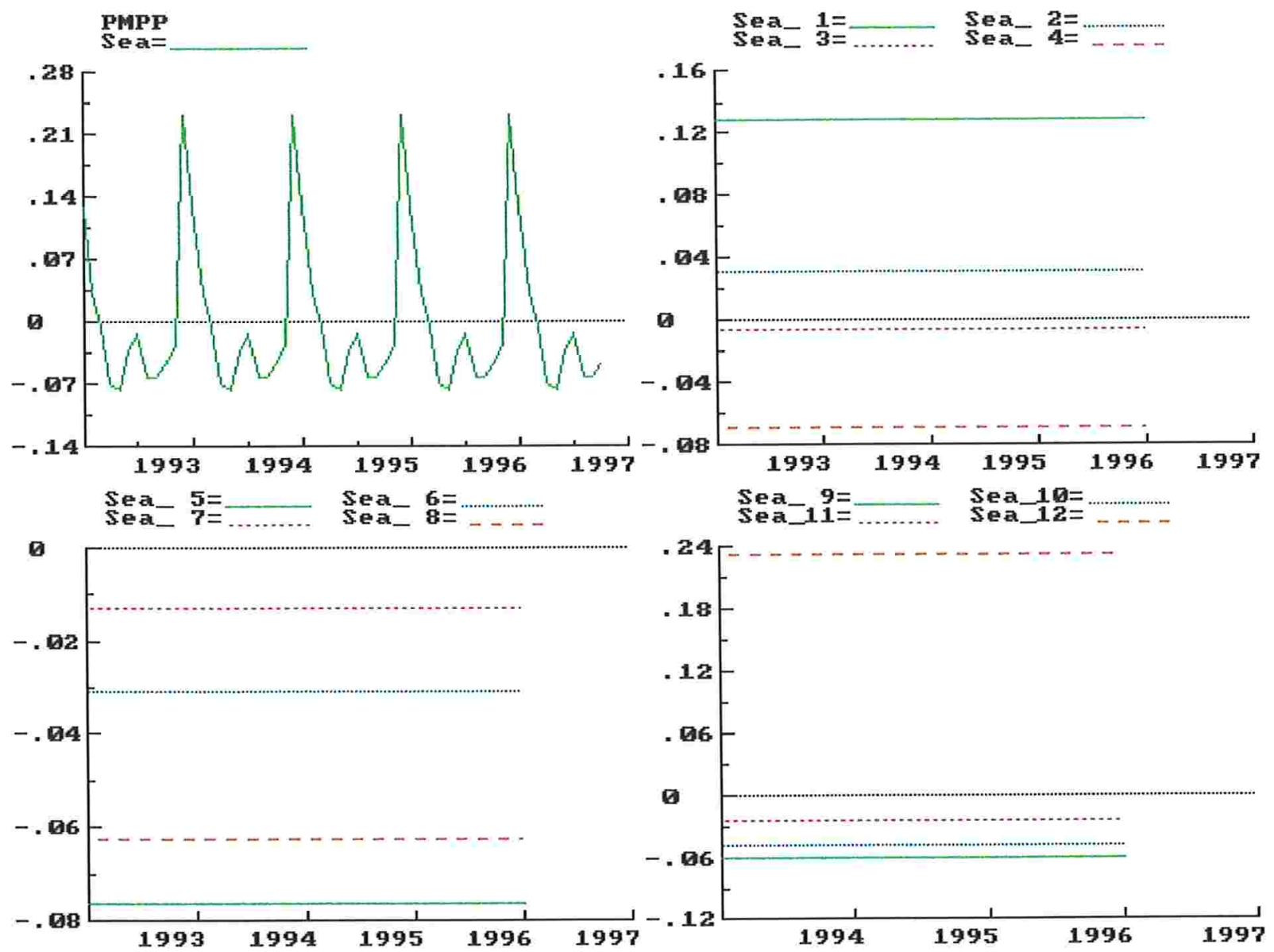




\section{GRÁFICO 6.3.2.3}

Componente sazonal e seus fatores mensais para o DV (modelo I).
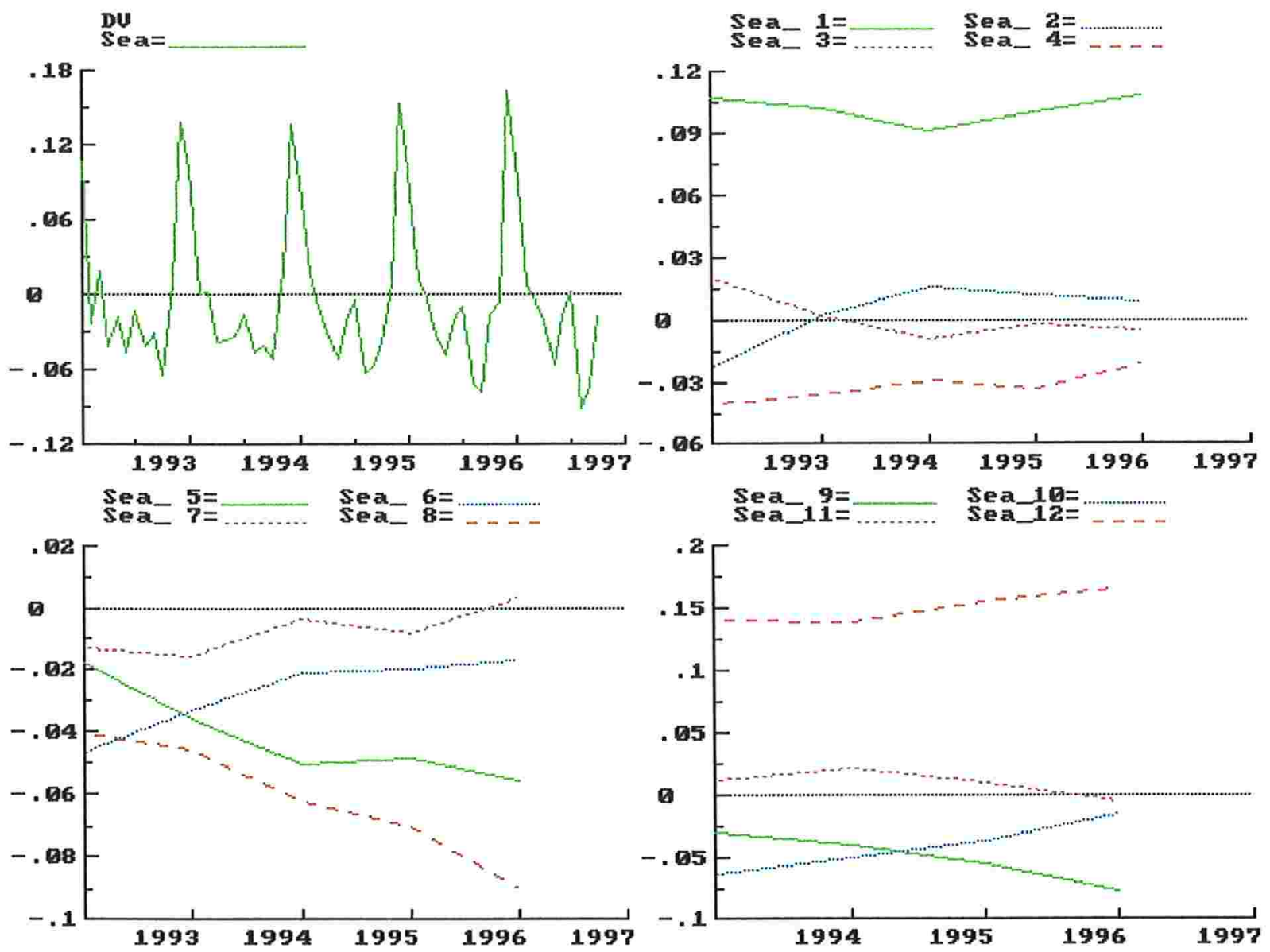

De acordo com os comportamentos dos efeitos sazonais mensais ao longo da amostra, gráficos 6.3.2.2 e 6.3.2.3, pode-se notar que, mesmo para o DV, não há alteração expressiva nos padrões sazonais. Principalmente a partir de 1994, seus efeitos mensais pouco variam ao longo da amostra. Outra característica é que os fatores sazonais que mais variam não são os fatores mais significativos, correspondentes aos meses de janeiro e dezembro, que, ao contrário, mantêm-se com poucas alterações.

Assim, reforçado pelo fato do tamanho da amostra ser reduzido, parece mais indicado considerar as duas sazonalidades determinísticas.

A sazonalidade para as variáveis no modelo é significativa, como também pode ser visto nos gráficos 6.3.2.2 e 6.3.2.3 anteriores e também pelos resultados dos testes de sazonalidade.

Desse modo, a sazonalidade será considerada determinística para as duas variáveis. Então, o novo modelo, 2, possui, com exceção da sazonalidade, as 
componentes e os coeficientes idênticos aos descritos para o modelo I. O modelo II é escrito conforme equação

$Y_{t}=\mu_{t}+\sum_{j=1}^{s-1} z_{j t} \gamma_{j}+\delta_{0} l_{t}+\delta_{1} l_{t-1}+\delta_{2} l_{t-2}+\delta_{3} l_{t-3}+\delta_{4} l_{t-4}+\varepsilon_{t}$

(Modelo II)

onde $\gamma_{\mathrm{j}}$ é a sazonalidade tradicional.

Uma importante opção do programa STAMP, o controle de parâmetros na estimação, será utilizada na estimação dos próximos modelos. Ela permite que certos parâmetros sejam restritos às suas fronteiras, indicando que o componente a ele associado é determinístico, e os outros parâmetros são estimados sob estas condições.

Na estimação dos parâmetros do modelo II ocorrem duas restrições realizadas pelo próprio programa, ambas no DV, uma no hiperparâmetro do nível e outra no da taxa de crescimento. Em conformidade com o comportamento da série no final da amostra, optouse por restringir o hiperparâmetro da taxa de crescimento.

Como a restrição no hiperparâmetro associado à taxa de crescimento equivale a torná-la constante, pode-se intuir que a estimativa deste coeficiente deverá ficar próxima de zero - uma média das taxas de inclinação antes e após a quebra estrutural de meados de 1994 -, o que parece adequado para a obtenção de boas previsões, pois a tendência do DV no final da amostra não é acentuadamente crescente ou decrescente.

A não restrição do hiperparâmetro do nível no modelo II justifica-se pela não estacionariedade das séries em estudo, sendo, portanto, indicado presença de ao menos nível estacástico no modelo final.

A propósito, a não restrição de parâmetros quando da estimação do modelo I, não tem influência alguma nas conclusões realizadas naquele momento.

Enfim, o modelo II tem hiperparâmetros iguais a zero para a taxa de crescimento no DV e na covariância entre as perturbações deste componente das séries.

As estimativas dos coeficientes da inflação e de suas defasagens, tabela 6.3.2.5, indicam que o coeficiente da defasagem de ordem quatro não é significativo tanto para o DV como para o PMPP. 
TABELA 6.3.2.5

Estimativas e estatísticas para os coeficientes das variáveis explicativas (modelo II).

\begin{tabular}{|c|c|c|c|c|c|}
\hline \multicolumn{2}{|c|}{ VARIÁVEL } & \multicolumn{4}{|c|}{ ESTATISTICAS } \\
\hline $\begin{array}{l}\text { DEPEN- } \\
\text { DENTE }\end{array}$ & $\begin{array}{l}\text { INDEPEN- } \\
\text { DENTE }\end{array}$ & COEFICIENTE & REQM & T-VALUE & P-VALUE \\
\hline PMPP & $\begin{array}{l}I_{t} \\
I_{t-1} \\
I_{t-2} \\
I_{t-3} \\
I_{t-4}\end{array}$ & $\begin{array}{r}-2.2721 \\
0.6340 \\
-1.0627 \\
0.6948 \\
-0.3105 \\
\end{array}$ & $\begin{array}{l}0.1648 \\
0.2501 \\
0.2629 \\
0.2448 \\
0.1578 \\
\end{array}$ & $\begin{array}{r}-13.785 \\
2.535 \\
-4.042 \\
2.838 \\
-1.968 \\
\end{array}$ & $\begin{array}{l}{[0.0000]^{* \star}} \\
{[0.0141]^{*}} \\
{[0.0002]^{* *}} \\
{[0.0063]^{* *}} \\
{[0.0540]}\end{array}$ \\
\hline DV & $\begin{array}{l}I_{t} \\
I_{t-1} \\
I_{t-2} \\
I_{t-3} \\
I_{t-4}\end{array}$ & $\begin{array}{r}-2.2773 \\
0.7105 \\
-1.4899 \\
0.8270 \\
-0.2869\end{array}$ & $\begin{array}{l}0.2241 \\
0.2864 \\
0.2959 \\
0.2820 \\
0.2151 \\
\end{array}$ & $\begin{array}{r}-10.161 \\
2.481 \\
-5.036 \\
2.933 \\
-1.334\end{array}$ & $\begin{array}{l}{[0.0000]^{* *}} \\
{[0.0161]^{*}} \\
{[0.0000]^{* *}} \\
{[0.0049]^{* *}} \\
{[0.1877]}\end{array}$ \\
\hline
\end{tabular}

Aa contrário do que se espera, os coeficientes das defasagens de ordem 1 e 3 possuem coeficientes positivos. Como tal fato pode estar ocorrendo devido à ausência de intervenções associadas ao plano Real, a inspeção nos resíduos auxiliares, tabela 6.3.2.6, pode justificar a necessidade da introdução de intervenções no modelo.

TABELA 6.3.2.6

Maiores valores dos resíduos do nível (modelo II).

\begin{tabular}{|c|l|l|l|l|}
\hline \multirow{2}{*}{ PERIOODO } & \multicolumn{2}{|c|}{ DV } & \multicolumn{2}{c|}{ PMPP } \\
\cline { 2 - 5 } & VALOR & P-VALUE & VALOR & P-VALUE \\
\hline $1994 / 06$ & 2.5945 & {$[0.0060]^{\star *}$} & 2.5945 & {$[0.0060]^{* *}$} \\
$1994 / 07$ & 3.4602 & {$[0.0005]^{\star *}$} & 3.4602 & {$[0.0005]^{\star \star}$} \\
$1995 / 10$ & 2.5073 & {$[0.0075]^{\star *}$} & 2.5073 & {$[0.0075]^{\star *}$} \\
\hline
\end{tabular}

Considerando que o nível da tendência possui para as duas variáveis o ponto 1994/07 como resíduo mais significantemente diferente de zero e como este período está associado a uma quebra estrutural notória, correspondente ao plano Real, o próximo modelo irá incorporar uma intervenção no nível deste período, além de excluir a defasagem de ordem quatro para o PMPP e para o DV.

Assim, o modelo III é escrito conforme a equação a seguir, com os componentes e os parâmetros que foram mantidos sendo idênticos aos do modelo II.

$Y_{t}=\mu_{t}+\sum_{j=1}^{s-1} z_{j t} \gamma_{j}+\delta_{0} l_{t}+\delta_{1} l_{t-1}+\left.\delta_{2}\right|_{t-2}+\left.\delta_{3}\right|_{t-3}+\lambda w_{t}+\varepsilon_{t}$

(Modelo III) 
onde $\lambda=\left(\lambda_{\text {PMPP }} \lambda_{\text {DVV }}\right)$ e $w_{t}$ é uma intervenção em 1994/07, uma dummy igual a zero antes deste ponto e igual a 1 após.

As duas restrições na estimação dos parâmetros efetuadas na taxa de crescimento da variável DV e na covariância das taxas de crescimento para o modelo II, também são incorporadas no modelo III.

Percebe-se, tabela 6.3.2.7, que a intervenção no mês de julho de 1994 é importante para as duas variáveis e as estimativas dos coeficientes são positivas, refletindo o aumento de nível das séries. Essa presença ocasiona uma diminuição na significância das estimativas dos parâmetros para as defasagens da inflação. Agora, para as duas variáveis somente a inflação contemporânea é significativa para um nível igual a 1\%. De acordo com os níveis descritivos obtidos, há indicações que as defasagens de ordem 1 e 3 são as menos importantes tanto para o PMPP como para o DV.

Assim, nos dois próximos modelos serão excluídas essas duas defasagens, uma de cada vez, mantendo-se as mesmas componentes, intervenção e restrições paramétricas do modelo III para melhor avaliação de suas importâncias na modelagem.

TABELA 6.3.2.7

Estimativas e estatísticas para os coeficientes das variáveis explicativas (modelo III).

\begin{tabular}{|c|c|c|c|c|c|}
\hline \multicolumn{2}{|c|}{ VARIÁVEL } & \multicolumn{3}{c|}{ ESTATISTICAS } \\
\hline DEPEN- & INDEPEN- & & & & \\
DENTE & DENTE & COEFICIENTE & REQM & T-VALUE & P-VALUE \\
\hline \multirow{3}{*}{ PMPP } & $\mathrm{I}_{\mathrm{t}}$ & -1.1732 & 0.2925 & -4.0110 & {$[0.0002]^{\star *}$} \\
& $\mathrm{I}_{\mathrm{t}-1}$ & -0.1927 & 0.2661 & -0.7241 & {$[0.4720]$} \\
& $\mathrm{I}_{\mathrm{t}-2}$ & -0.3671 & 0.2356 & -1.5579 & {$[0.1249]$} \\
& $\mathrm{I}_{\mathrm{t}-3}$ & 0.1120 & 0.1508 & 0.7362 & {$[0.4647]$} \\
& nivel 94/07 & 0.2756 & 0.0666 & 4.1380 & {$[0.0001]^{\star \star}$} \\
\hline \multirow{4}{*}{ DV } & $\mathrm{I}_{\mathrm{t}}$ & -0.8289 & 0.3081 & -2.6902 & {$[0.0094]^{\star *}$} \\
& $\mathrm{I}_{\mathrm{t}-1}$ & -0.3612 & 0.2753 & -1.3122 & {$[0.1948]$} \\
& $\mathrm{I}_{\mathrm{t}-2}$ & -0.6501 & 0.2457 & -2.6464 & {$[0.0105]^{*}$} \\
& $\mathrm{I}_{\mathrm{t}-3}$ & 0.2269 & 0.1841 & 1.2325 & {$[0.2229]$} \\
& nivel 94/07 & 0.4051 & 0.0745 & 5.4319 & {$[0.0000]^{\star *}$} \\
\hline
\end{tabular}

Os resultados para as estimativas dos coeficientes das variáveis independentes do modelo IV sem a variável inflação defasada de ordem 3 encontram-se na tabela 6.3.2.8. Pode-se verificar que para o PMPP, a $5 \%$, os coeficientes estimados das defasagens da inflação de ordem 1 e 2 não são estatisticamente diferentes de zero e que para o DV, a 
$2 \%$, além das defasagens, a inflação contemporânea não possui coeficiente estimado significativamente diferente de zero.

TABELA 6.3.2.8

Estimativas e estatísticas para os coeficientes das variáveis explicativas (modelo IV).

\begin{tabular}{|c|c|c|c|c|l|}
\hline \multicolumn{2}{|c|}{ VARIÁVEL } & \multicolumn{4}{|c|}{ ESTATISTICAS } \\
\hline DEPEN- & INDEPEN- & & & & \\
DENTE & DENTE & COEFICIENTE & REQM & T-VALUE & P-VALUE \\
\hline P & $\mathrm{I}_{\mathrm{t}}$ & -1.0632 & 0.2588 & -4.1081 & {$[0.0001]^{* *}$} \\
M & $\mathrm{I}_{\mathrm{t}-1}$ & -0.3088 & 0.2235 & -1.3820 & {$[0.1725]$} \\
$\mathrm{P}$ & $\mathrm{I}_{\mathrm{t}-2}$ & -0.2125 & 0.1411 & -1.5059 & {$[0.1377]$} \\
$\mathrm{P}$ & nivel $94 / 07$ & 0.3063 & 0.0598 & 5.1197 & {$[0.0000]^{* *}$} \\
\hline & $\mathrm{I}_{\mathrm{t}}$ & -0.6597 & 0.2868 & -2.3006 & {$[0.0252]^{*}$} \\
$\mathrm{D}$ & $\mathrm{I}_{\mathrm{t}-1}$ & -0.5348 & 0.2491 & -2.1466 & {$[0.0362]^{*}$} \\
$\mathrm{~V}$ & $\mathrm{I}_{\mathrm{t}-2}$ & -0.4295 & 0.1816 & -2.3648 & {$[0.0215]^{*}$} \\
& nivel 94/07 & 0.4433 & 0.0706 & 6.2793 & {$[0.0000]^{* *}$} \\
\hline
\end{tabular}

TABELA 6.3.2.9

Estimativas e estatísticas para os coeficientes das variáveis explicativas (modelo V).

\begin{tabular}{|c|c|c|c|c|l|}
\hline \multicolumn{2}{|c|}{ VARIÁVEL } & \multicolumn{4}{|c|}{ ESTATISTICAS } \\
\hline DEPEN- & INDEPEN- & & & & \\
DENTE & DENTE & COEFICIENTE & REQM & T-VALUE & P-VALUE \\
\hline $\mathrm{P}$ & $\mathrm{I}_{\mathrm{t}}$ & -1.3493 & 0.1585 & -8.5138 & {$[0.0000]^{* *}$} \\
$\mathrm{M}$ & $\mathrm{I}_{-2}$ & -0.5034 & 0.1361 & -3.6978 & {$[0.0005]^{* *}$} \\
$\mathrm{P}$ & $\mathrm{I}_{\mathrm{t}-3}$ & 0.1694 & 0.1280 & 1.3234 & {$[0.1911]^{* *}$} \\
$\mathrm{P}$ & nível $94 / 07$ & 0.2436 & 0.0504 & 4.8326 & {$[0.0000]^{*}$} \\
\hline & $\mathrm{I}_{\mathrm{t}}$ & -1.1471 & 0.1909 & -6.0087 & {$[0.0000]^{* *}$} \\
$\mathrm{D}$ & $\mathrm{I}_{\mathrm{t}-2}$ & -0.8896 & 0.1653 & -5.3823 & {$[0.0000]^{* \star}$} \\
$\mathrm{V}$ & $\mathrm{I}_{\mathrm{t}-3}$ & 0.3386 & 0.1645 & 2.0576 & {$[0.0443]^{*}$} \\
& nível 94/07 & 0.3424 & 0.0579 & 5.9147 & {$[0.0000]^{* *}$} \\
\hline
\end{tabular}

Para o modelo $V$ sem a defasagem da inflação de ordem 1, os resultados, tabela 6.3.2.9, indicam que a defasagem de ordem 3 pode ser excluída do modelo, a $1 \%$, tanto para 0 PMPP quanto para o DV. Para as outras variáveis, há indicações que os coeficientes estimados são diferentes de zero.

Pelo exposto, o novo modelo a ser estimado excluirá tanto a defasagem de ordem 1 quanto a de ordem 3. Serão mantidas a inflação contemporânea, a defasagem de ordem 2, a intervenção no nível do período 1994/07, as sazonalidades fixas e, a princípio, os componentes estocásticos de tendência, nível, taxa de crescimento e o componente irregular para as duas variáveis. Esse modelo é descrito pela equação 


$$
Y_{t}=\mu_{t}+\sum_{j=1}^{s-1} z_{j t} \gamma_{j}+\delta_{0} l_{t}+\delta_{2} l_{t-2}+\lambda w_{t}+\varepsilon_{t}
$$

A estimativa inicial do modelo sugere as duas restrições nos parâmetros aplicadas anteriormente, ou seja, são restritos a zero os hiperparâmetros correspondentes à taxa de crescimento de DV e da covariância entre as taxas de crescimento das variáveis.

Após as restrições, os valores estimados para os hiperparâmetros nesse modelo VI, tabela 6.3.2.10, mostram que o componente com maior variabilidade geral é o nível para o DV. Para o PMPP, o componente irregular apresenta desvio padrão muito maior do que o dos outros componentes, ou seja, grande parte da variabilidade é dada pelo componente não explicado pelo modelo, o que pode ser reflexo de eventual falta de especificação do modelo.

TABELA 6.3.2.10

Estimativas dos hiperparâmetros (modelo VI).

\begin{tabular}{|l|c|c|c|c|}
\hline \multirow{2}{*}{ COMPONENTE } & \multicolumn{2}{|c|}{ DV } & \multicolumn{2}{c|}{ PMPP } \\
\cline { 2 - 5 } & Desvio Padrão & Razão q & Desvio Padrão & Razão q \\
\hline Irregular & 0.02264 & $(0.7784)$ & 0.02668 & $(6.0292)$ \\
Nível & 0.02909 & $(1.0000)$ & 0.00443 & $(1.0000)$ \\
Taxa de crescimento & 0.00000 & $(0.0000)$ & 0.00235 & $(0.5313)$ \\
\hline
\end{tabular}

As matrizes de covariância estimadas para as perturbações dos componentes estão na tabela 6.3.2.11, os valores em itálico correspondem às estimativas das correlaçöes entre os hiperparâmetros dos componentes das variáveis.

TABELA 6.3.2.11

Variâncias, covariâncias e correlações (em itálico) das perturbações dos componentes.

\begin{tabular}{|l|c|c|c|c|c|c|}
\hline \multirow{2}{*}{ VARIÁVEL } & \multicolumn{2}{|c|}{ IRREGULAR } & \multicolumn{2}{c|}{ NÍVEL } & \multicolumn{2}{c|}{ TAXA DE } \\
\cline { 2 - 7 } & PMESCIMENTO \\
\hline PMPP & 0.0007 & DV & PMPP & DV & PMPP & DV \\
\hline DV & 0.0004 & 0.0005 & 0.0000 & $\mathbf{0 . 9 9 9 8}$ & 0.0000 & $\mathbf{0 . 0 0 0 0}$ \\
\hline
\end{tabular}

Os zeros na matriz da taxa de crescimento são decorrentes das restrições impostas quando da estimação dos parâmetros do modelo. A estimativa da correlação entre as perturbações das duas variáveis para o nivel é expressiva (0.99980), sugerindo que um modelo com nível comum pode apresentar melhor poder preditivo. 
A correlação cruzada contemporânea e a defasada de um lag nos dois sentidos entre os valores estimados para a tendência das séries não é tão expressiva, são pouco inferiores a 0.70 , o que poderia justificar a não inclusão de nível comum no modelo. Porém, o fator mais determinante para se abandonar a idéia de nível comum é que modelos estimados com nível comum não melhoram e sim empobrecem a capacidade preditiva com relação ao modelo VI atual.

Desse modo, descarta-se a utilização de nivel comum com os dados atuais, apesar da indicação dada pela estimativa da correlação entre as perturbações dos níveis das variáveis.

O gráfico 6.3.2.4 mostra os componentes suavizados do modelo $\mathrm{VI}$ estimados para o PMPP, verifica-se que a tendência acompanha os movimentos da série transformada. Para a taxa de crescimento, ocorre ao longo da amostra a esperada mudança de sinal do coeficiente estimado, ocorrendo no final da amostra a estabilização de seu valor. No último período da amostra a taxa de crescimento é próxima a $24 \%$ ao ano para a série original.

A sazonalidade fixa, como intuído anteriormente, tem aparência significativa, com padrões mais acentuados nos meses de dezembro e janeiro. Para o irregular nota-se certa estabilização relativa a partir de meados de 1994. 
GRÁFICO 6.3.2.4

Componentes estimados para o PMPP (modelo Vl).

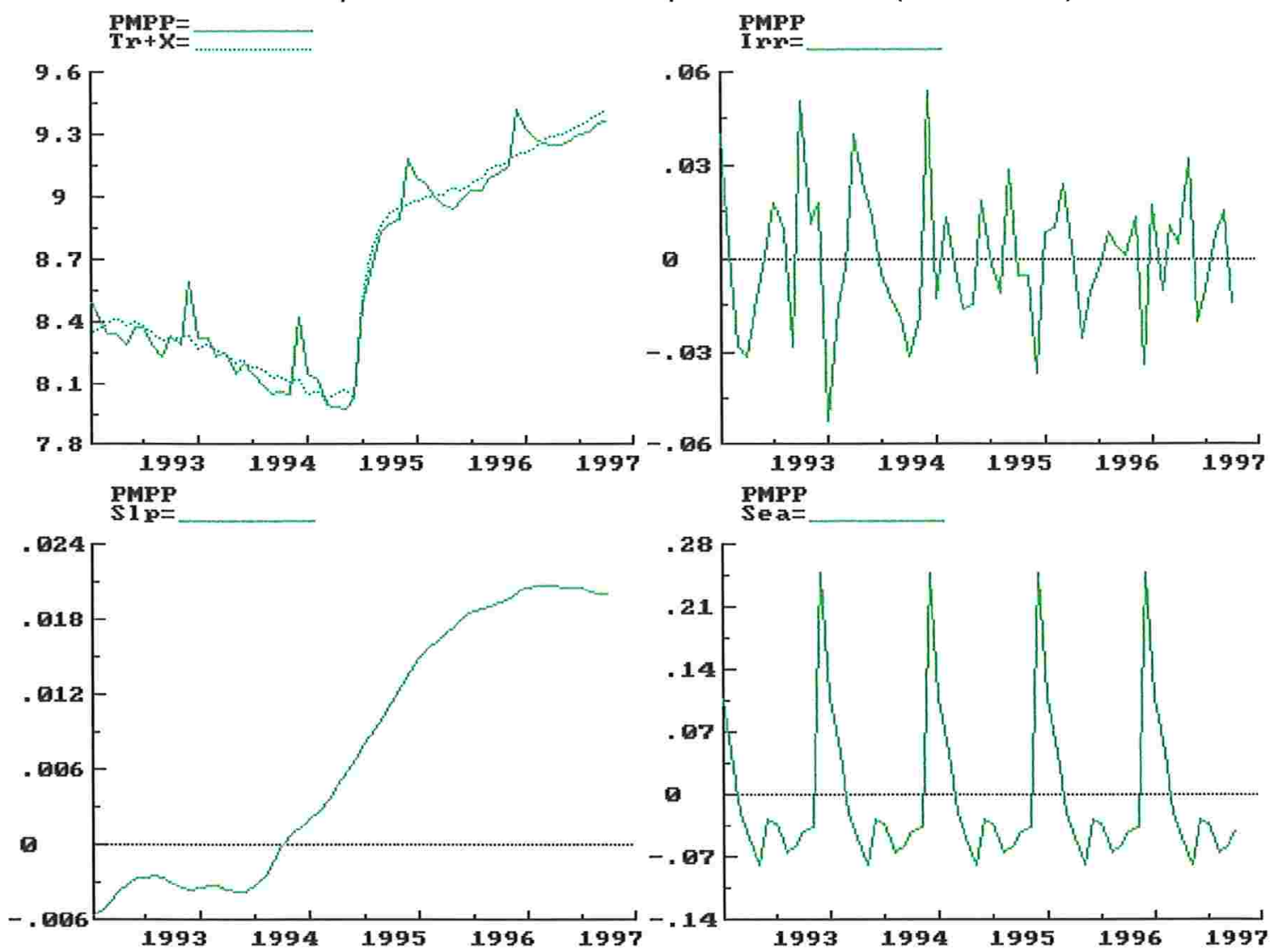

O gráfico 6.3.2.5 ilustra os componentes suavizados estimados para o DV. A tendência apresenta-se no final da amostra levemente em declínio, a taxa de crescimento considerada fixa na estimação dos parâmetros possui valor próximo a -0.0065 , refletindo decréscimo próximo a $7.75 \%$ para a série original, o que parece razoável para o comportamento apresentado pela série no final da amostra. Pode-se perceber a presença de sazonalidade com efeitos mais acentuados nos períodos de início e final de ano.

A incidência de altos percentuais de depósito compulsório sobre o DV tem feito com que os agentes financeiros busquem, mais e mais, formas substitutas para seu financeiro de liquidez. Por exemplo, os bancos efetuaram sistematicamente transferências automáticas das contas correntes para aplicações em fundos, quase sempre de curto prazo.

Talvez fosse recomendável a retirada da taxa de crescimento para o DV, devido à sua não significância, deixando a tendência exclusivamente em função do nível. Contudo, como retirar a taxa de crescimento do DV e manter a do PMPP não é um procedimento 
possível no STAMP, optou-se por manter a taxa de crescimento constante para DV, considerando que ela é significante para o PMPP.

O irregular e a sazonalidade estimadas do DV têm comportamentos semelhantes aos descritos para esses componentes do PMPP.

\section{GRÁFICO 6.3.2.5}

Componentes estimados para o DV (modelo VI).
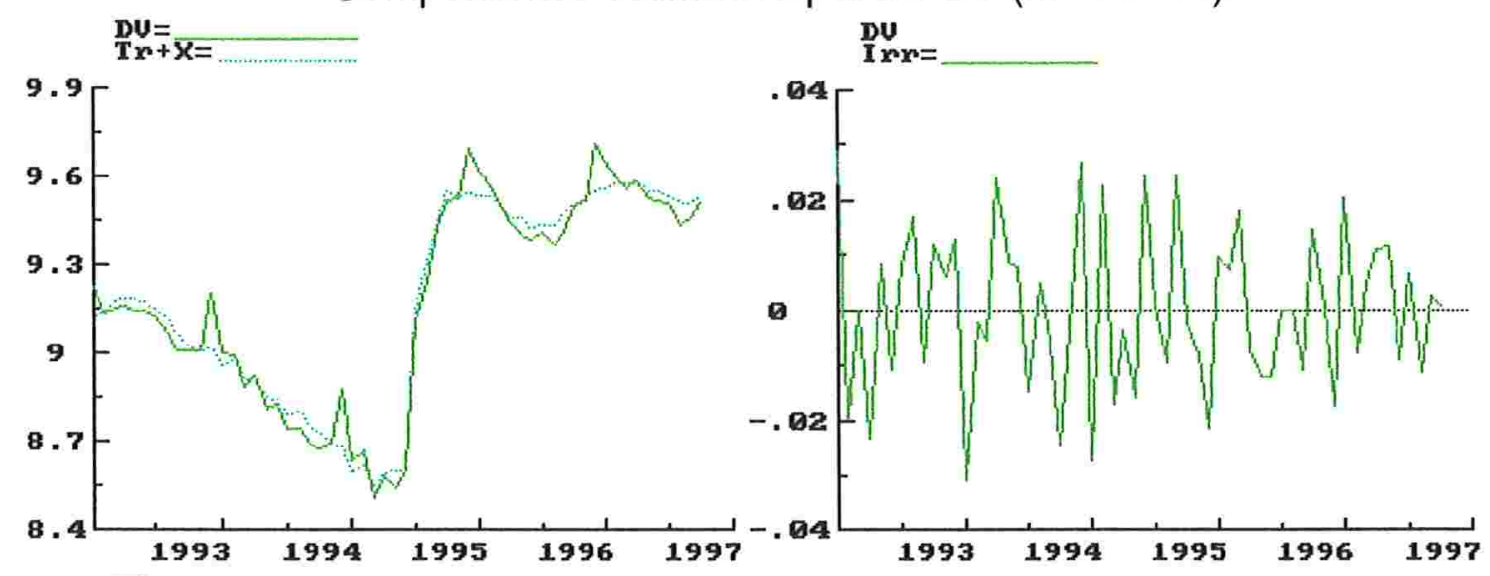

Sip

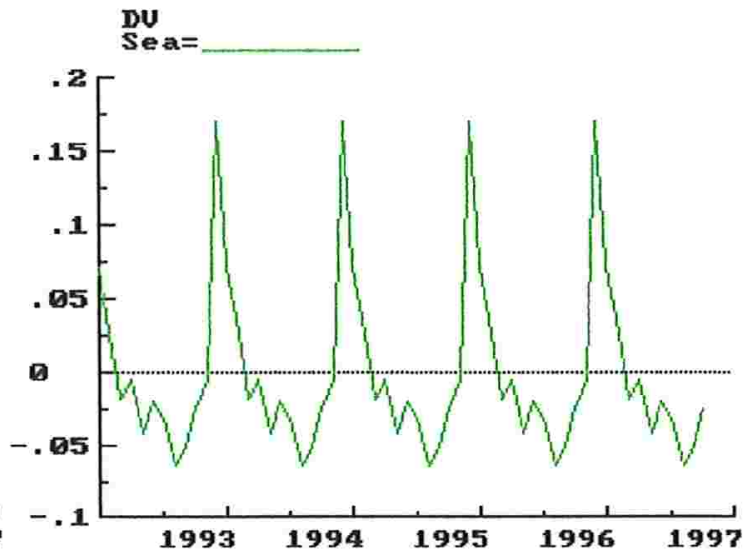

A tabela 6.3.2.12 mostra as estimativas para os coeficientes das variáveis independentes e suas estatísticas, todas são significativas e cumprem as esperadas relações com as variáveis dependentes, isto é, os coeficientes estimados para a inflação contemporânea, mais importante, e sua defasagem são negativos para o DV e para o PMPP. Já a intervenção, possui coeficiente estimado positivo, indicando aumento de nível para as séries originais próximo a $28,5 \%(100 *(\exp (0.2509)-1)))$ para o PMPP e $42,2 \%$ para DV. 
TABELA 6.3.2.12

Estimativas e estatísticas para os coeficientes das variáveis explicativas (modelo VI).

\begin{tabular}{|c|c|c|c|c|c|}
\hline \multicolumn{2}{|c|}{ VARIÁVEL } & \multicolumn{4}{|c|}{ ESTATISTICAS } \\
\hline DEPEN- & INDEPEN- & & & & \\
DENTE & DENTE & COEFICIENTE & REQM & T-VALUE & P-VALUE \\
\hline \multirow{3}{*}{ PMPP } & $I_{t}$ & -1.3451 & 0.1606 & -8.374 & {$[0.0000]^{* *}$} \\
& $I_{t-2}$ & -0.3786 & 0.0924 & -4.098 & {$[0.0001]^{* *}$} \\
& nivel $94 / 07$ & 0.2509 & 0.0507 & 4.951 & {$[0.0000]^{* *}$} \\
\hline \multirow{2}{*}{ DV } & $I_{t}$ & -1.1207 & 0.1987 & -5.640 & {$[0.0000]^{* *}$} \\
& $I_{t-2}$ & -0.6998 & 0.1429 & -4.896 & {$[0.0000]^{* *}$} \\
& nivel 94/07 & 0.3518 & 0.0605 & 5.815 & {$[0.0000]^{* *}$} \\
\hline
\end{tabular}

O ajuste do modelo para as duas variáveis é satisfatório, de acordo com os resultados apresentados na tabela 6.3.12 e na matriz de covariância dos erros de previsão a seguir.

TABELA 6.3.2.13

Covariâncias dos erros de previsão.

\begin{tabular}{|c|c|c|}
\hline & PMPP & DV \\
\hline PMPP & 0.0008 & 0.0005 \\
DV & 0.0005 & 0.0012 \\
\hline
\end{tabular}

Os valores estimados para a variância e para a covariância dos erros de previsão para as séries transformadas são aceitáveis, o que também ocorre com as estimativas do erro padrão e do desvio médio dos erros de previsão. O erro relativo mostra-se adequado, pois indica que o erro médio de previsão a um passo para as previsões do modelo é de aproximadamente $0,0545 \%$ e $0,0814 \%$ para PMPP e DV, respectivamente. A estimativa da razão (VEP / DM.) ao quadrado para o PMPP e o DV são, respectivamente, iguais a 1.374002 e 1.420574 , também espelhando que o modelo não está mal ajustado, não se encontram muito afastadas do valor ideal 1.

Os coeficientes de determinação são favoráveis tanto para o PMPP quanto para o DV, apresentando valores superiores a $80 \%$ em suas três versões. 
Tabela 6.3.2.14

Estatísticas da qualidade de ajuste (modelo VI).

\begin{tabular}{|c|c|c|}
\hline \multirow[b]{2}{*}{ ESTATÍSTICAS } & \multicolumn{2}{|c|}{ ESTIMATIVAS } \\
\hline & PMPP & DV \\
\hline Log-Verossimilhança & 260.83 & 260.83 \\
\hline Variância dos erros de previsão (VEP) & 0.0008 & 0.0012 \\
\hline Erro Padrão & 0.0283 & 0.0349 \\
\hline Desvio médio dos erros de previsão (DM) & 0.0006 & 0.0008 \\
\hline $2 \mathrm{VEP} / \pi \mathrm{DM}^{2}$ & 1.3740 & 1.4206 \\
\hline Erro relativo (100 x DM) & 0.0545 & 0.0814 \\
\hline Normalidade & $0.737[0.6919]$ & $1.401[0.4964]$ \\
\hline$H(18)$ & $0.454[0.9484]$ & $1.185[0.3613]$ \\
\hline$r(1)$ & 0.0501 & -0.0603 \\
\hline$r(8)$ & 0.0099 & -0.1802 \\
\hline DW & 1.6599 & 1.9178 \\
\hline $\mathrm{Q}(8,6)$ & $7.426[0.2832]$ & $8.362[0.2128]$ \\
\hline Coeficiente de determinação & 0.9964 & 0.9899 \\
\hline baseado em diferenças & 0.9497 & 0.8976 \\
\hline baseado em dif. em torno média saz. $\mathrm{RS}^{2}$ & 0.8525 & 0.8123 \\
\hline Critério de Informação de Akaike & -5.7501 & -5.3333 \\
\hline de Schwartz (Bayes) & -4.3291 & -3.9123 \\
\hline
\end{tabular}

Os valores estimados para os resíduos do modelo ajustado mostram-se bem comportados para as duas variáveis, não indicando falta do cumprimento das suposições de normalidade, homocedasticidade e ausência de autocorrelação serial.

Os resíduos do modelo estimado para PMPP, mostrados no gráfico 6.3.2.6 e na tabela 6.3.2.15, não apresentam correlação serial, as estatísticas do teste Box-Ljung sugerem falta de padrão de dependência entre eles, e o teste de DW possui valor (1.6599). A suposição de normalidade não é rejeitada pelos testes BS e DH com níveis descritivos iguais, respectivamente, a 0.6919 e 0.2679 . A falta de padrão sistemático dos resíduos é também indicada pelo gráfico da soma acumulada (CUSUM) dos resíduos padronizados que não cruza as linhas de fronteira baseadas em nível de significância de $10 \%$.

A heterocedasticidade dos resíduos é fortemente rejeitada pelo o teste que compara as variâncias do início e do final da amostra, cujo nível descritivo é igual a [0.9484]. 
GRÁFICO 6.3.2.6

Estimativas para os resíduos do PMPP (modelo VI).
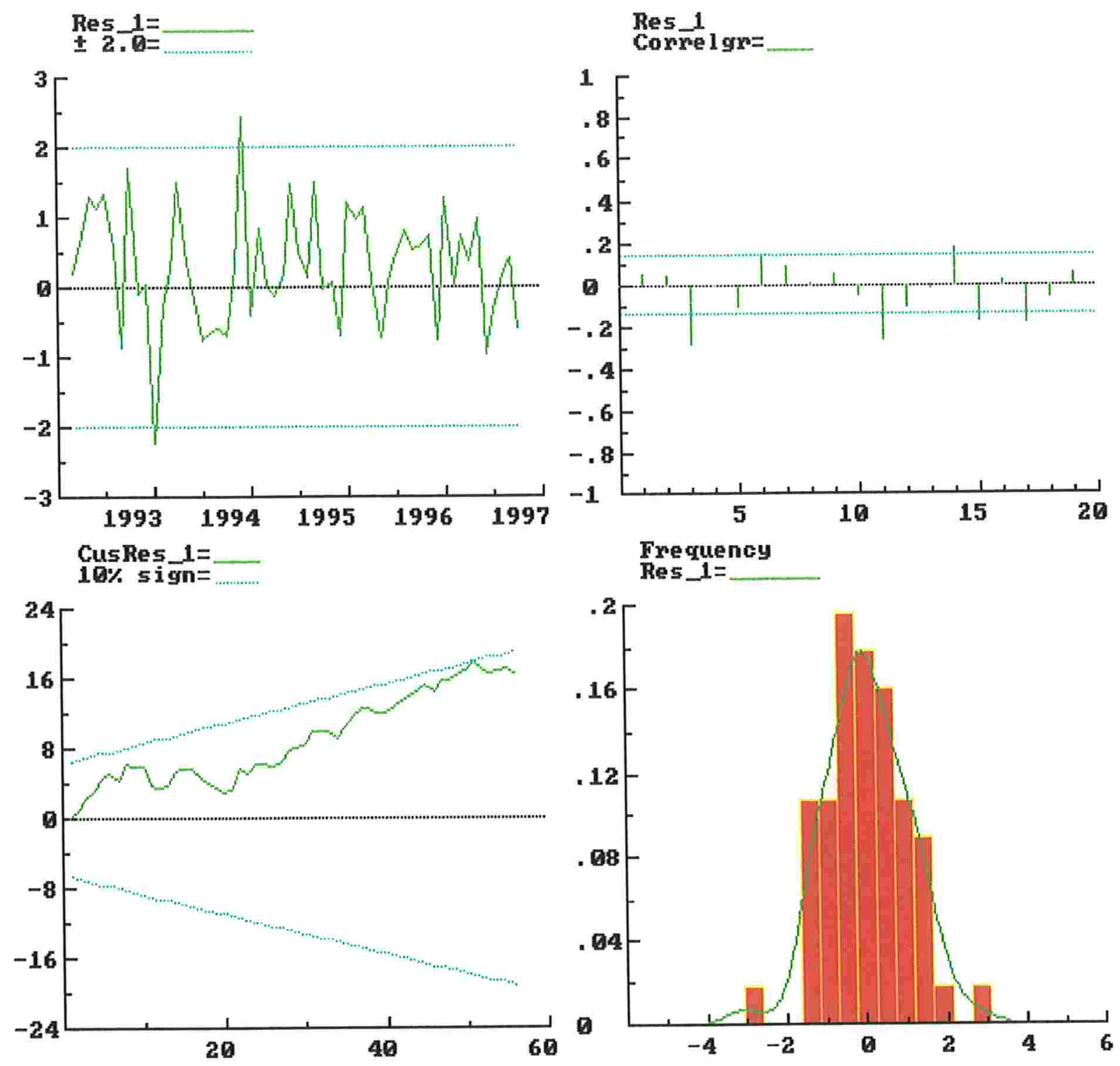
TABELA 6.3.2.15

Correlações seriais e estatísticas sobre suas significâncias para os resíduos do PMPP.

(Desvio assintótico para correlações $(1 / \sqrt{n})$ igual a 0.1336 )

\begin{tabular}{|c|c|c|c|c|}
\hline LAG & $\begin{array}{c}\text { GRAUS DE } \\
\text { LIBERDADE }\end{array}$ & $\begin{array}{c}\text { AUTOCOR- } \\
\text { RELAÇÃO }\end{array}$ & $\begin{array}{c}\text { TESTE BOX- } \\
\text { LJUNG }\end{array}$ & $\begin{array}{c}\text { NIVEL } \\
\text { DESCRITIVO }\end{array}$ \\
\hline 1 & 0 & 0.0501 & & \\
2 & 0 & 0.0429 & & \\
3 & 1 & -0.2780 & 4.9960 & {$[0.0254]$} \\
4 & 2 & -0.0033 & 4.9967 & {$[0.0822]$} \\
5 & 3 & -0.1030 & 5.6721 & {$[0.1287]$} \\
6 & 4 & 0.1390 & 6.9276 & {$[0.1398]$} \\
7 & 5 & 0.0862 & 7.4198 & {$[0.1912]$} \\
8 & 6 & 0.0099 & 7.4264 & {$[0.2832]$} \\
9 & 7 & 0.0484 & 7.5882 & {$[0.3703]$} \\
10 & 8 & -0.0483 & 7.7530 & {$[0.4580]$} \\
11 & 9 & -0.2618 & 12.7017 & {$[0.1766]$} \\
12 & 10 & -0.1011 & 13.4560 & {$[0.1993]$} \\
13 & 11 & -0.0178 & 13.4801 & {$[0.2631]$} \\
14 & 12 & 0.1777 & 15.9207 & {$[0.1949]$} \\
15 & 13 & -0.1682 & 18.1614 & {$[0.1515]$} \\
16 & 14 & 0.0154 & 18.1807 & {$[0.1987]$} \\
17 & 15 & -0.1785 & 20.8354 & {$[0.1422]$} \\
18 & 16 & -0.0634 & 21.1786 & {$[0.1717]$} \\
19 & 17 & 0.0474 & 21.3762 & {$[0.2099]$} \\
20 & 18 & -0.0013 & 21.3763 & {$[0.2609]$} \\
\hline
\end{tabular}

Os comentários descritos para os resíduos do PMPP se estendem, em geral, para os do DV, mostrados no gráfico 6.3.2.7 e tabela 6.3.2.16.

A estrutura dos resíduos apresenta aleatoriedade, conforme os resultados do teste Box-Ljung e do teste DW (1.9178) que indicam falta de padrão de dependência. O gráfico da soma acumulada (CUSUM) dos resíduos padronizados reforça a falta de padrão sistemático dos resíduos, as linhas de fronteira baseadas em nível de significância de $10 \%$ não são ultrapassadas.

A suposição de normalidade é aceita pelos testes BS e DH com níveis descritivos iguais a 0.4964 e 0.4450 , respectivamente.

A presença de variância constante no período da amostra pode ser admitida com relativa segurança, pois o teste da comparação das variâncias do terço inicial e do final da amostra fornece nível descritivo igual a [0.3613]. 
GRÁFICO 6.3.2.7

Estimativas para os resíduos do DV (modelo VI).
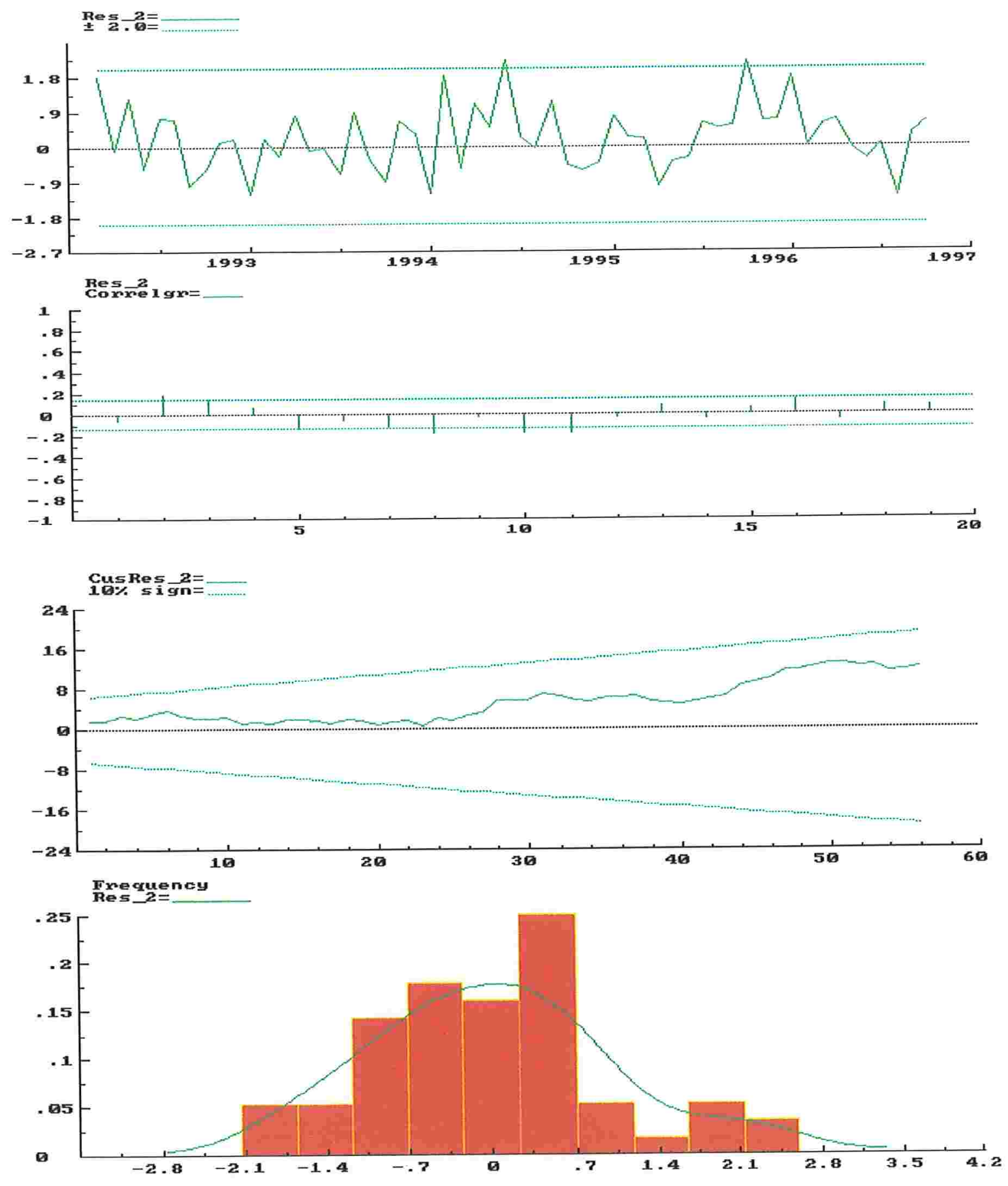
TABELA 6.3.2.16

Correlações seriais e estatísticas sobre suas significâncias para os resíduos do DV.

(Desvio assintótico para correlações $(1 / \sqrt{n})$ igual a 0.1336 )

\begin{tabular}{|c|c|c|c|c|}
\hline LAG & $\begin{array}{c}\text { GRAUS DE } \\
\text { LIBERDADE }\end{array}$ & $\begin{array}{c}\text { AUTOCOR- } \\
\text { RELAÇÃO }\end{array}$ & $\begin{array}{c}\text { TESTE BOX- } \\
\text { LJUNG }\end{array}$ & $\begin{array}{c}\text { NIVEL } \\
\text { DESCRITIVO }\end{array}$ \\
\hline 1 & 0 & -0.0603 & & \\
2 & 0 & 0.1786 & & \\
3 & 1 & 0.1374 & 3.2908 & {$[0.0697]$} \\
4 & 2 & 0.0607 & 3.5210 & {$[0.1720]$} \\
5 & 3 & -0.1370 & 4.7168 & {$[0.1937]$} \\
6 & 4 & -0.0648 & 4.9895 & {$[0.2884]$} \\
7 & 5 & -0.1332 & 6.1659 & {$[0.2904]$} \\
8 & 6 & -0.1802 & 8.3625 & {$[0.2127]$} \\
9 & 7 & -0.0292 & 8.4215 & {$[0.2969]$} \\
10 & 8 & -0.1884 & 10.9276 & {$[0.2058]$} \\
11 & 9 & -0.1886 & 13.4946 & {$[0.1415]$} \\
12 & 10 & -0.0381 & 13.6016 & {$[0.1920]$} \\
13 & 11 & 0.0723 & 13.9964 & {$[0.2332]$} \\
14 & 12 & -0.0511 & 14.1982 & {$[0.2882]$} \\
15 & 13 & 0.0509 & 14.4033 & {$[0.3461]$} \\
16 & 14 & 0.1331 & 15.8416 & {$[0.3231]$} \\
17 & 15 & -0.0643 & 16.1859 & {$[0.3698]$} \\
18 & 16 & 0.0726 & 16.6367 & {$[0.4095]$} \\
19 & 17 & 0.0567 & 16.9186 & {$[0.4599]$} \\
20 & 18 & -0.0343 & 17.0246 & {$[0.5214]$} \\
\hline
\end{tabular}

Semelhantemente aos resíduos do modelo para a base monetária existem, tanto nos resíduos do PMPP como nos do DV, valores estimados fora dos intervalos de confiança. Embora isto possa indicar alguma má especificação do modelo, os resultados já comentados e em especial as capacidades preditivas do modelo, a serem descritas, para as duas variáveis, justificam, sem um rigor excessivo, a classificação deste como um modelo de boas qualidades.

\subsection{3 - Poder preditivo do modelo bivariado papel moeda em poder do público e depósito a vista.}

A capacidade preditiva do modelo é aceitável conforme os resultado dos testes e das estatísticas para as previsões a um e a mais de um passo para os últimos seis períodos da amostra, tabela 6.3.3.1. A não rejeição de correta especificação do modelo para as previsões a um passo ocorre para as duas variáveis com níveis descritivos superiores a $64 \%$ no teste de Chow. 
Nas previsões a mais de um passo, para as duas variáveis, o erro absoluto médio por período é próximo a 0.5 para a série transformada, valor que corresponde a pouco mais de $5 \%$ dos valores observados, podendo, então, as previsões serem consideradas, no mínimo, razoáveis.

TABELA 6.3.3.1

Níveis descritivos dos testes e estatísticas da capacidade preditiva (modelo VI).

\begin{tabular}{|c|c|c|c|}
\hline \multicolumn{2}{|c|}{ the } & \multicolumn{2}{|c|}{ VARIÁVEL } \\
\hline TIPO DE TESTE & TESTE/ESTATÍSTICA & PMPP & DV \\
\hline UM PASSO & Chow & {$[0.6481]$} & [0.6852] \\
\hline VÁRIOS PASSOS & Soma dos erros absolutos de previsão & 2.9644 & 3.0328 \\
\hline VÁRIOS PASSOS & Soma dos erros quadrados de previsão & 2.3191 & 2.3081 \\
\hline
\end{tabular}

Para as previsões pontuais das duas séries originais, nota-se, no caso das previsões a um passo, que, para o PMPP, o modelo fornece previsões com erros absolutos inferiores a $4,09 \%$ dos valores observados, e que, para o DV, cinco dos seis períodos são previstos com erros absolutos inferiores a $3,04 \%$ dos valores observados, sendo o maior erro igual a $7,17 \%$ - tabela 6.3.3.2.

Nas duas variáveis, para as previsões a um passo, há equilíbrio entre erros positivos e negativos e certa aleatoriedade entre eles.

Enfim, o modelo avaliado pelas previsões a um passo para períodos dentro da amostra, que foram usados na estimação dos parâmetros do modelo, apresenta boa precisão e falta de viés para as duas variáveis.

TABELA 6.3.3.2

Previsões a um passo para as séries originais e seus erros relativos.

\begin{tabular}{|l|c|c|c|c|r|r|}
\hline \multirow{2}{*}{ PERÍODO } & \multicolumn{3}{|c|}{ PMPP } & \multicolumn{3}{c|}{ DV } \\
\cline { 2 - 7 } & $\begin{array}{c}\text { VALOR } \\
\text { OBS. }\end{array}$ & $\begin{array}{c}\text { PREVISÃO } \\
\text { UM PASSO }\end{array}$ & ERRO & $\begin{array}{c}\text { VALOR } \\
\text { OBS. }\end{array}$ & $\begin{array}{c}\text { PREVISÃO } \\
\text { UM PASSO }\end{array}$ & ERRO \\
\hline mai/96 & 10347 & 9925 & 422 & 13714 & 13772 & -58 \\
jun/96 & 10599 & 11033 & -434 & 13671 & 13905 & -234 \\
jul/96 & 10865 & 11019 & -154 & 13533 & 13512 & 21 \\
ago/96 & 11047 & 10966 & 81 & 12563 & 13464 & -901 \\
set/96 & 11424 & 11230 & 194 & 12911 & 12726 & 185 \\
out/96 & 11571 & 11858 & -287 & 13498 & 13088 & 410 \\
\hline
\end{tabular}

O gráfico 6.3.3.1 a seguir mostra as previsões e os valores observados das duas variáveis transformadas, percebe-se que os valores observados estão quase sempre muito mais 
próximos das previsões do que de algum extremo dos seus intervalos de confiança (coeficiente de 68\%), o que também ocorre para os valores não transformados.

\section{GRÁFICO 6.3.3.1}

Previsões a um passo para as séries transformadas (modelo $\mathrm{VI}$ ).
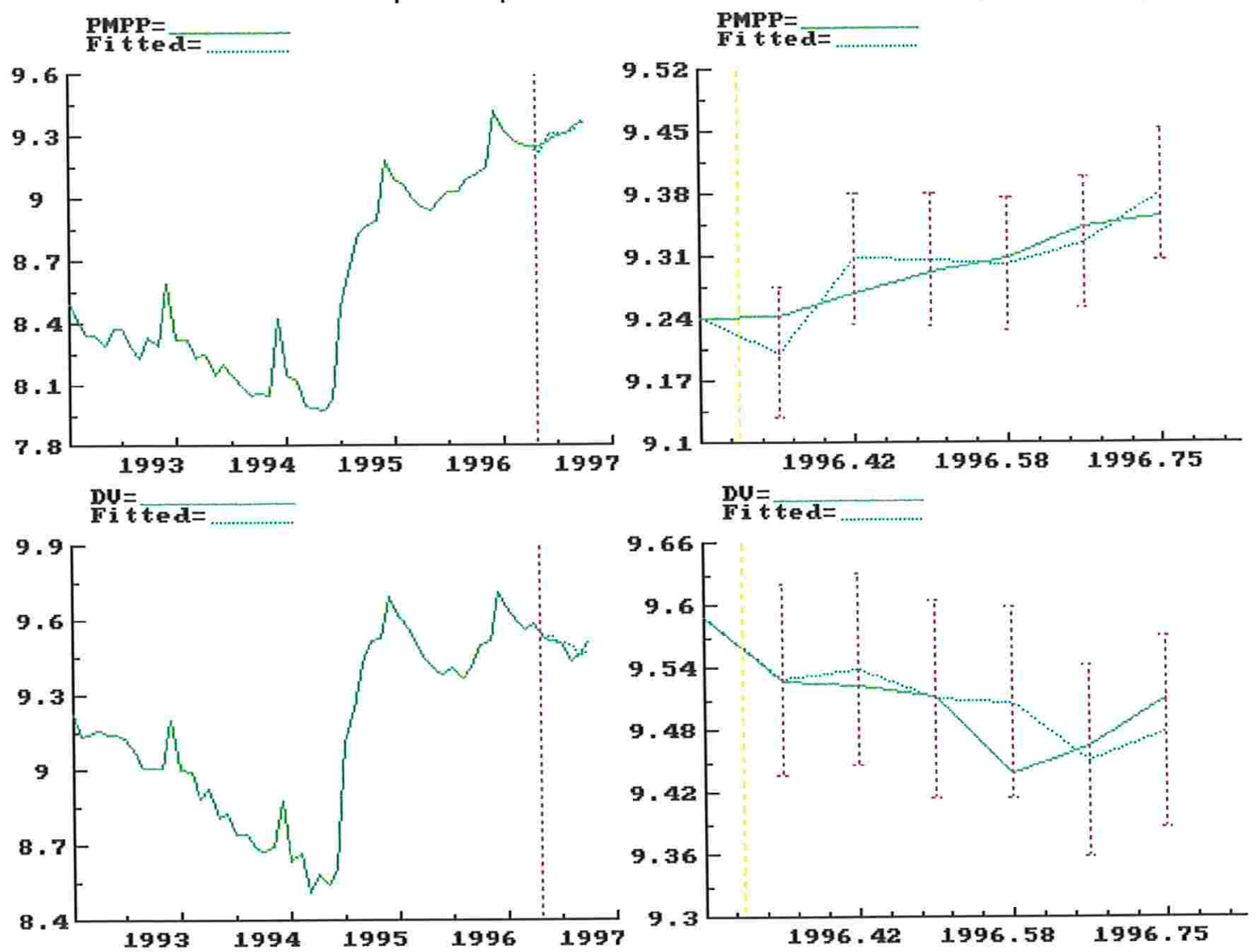

No caso das previsões a vários passos para as séries originais ${ }^{4}$, tabela 6.3.3.3, o modelo, de novo, mostra-se apropriado. Isto, considerando que, para nenhuma das variáveis, os erros absolutos aumentam sistematicamente com o passar do tempo e sendo relativamente reduzidos. As previsões são acuradas principalmente para o PMPP, que tem os seis erros absolutos inferiores a 4,09\%. Das previsões a mais de um passo para o DV original, são quatro os períodos que possuem erro percentual inferior a $3 \%$, sendo o de maior erro igual a $8,46 \%$.

Há, ainda, nas previsões para o PMPP, aleatoriedade nos erros, o que, contudo, não vale para o DV, cujos erros são sempre do mesmo sinal - previsões acima dos

\footnotetext{
${ }^{4}$ Ressalte-se que a diferença nas previsőes a um passo e a mais de um passo dentro da amostra para o primeiro mês (maio) previsto nas variáveis originais é devida à correção na retransformação das previsões logaritmadas, já que o STAMP fornece resultados diferentes para os EQM destas previsöes.
} 
observados. Este fato é até aceitável considerando que as previsões são realizadas somente com informações até abril/96.

TABELA 6.3.3.3

Previsões a vários passos para as séries originais e seus erros relativos.

\begin{tabular}{|l|c|c|c|c|c|c|}
\hline & \multicolumn{3}{|c|}{ PMPP } & \multicolumn{3}{c|}{ DV } \\
\cline { 2 - 7 } & $\begin{array}{c}\text { VALOR } \\
\text { PERIODO }\end{array}$ & $\begin{array}{c}\text { PRISÃO } \\
\text { VÁRIOS } \\
\text { PASSOS }\end{array}$ & ERRO & $\begin{array}{c}\text { VALOR } \\
\text { OBS. }\end{array}$ & $\begin{array}{c}\text { PREVISÃO } \\
\text { VÁRIOS } \\
\text { PASSOS }\end{array}$ & ERRO \\
\hline mai/96 & 10347 & 9923 & 424 & 13714 & 13769 & -55 \\
jun/96 & 10599 & 10852 & -253 & 13671 & 14081 & -410 \\
jul/96 & 10865 & 10983 & -118 & 13533 & 13740 & -207 \\
ago/96 & 11047 & 10978 & 69 & 12563 & 13626 & -1063 \\
set/96 & 11424 & 11238 & 186 & 12911 & 13623 & -712 \\
out/96 & 11571 & 11767 & -196 & 13498 & 13901 & -403 \\
\hline
\end{tabular}

As previsões a vários passos para as séries transformadas estão ilustradas no gráfico 6.3.3.2, nota-se, como nas previsões a um passo, que quase todos os valores observados nas duas variáveis estão muito mais perto das previsões do que de um dos extremos do intervalo com coeficiente de confiança de uma REQM

GRÁFICO 6.3.3.2

Previsões a vários passos para as séries transformadas (modelo VI).
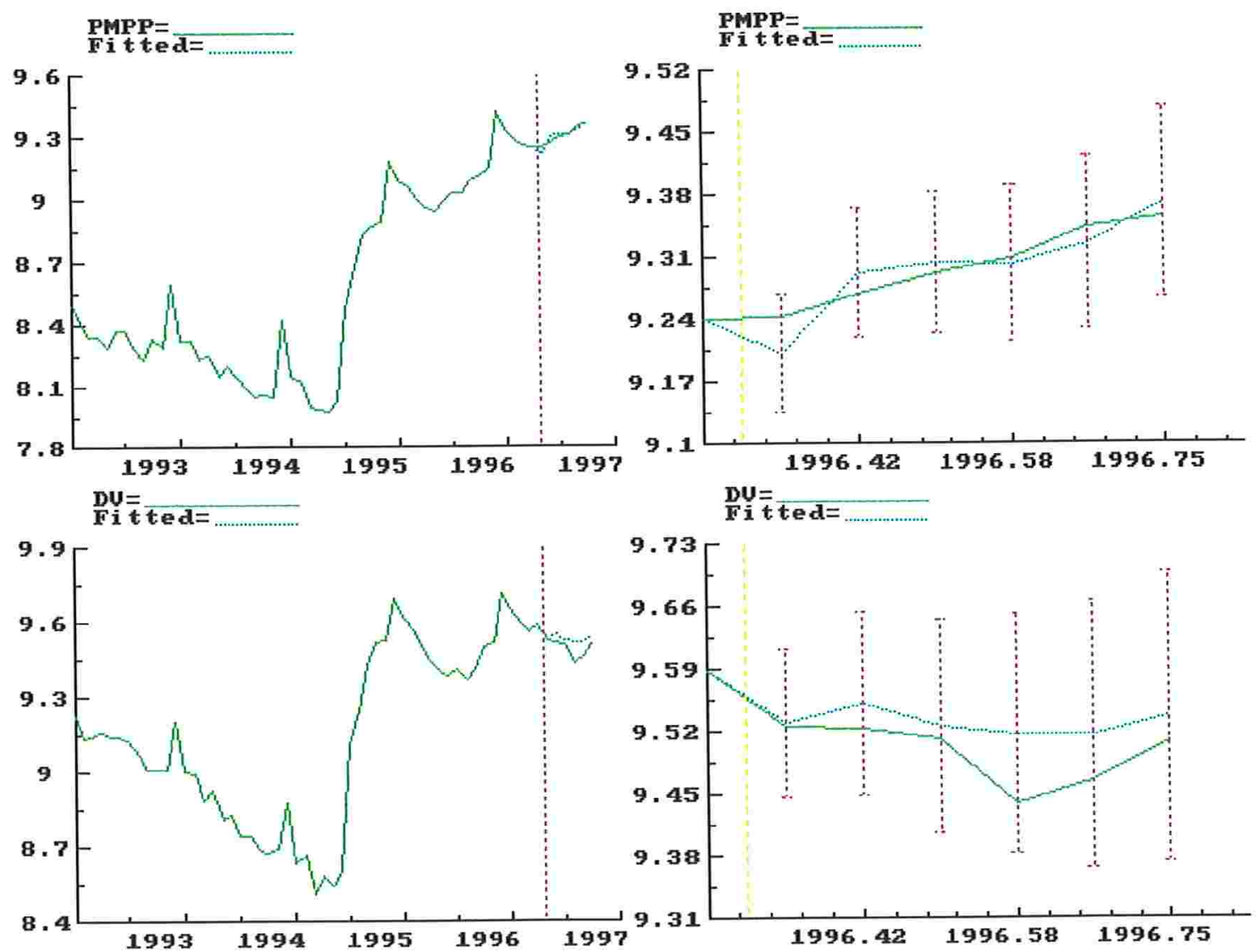
O comportamento dos resíduos auxiliares estimados é adequado pois a quantidade estatisticamente diferentes de zero, a $1 \%$ de significância, é reduzida para as duas variáveis, tanto no irregular como no nível, tabela 6.3.3.4. Não há, ainda, rejeição da hipótese de que os resíduos auxiliares apresentem distribuição normal para quaisquer dos testes (BS e $\mathrm{DH}$ ) aos níveis de significância usuais, na realidade nenhum nível descritivo é inferior a $35 \%$.

TABELA 6.3.3.4

Maiores valores dos resíduos auxiliares.

\begin{tabular}{|l|l|l|l|c|c|c|}
\hline \multirow{2}{*}{ COMPONENTE } & \multicolumn{3}{|c|}{ DV } & \multicolumn{3}{c|}{ PMPP } \\
\cline { 2 - 7 } & PERIODO & VALOR & P-VALUE & PERIOODO & VALOR & P-VALUE \\
\hline Irregular & $1992 / 01$ & 2.3961 & {$[0.0099]^{* *}$} & $1993 / 12$ & 2.4657 & {$[0.0083]^{* *}$} \\
Nivel & $1995 / 10$ & 2.6071 & {$[0.0058]^{* \star}$} & $1995 / 10$ & 2.6071 & {$[0.0058]^{* *}$} \\
\hline
\end{tabular}

Face ao baixo número de pontos das séries, a introdução de uma intervenção em um ou mais desses pontos somente seria justificável se provocasse melhora significativa no poder preditivo do modelo, tendo em vista que o interesse é exclusivamente de se obter projeções para as séries. Contudo, a introdução de intervenções nesses pontos, i.e., 1992/01 e 1995/10, não surtiram melhora no poder preditivo do modelo atual.

Desse modo, o modelo estrutural eleito como o mais adequado para se realizar previsões é o modelo $\mathrm{VI}$, que pode, com os coeficientes e desvios estimados, ser descrito conforme a equação

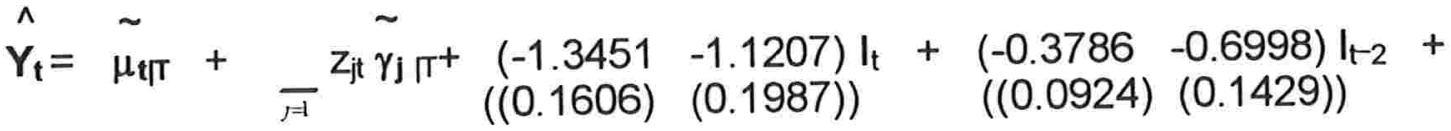

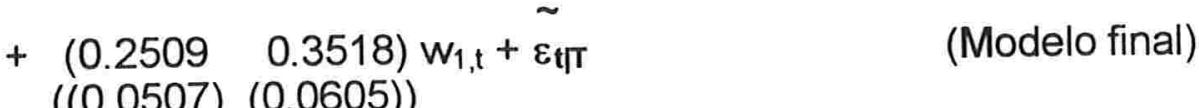

Os valores estimados para as componentes do último período da amostra, que servirão de base para a obtenção das previsões desejadas, são fornecidos para o PMPP e para o DV nas tabelas 6.3.3.5 e 6.3.3.6, respectivamente. 
TABELA 6.3.3.5

Coeficientes estimados e significâncias para o último ponto da amostra do PMPP.

\begin{tabular}{|l|c|c|c|c|}
\hline \multicolumn{1}{|c|}{ VARIÁVEL } & COEFICIENTE & REQM & t-value & $\begin{array}{c}\text { NIVEL } \\
\text { DESCRITIVO }\end{array}$ \\
\hline nível & 9.4151 & 0.0169 & 557.82 & {$[0.0000]^{* *}$} \\
taxa de cresc. & 0.0201 & 0.0052 & 3.8576 & {$[0.0003]^{* *}$} \\
saz. 1 & 0.1083 & 0.0123 & 8.7942 & {$[0.0000]^{* *}$} \\
saz. 2 & 0.0486 & 0.0121 & 4.0018 & {$[0.0002]^{* *}$} \\
saz. 3 & -0.0208 & 0.0119 & -1.7409 & {$[0.0872]^{* *}$} \\
saz. 4 & -0.0475 & 0.0120 & -3.9698 & {$[0.0002]^{* *}$} \\
saz. 5 & -0.0781 & 0.0119 & -6.538 & {$[0.0000]^{* *}$} \\
saz. 6 & -0.0266 & 0.0121 & -2.2057 & {$[0.0315]^{*}$} \\
saz. 7 & -0.0310 & 0.0129 & -2.4019 & {$[0.0197]^{*}$} \\
saz. 8 & -0.0638 & 0.0127 & -5.0297 & {$[0.0000]^{* *}$} \\
saz. 9 & -0.0577 & 0.0121 & -4.7477 & {$[0.0000]^{* *}$} \\
saz. 10 & -0.0417 & 0.0123 & -3.4046 & {$[0.0012]^{* *}$} \\
saz. 11 & -0.0373 & 0.0133 & -2.8117 & {$[0.0068]^{* *}$} \\
\hline
\end{tabular}

TABELA 6.3.3.6

Coeficientes estimados e significâncias para o último ponto da amostra do DV.

\begin{tabular}{|l|c|c|c|c|}
\hline \multicolumn{1}{|c|}{ VARIÁVEL } & COEFICIENTE & REQM & t-value & $\begin{array}{c}\text { NIVEL } \\
\text { DESCRITIVO }\end{array}$ \\
\hline nível & 9.5376 & 0.0228 & 418.49 & {$[0.0000]^{* *}$} \\
taxa de cresc. & -0.0065 & 0.0040 & -1.6166 & {$[0.1116]$} \\
saz. 1 & 0.0715 & 0.0171 & 4.1721 & {$[0.0001]^{* *}$} \\
saz. 2 & 0.0256 & 0.0170 & 1.5108 & {$[0.1365]$} \\
saz. 3 & -0.0198 & 0.0166 & -1.1946 & {$[0.2373]$} \\
saz. 4 & -0.0059 & 0.0165 & -0.3590 & {$[0.7209]$} \\
saz. 5 & -0.0432 & 0.0166 & -2.6022 & {$[0.0118]^{*}$} \\
saz. 6 & -0.0211 & 0.0169 & -1.2510 & {$[0.2161]$} \\
saz. 7 & -0.0318 & 0.0177 & -1.7940 & {$[0.0782]$} \\
saz. 8 & -0.0634 & 0.0176 & -3.5947 & {$[0.0007]^{* *}$} \\
saz. 9 & -0.0507 & 0.0170 & -2.9898 & {$[0.0041]^{* *}$} \\
saz. 10 & -0.0257 & 0.0174 & -1.4763 & {$[0.1455]$} \\
saz. 11 & -0.0051 & 0.0180 & -0.2846 & {$[0.7770]$} \\
\hline
\end{tabular}

\section{Conclusão: previsões condicionais.}

A busca das projeções para as observações futuras funcionou como principal foco deste estudo. Portanto, o interesse maior foi na aplicação de uma metodologia para se conseguir resultados úteis. Assim, o produto final desta dissertação é o conjunto de previsões condicionais obtidas para as variáveis econômicas brasileiras base monetária, depósito a vista e papel moeda em poder do público. 
Os modelos obtidos serão usados durante o prazo que se mostrarem válidos como preditores e por possuírem boa adaptação aos dados, ou seja, as últimas observações podem ter pesos maiores na determinação do futuro, poderão existir, sob condições regulares, por período razoável. Há de se pesar contra a utilização do modelo por um grande horizonte de tempo, as mudanças que são constantes na economia brasileira.

A separação dos componentes não observados no modelo mostrou-se bastante ilustrativa, permitindo visualização de questões econômicas marcantes e conhecimentos mais detalhados das séries. Os modelos estruturais são realmente apropriados para salientar características reveladoras das séries temporais.

Um caminho natural para se tentar o aperfeiçoamento dos modelos aqui descritos é a elaboração de um modelo multivariado, que provavelmente englobaria as variáveis dependentes aqui descritas além de outras variáveis adequadas. Isto, porque com o passar do tempo aumenta a amostra e é provável que a relação entre as variáveis seja mais estável. Talvez relações de tendências comuns possam ficar mais evidentes e contribuam para melhores previsões.

Assim, as previsões são conseguidas considerando um cenário para a inflação (IGP-DI), conforme tabela 7.1, definido por consenso por grupo de cenaristas a partir de discussões sobre informações de formadores de opinião, economistas, financistas, professores, consultores, assessores etc.

TABELA 7.1

Cenário e valores observados para a inflação (IGP-DI).

\begin{tabular}{|l|c|c|}
\hline PERÍODO & $\begin{array}{c}\text { IGP-DI previsto } \\
\text { (\% a.m.) }\end{array}$ & $\begin{array}{c}\text { IGP-DI observado } \\
\text { (\% a.m.) }\end{array}$ \\
\hline nov/96 & 0,56 & 0,28 \\
dez & 0,62 & 0,88 \\
jan/97 & 0,65 & 1,58 \\
fev & 0,56 & 0,42 \\
mar & 0,56 & 1,16 \\
abr & 0,65 & 0,59 \\
mai & 0,67 & 0,30 \\
jun & 0,78 & 0,70 \\
jul & 0,76 & 0,09 \\
ago & 0,65 & $-0,04$ \\
set & 0,67 & 0,58 \\
out & 0,57 & 0,34 \\
\hline
\end{tabular}


Enfim, as previsões obtidas para a base monetária são ilustradas no gráfico 7.1. Os valores pontuais retransformados para a série original, considerado o ajuste do viés da transformação exponencial pura, e seus intervalos com coeficiente de confiança igual a $68 \%$ estão na tabela 7.2 , que também contém os valores observados ocorridos para o período.

A comparação entre as previsões e as observações indica uma clara quebra estrutural em janeiro de 1997. Tal salto no nível decorre da instituição da contribuição provisória de movimentação financeira (CPMF). A cobrança do tributo ocasionou aumento nas reservas bancárias, que são um percentual dos depósitos a vista, que, por isto, aumentaram muito.

A mudança de nível deve ser considerada na especificação de um novo modelo e no julgamento preditivo do modelo atual pela comparação entre valores observado e previsões.

Os movimentos sazonais previstos pelo modelo parecem razoáveis e os erros de previsão não são tão instáveis e aumentam com o aumento de nível que a série apresentou. Registre-se que não foi fácil escolher modelo e previsões no final de 1996 tendo ciência do início da cobrança da CPMF. 
GRÁFICO 7.1

Previsões para a BM transformada e original.

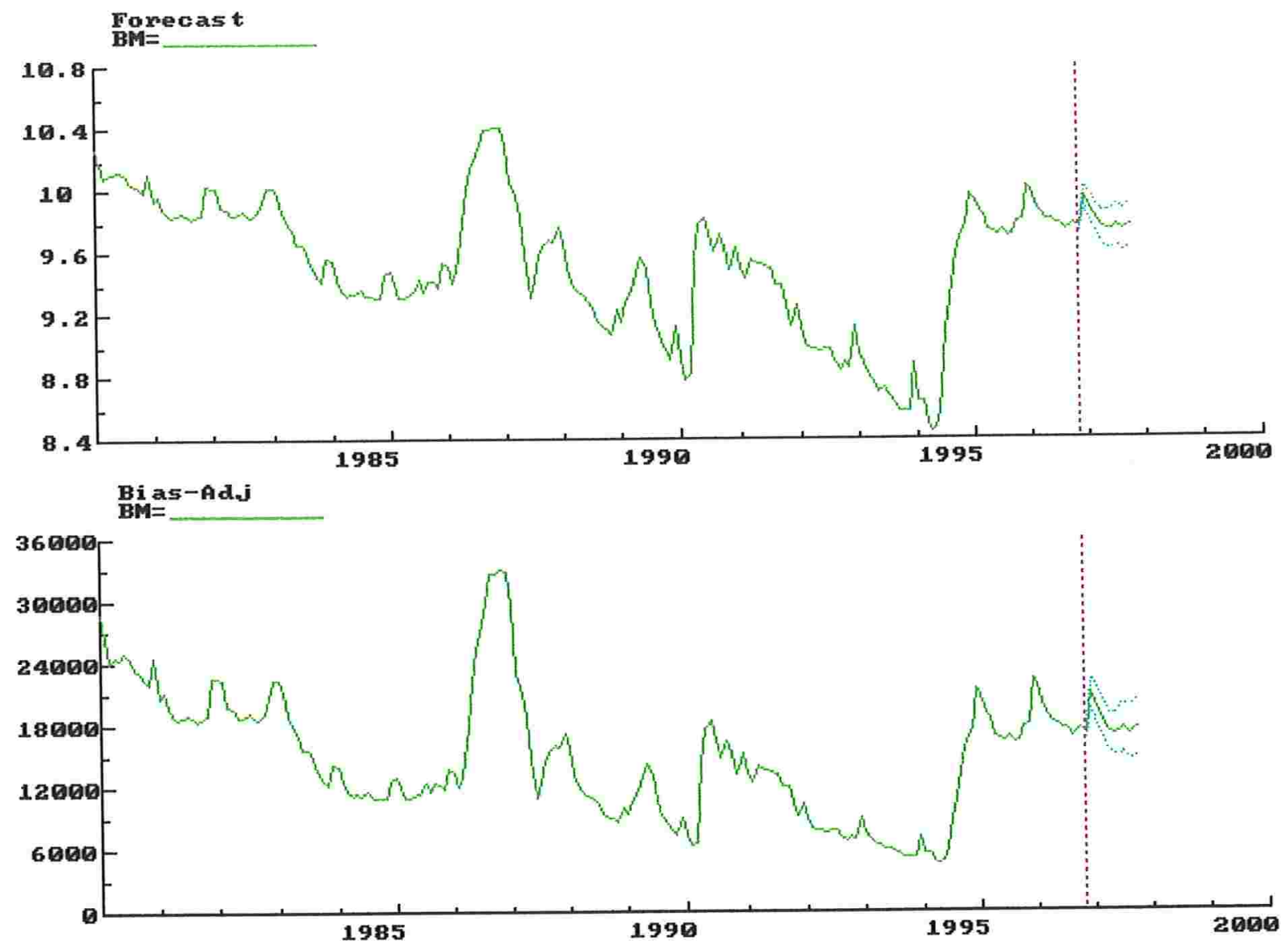

TABELA 7.2

Valores observados e previstos para a BM média mensal.

\begin{tabular}{|c|c|c|c|c|c|}
\hline PERIOODO & OBSERVADO & PREVISÃO & REQM & \multicolumn{2}{|c|}{ INTERVALO ( \pm 1REQM) } \\
\hline NOV/96 & 16859 & 17303 & 851 & 16452 & 18154 \\
DEZ/96 & 20106 & 21174 & 1402 & 19772 & 22576 \\
JAN/97 & 20620 & 20052 & 1607 & 18445 & 21659 \\
FEV/97 & 22610 & 18720 & 1724 & 16996 & 20444 \\
MAR/97 & 24697 & 17944 & 1843 & 16101 & 19788 \\
ABR/97 & 24672 & 17213 & 1934 & 15278 & 19147 \\
MAI/97 & 24450 & 17103 & 2074 & 15029 & 19177 \\
JUN/97 & 24707 & 17214 & 2229 & 14985 & 19443 \\
JUL/97 & 25794 & 17655 & 2424 & 15231 & 20079 \\
AGO/97 & 24986 & 17183 & 2487 & 14696 & 19670 \\
SET/97 & 26151 & 17438 & 2646 & 14792 & 20084 \\
OUT/97 & 26656 & 17677 & 2779 & 14898 & 20456 \\
\hline
\end{tabular}


Finalmente, considerando o mesmo cenário para a inflação descrito na tabela 7.1, são obtidas, através do modelo VI, as previsões para as variáveis DV e PMPP, a valores de outubro/96, mostradas no gráfico 7.2 e nas tabelas 7.3 e 7.4.

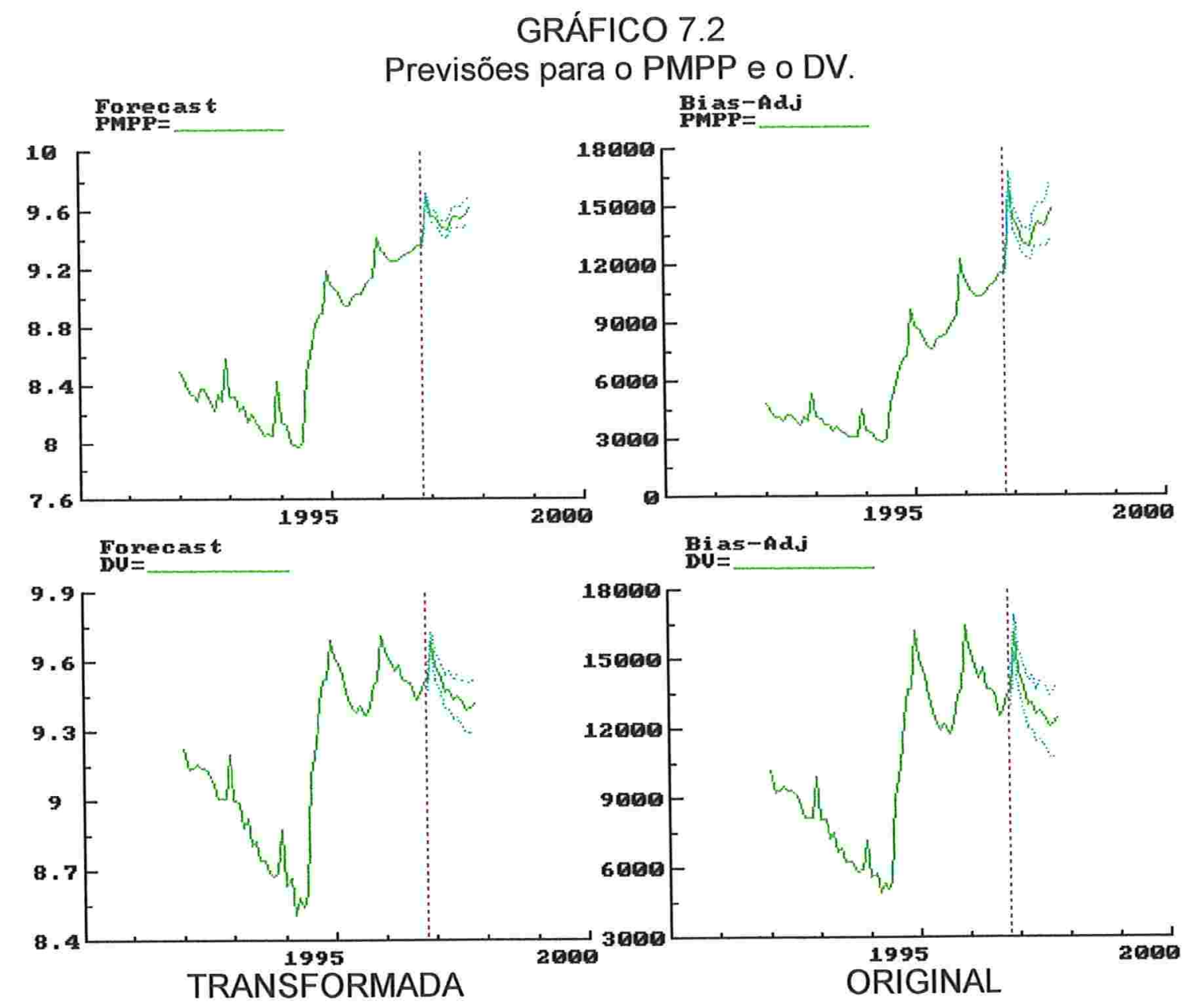

TABELA 7.3

Valores observados e previstos para o DV médio mensal.

\begin{tabular}{|c|c|c|c|c|c|}
\hline PERIODO & OBSERVADO & PREVISÃO & REQM & INTERVALO (COEFIENTE 50\%) \\
\hline NOV/96 & 12522 & 13625 & 573 & 13052 & 14198 \\
DEZ/96 & 14352 & 16109 & 842 & 15267 & 16952 \\
JAN/97 & 15921 & 14476 & 885 & 13591 & 15362 \\
FEV/97 & 22202 & 13753 & 952 & 12801 & 14705 \\
MAR/97 & 23106 & 13061 & 1002 & 12059 & 14063 \\
ABR/97 & 22903 & 13160 & 1103 & 12058 & 14263 \\
MAI/97 & 23008 & 12601 & 1141 & 11460 & 13742 \\
JUN/97 & 23104 & 12782 & 1241 & 11542 & 14023 \\
JUL/97 & 23081 & 12574 & 1300 & 11274 & 13874 \\
AGO/97 & 24000 & 12117 & 1327 & 10790 & 13444 \\
SET/97 & 24794 & 12198 & 1409 & 10790 & 13607 \\
OUT/97 & 25582 & 12458 & 1512 & 10946 & 13970 \\
\hline
\end{tabular}


TABELA 7.4

Valores observados e previstos para o PMPP médio mensal.

\begin{tabular}{|c|c|c|c|c|c|}
\hline PERIODO & OBSERVADO & PREVISÄO & REQM & \multicolumn{2}{|c|}{ INTERVALO (COEFIENTE 68\%) } \\
\hline NOV/96 & 11811 & 11973 & 405 & 11568 & 12378 \\
DEZ/96 & 14641 & 16226 & 598 & 15629 & 16824 \\
JAN/97 & 14254 & 14380 & 582 & 13798 & 14963 \\
FEV/97 & 13943 & 13838 & 621 & 13218 & 14459 \\
MAR/97 & 13783 & 13175 & 656 & 12519 & 13831 \\
ABR/97 & 13506 & 13081 & 724 & 12357 & 13804 \\
MAI/97 & 13555 & 12944 & 794 & 12150 & 13739 \\
JUN/97 & 13655 & 13885 & 943 & 12942 & 14828 \\
JUL/97 & 13908 & 14115 & 1058 & 13057 & 15173 \\
AGO/97 & 13892 & 13959 & 1150 & 12809 & 15109 \\
SET/97 & 13998 & 14336 & 1294 & 13042 & 15629 \\
OUT/97 & 14184 & 14899 & 1467 & 13431 & 16366 \\
\hline
\end{tabular}

Apesar das observações estarem a preços correntes e as previsões a preços de outubro de 1996, pode-se ter noção dos resultados do modelo considerando que a inflação do período foi pouco expressiva. Verifica-se, então, que os níveis do PMPP sofreram inexpressiva alteração e que o modelo previu bem esses valores, somente a previsão do mês de dezembro de 1996 ficou fora do intervalo com coeficiente de confiança igual a $68 \%$.

Para o DV, as previsões foram distantes dos valores observados devido à implementação da cobrança da CPMF que ocasionou a forte alteração no nível da série. 


\section{8 - Referências bibliográficas}

de Jong, P. (1988). The Likelihood for a state space model. Biometrika, 75, 165-169.

de Jong, P. (1991). The diffuse Kalman filter, The Annals of Statistics, 19, 1073-1083.

de Jong, P. \& Chu-Chun-Lin, S. (1994). Fast likelihood evaluatioon and prediction for nonstationary state space models, Biometrika, 81, 133-142

Doornik, J.A. \& Hendry, D.F. (1994). PcGive 8.0: An Interactive Econometric Modelling System. Oxford: Institute of Economics and Statistics, University of Oxford.

Harvey, A.C. (1989). Forecasting, Structural Time Series Models, and the Kalman Filter. Cambridge: Cambridge University Press.

Harvey, A.C. (1990). The Econometric Analysis of Time Series. New York: Philip Allan.

Harvey, A.C. (1993). Time Series Models, $2^{\mathrm{a}}$ edição. New York: Philip Allan.

Harvey, A.C. \& Koopman, S.J. (1992). Diagnostics checking of unobserved componentes time series models, Journal of Economics and Business Statistics, 10, 377-389.

Koopman, S. J., Harvey, A. C., Doornik, J. A. \& Shephard, N. (1995). STAMP 5.0: Structural Time Series Analyser, Modeller and Predictor. London: Chapman \& Hall.

Koopman, S. J. (1993). Disturbance Smoother for state space models, Biometrika 80, 117126.

Lopes, H. F., Schmidt, A. M. \& Moreira, A. R. B. (1996). Estimação de Hiperparâmetros em Modelos de Previsão. Texto de Discussão nº 449, IPEA.

Priestley, M. B. (1981). Spectral Analysis and Time Series. London: Academic Press.

Stock, J. (1994). Units Roots, Structural Breaks and Trend, em Engle, R.F. e McFadden, D.L. (Ed.) Handbook of Econometrics, vol IV, Capítulo 46, páginas 2737-2840, Amsterdam: Elsevier. 
IGP-DI EM PERCENTAGEM, VARIÁVEIS A VALORES DE OUT/96 EM MILHÕES DE REAIS (R\$ MILHŌES)

\begin{tabular}{|c|c|c|c|c|c|c|c|c|c|}
\hline DATA & |GP-DI| & $\begin{array}{c}\text { FATOR } \\
\text { DO } \\
\text { IGP-DI }\end{array}$ & $\begin{array}{c}\text { LOG } \\
\text { FATOR } \\
\text { DO } \\
\text { IGP-DI }\end{array}$ & $\begin{array}{c}\text { BM MÉDIA } \\
\text { MENSAL A } \\
\text { PREÇOS } \\
\text { CONSTAN- } \\
\text { TES OUT/96 } \\
\end{array}$ & LOG BM & \begin{tabular}{|c|} 
PMPP \\
MÉDIO \\
MENSAL A \\
PREÇOS \\
CONSTAN- \\
TES OUT/96 \\
\end{tabular} & LOG PMPP & \begin{tabular}{|c|} 
DV MÉDIO \\
MENSAL A \\
PREÇOS \\
CONSTAN- \\
TES \\
OUT/96 \\
\end{tabular} & LOG DV \\
\hline Jan/80 & 6,32 & 1,0632 & 0,0613 & 28803 & 10,268 & & & & \\
\hline Fev/80 & 4,09 & 1,0409 & 0,0401 & 26483 & 10,184 & & & & \\
\hline Mar/80 & 6,79 & 1,0679 & 0,0657 & 24131 & 10,091 & & & & \\
\hline $\mathrm{Abr} / 80$ & 5,69 & 1,0569 & 0,0553 & 24730 & 10,116 & & & & \\
\hline Mai/80 & 6,33 & 1,0633 & 0,0614 & 24514 & 10,107 & & & & \\
\hline Jun/80 & 5,65 & 1,0565 & 0,0550 & 25015 & 10,127 & & & & \\
\hline $\mathrm{Jul} / 80$ & 8,45 & 1,0845 & 0,0811 & 24565 & 10,109 & & & & \\
\hline Ago/80 & 7,01 & 1,0701 & 0,0678 & 23494 & 10,065 & & & & \\
\hline Set/80 & 5,34 & 1,0534 & 0,0520 & 23224 & 10,053 & & & & \\
\hline Out/80 & 7,60 & 1,0760 & 0,0733 & 22486 & 10,021 & & & & \\
\hline Nov/80 & 7,49 & 1,0749 & 0,0723 & 22024 & 10,000 & & & & \\
\hline Dez/80 & 5,98 & 1,0598 & 0,0580 & 24705 & 10,115 & & & & \\
\hline Jan/81 & 6,58 & 1,0658 & 0,0637 & 20752 & 9,940 & & & & \\
\hline Fev/81 & 8,47 & 1,0847 & 0,0813 & 21262 & 9,965 & & & & \\
\hline Mar/81 & 7,32 & 1,0732 & 0,0706 & 19644 & 9,886 & & & & \\
\hline Abr/81 & 5,45 & 1,0545 & 0,0531 & 18915 & 9,848 & & & & \\
\hline Mai/81 & 6,18 & 1,0618 & 0,0599 & 18626 & 9,832 & & & & \\
\hline Jun/81 & 4,47 & 1,0447 & 0,0437 & 18865 & 9,845 & & & & \\
\hline $\mathrm{Jul} / 81$ & 5,18 & 1,0518 & 0,0505 & 19166 & 9,861 & & & & \\
\hline Ago/81 & 6,65 & 1,0665 & 0,0644 & 18894 & 9,847 & & & & \\
\hline Set/81 & 5,08 & 1,0508 & 0,0496 & 18468 & 9,824 & & & & \\
\hline Out/81 & 4,40 & 1,0440 & 0,0430 & 18999 & 9,852 & & & & \\
\hline Nov/81 & 5,26 & 1,0526 & 0,0513 & 19004 & 9,852 & & & & \\
\hline Dez/81 & 3,80 & 1,0380 & 0,0373 & 22650 & 10,028 & & & & \\
\hline Jan/82 & 6,36 & 1,0636 & 0,0616 & 22603 & 10,026 & & & & \\
\hline Fev/82 & 6,79 & 1,0679 & 0,0657 & 22521 & 10,022 & & & & \\
\hline Mar/82 & 7,21 & 1,0721 & 0,0696 & 19900 & 9,898 & & & & \\
\hline $\mathrm{Abr} / 82$ & 5,38 & 1,0538 & 0,0524 & 19634 & 9,885 & & & & \\
\hline Mai/82 & 6,16 & 1,0616 & 0,0597 & 18919 & 9,848 & & & & \\
\hline Jun/82 & 7,99 & 1,0799 & 0,0769 & 18828 & 9,843 & & & & \\
\hline Jul/82 & 6,02 & 1,0602 & 0,0585 & 19280 & 9,867 & & & & \\
\hline Ago/82 & 5,81 & 1,0581 & 0,0564 & 18883 & 9,846 & & & & \\
\hline Set/82 & 3,68 & 1,0368 & 0,0361 & 18763 & 9,840 & & & & \\
\hline Out/82 & 4,79 & 1,0479 & 0,0468 & 19314 & 9,869 & & & & \\
\hline Nov/82 & 5,00 & 1,0500 & 0,0488 & 20633 & 9,935 & & & & \\
\hline Dez/82 & 6,14 & 1,0614 & 0,0596 & 22511 & 10,022 & & & & \\
\hline Jan/83 & 9,02 & 1,0902 & 0,0863 & 22554 & 10,024 & & & & \\
\hline Fev/83 & 6,55 & 1,0655 & 0,0634 & 21252 & 9,964 & & & & \\
\hline Mar/83 & 10,05 & 1,1005 & 0,0957 & 19136 & 9,859 & & & & \\
\hline $\mathrm{Abr} / 83$ & 9,20 & 1,0920 & 0,0880 & 17722 & 9,783 & & & & \\
\hline Mai/83 & 6,70 & 1,0670 & 0,0649 & 17120 & 9,748 & & & & \\
\hline Jun/83 & 12,30 & 1,1230 & 0,1160 & 15744 & 9,664 & & & & \\
\hline $\mathrm{Jul} / 83$ & 13,29 & 1,1329 & 0,1248 & 15778 & 9,666 & & & & \\
\hline Ago/83 & 10,13 & 1,1013 & 0,0965 & 14907 & 9,610 & & & & \\
\hline Set/83 & 12,80 & 1,1280 & 0,1204 & 13793 & 9,532 & & & & \\
\hline Out/83 & 13,25 & 1,1325 & 0,1245 & 12685 & 9,448 & & & & \\
\hline Nov/83 & 8,43 & 1,0843 & 0,0809 & 12280 & 9,416 & & & & \\
\hline
\end{tabular}




\begin{tabular}{|c|c|c|c|c|c|c|c|c|c|}
\hline DATA & |GP-DI & \begin{tabular}{|c|} 
FATOR \\
DO \\
IGP-DI \\
\end{tabular} & $\begin{array}{l}\text { LOG } \\
\text { FATOR } \\
\text { DO } \\
\text { IGP-DI }\end{array}$ & \begin{tabular}{|c|} 
BM MÉDIA \\
MENSAL A \\
PREÇOS \\
CONSTAN- \\
TES OUT/96 \\
\end{tabular} & LOG BM & \begin{tabular}{|c|} 
PMPP \\
MÉDIO \\
MENSAL A \\
PREÇOS \\
CONSTAN- \\
TES OUT/96 \\
\end{tabular} & LOG PMPP & \begin{tabular}{|c|} 
DV MÉDIO \\
MENSAL A \\
PREÇOS \\
CONSTAN- \\
TES \\
OUT/96 \\
\end{tabular} & LOG DV \\
\hline Dez/83 & 7,57 & 1,0757 & 0,0730 & 14221 & 9,562 & & & & \\
\hline Jan/84 & 9,80 & 1,0980 & 0,0935 & 14115 & 9,555 & & & & \\
\hline $\mathrm{Fev} / 84$ & 12,26 & 1,1226 & 0,1156 & 12496 & 9,433 & & & & \\
\hline Mar/84 & 9,96 & 1,0996 & 0,0950 & 11688 & 9,366 & & & & \\
\hline $\mathrm{Abr} / 84$ & 8,93 & 1,0893 & 0,0856 & 11208 & 9,324 & & & & \\
\hline Mai/84 & 8,86 & 1,0886 & 0,0849 & 11420 & 9,343 & & & & \\
\hline Jun/84 & 9,24 & 1,0924 & 0,0884 & 11377 & 9,339 & & & & \\
\hline $\mathrm{Jul} / 84$ & 10,32 & 1,1032 & 0,0982 & 11746 & 9,371 & & & & \\
\hline $\mathrm{Ago} / 84$ & 10,62 & 1,1062 & 0,1009 & 11280 & 9,331 & & & & \\
\hline Set/84 & 10,51 & 1,1051 & 0,0999 & 11178 & 9,322 & & & & \\
\hline Out/84 & 12,58 & 1,1258 & 0,1185 & 11136 & 9,318 & & & & \\
\hline Nov/84 & 9,88 & 1,0988 & 0,0942 & 11088 & 9,314 & & & & \\
\hline Dez/84 & 10,53 & 1,1053 & 0,1002 & 12789 & 9,456 & & & & \\
\hline Jan/85 & 12,64 & 1,1264 & 0,1190 & 13106 & 9,481 & & & & \\
\hline Fev/85 & 10,16 & 1,1016 & 0,0968 & 12172 & 9,407 & & & & \\
\hline Mar/85 & 12,71 & 1,1271 & 0,1196 & 11043 & 9,310 & & & & \\
\hline Abr/85 & 7,22 & 1,0722 & 0,0697 & 11139 & 9,318 & & & & \\
\hline Mai/85 & 7,78 & 1,0778 & 0,0749 & 11220 & 9,325 & & & & \\
\hline Jun/85 & 7,84 & 1,0784 & 0,0755 & 11549 & 9,354 & & & & \\
\hline $\mathrm{Jul} / 85$ & 8,92 & 1,0892 & 0,0854 & 12483 & 9,432 & & & & \\
\hline Ago/85 & 14,00 & 1,1400 & 0,1310 & 11610 & 9,360 & & & & \\
\hline Set/85 & 9,13 & 1,0913 & 0,0874 & 12406 & 9,426 & & & & \\
\hline Out/85 & 9,05 & 1,0905 & 0,0866 & 12272 & 9,415 & & & & \\
\hline Nov/85 & 14,95 & 1,1495 & 0,1393 & 11861 & 9,381 & & & & \\
\hline Dez/85 & 13,20 & 1,1320 & 0,1240 & 13915 & 9,541 & & & & \\
\hline Jan/86 & 17,79 & 1,1779 & 0,1637 & 13600 & 9,518 & & & & \\
\hline Fev/86 & 14,98 & 1,1498 & 0,1396 & 12181 & 9,408 & & & & \\
\hline Mar/86 & 5,52 & 1,0552 & 0,0538 & 13098 & 9,480 & & & & \\
\hline $\mathrm{Abr} / 86$ & $-0,58$ & 0,9942 & $-0,0058$ & 18063 & 9,802 & & & & \\
\hline Mai/86 & 0,32 & 1,0032 & 0,0032 & 22262 & 10,011 & & & & \\
\hline Jun/86 & 0,53 & 1,0053 & 0,0053 & 25392 & 10,142 & & & & \\
\hline $\mathrm{Jul} / 86$ & 0,63 & 1,0063 & 0,0063 & 27867 & 10,235 & & & & \\
\hline Ago/86 & 1,33 & 1,0133 & 0,0132 & 29899 & 10,306 & & & & \\
\hline Set/86 & 1,09 & 1,0109 & 0,0109 & 32730 & 10,396 & & & & \\
\hline Out/86 & 1,39 & 1,0139 & 0,0138 & 32727 & 10,396 & & & & \\
\hline Nov/86 & 2,46 & 1,0246 & 0,0243 & 33076 & 10,407 & & & & \\
\hline Dez/86 & 7,56 & 1,0756 & 0,0729 & 32977 & 10,404 & & & & \\
\hline Jan/87 & 12,04 & 1,1204 & 0,1137 & 29458 & 10,291 & & & & \\
\hline Fev/87 & 14,11 & 1,1411 & 0,1320 & 23105 & 10,048 & & & & \\
\hline Mar/87 & 15,00 & 1,1500 & 0,1398 & 21193 & 9,961 & & & & \\
\hline Abr/87 & 20,08 & 1,2008 & 0,1830 & 18761 & 9,840 & & & & \\
\hline Mai/87 & 27,58 & 1,2758 & 0,2436 & 14712 & 9,596 & & & & \\
\hline Jun/87 & 25,88 & 1,2588 & 0,2301 & 11149 & 9,319 & & & & \\
\hline $\mathrm{Jul} / 87$ & 9,33 & 1,0933 & 0,0892 & 12447 & 9,429 & & & & \\
\hline Ago/87 & 4,50 & 1,0450 & 0,0440 & 14622 & 9,590 & & & & \\
\hline Set/87 & 8,02 & 1,0802 & 0,0771 & 15715 & 9,662 & & & & \\
\hline Out/87 & 11,15 & 1,1115 & 0,1057 & 16003 & 9,681 & & & & \\
\hline Nov/87 & 14,46 & 1,1446 & 0,1351 & 15888 & 9,673 & & & & \\
\hline Dez/87 & 15,89 & 1,1589 & 0,1475 & 17376 & 9,763 & & & & \\
\hline
\end{tabular}




\begin{tabular}{|c|c|c|c|c|c|c|c|c|c|}
\hline DATA & IGP-DI & $\begin{array}{c}\text { FATOR } \\
\text { DO } \\
\text { IGP-DI }\end{array}$ & $\begin{array}{c}\text { LOG } \\
\text { FATOR } \\
\text { DO } \\
\text { IGP-DI }\end{array}$ & $\begin{array}{c}\text { BM MÉDIA } \\
\text { MENSAL A } \\
\text { PREÇOS } \\
\text { CONSTAN- } \\
\text { TES OUT/96 }\end{array}$ & LOG BM & \begin{tabular}{|c|} 
PMPP \\
MÉDIO \\
MENSAL A \\
PREÇOS \\
CONSTAN- \\
TES OUT/96 \\
\end{tabular} & LOG PMPP & \begin{tabular}{|c|} 
DV MÉDIO \\
MENSAL A \\
PREÇOS \\
CONSTAN- \\
TES \\
OUT/96 \\
\end{tabular} & LOG DV \\
\hline Jan/88 & 19,14 & 1,1914 & 0,1751 & 15672 & 9,660 & & & & \\
\hline Fev/88 & 17,65 & 1,1765 & 0,1625 & 13295 & 9,495 & & & & \\
\hline Mar/88 & 18,16 & 1,1816 & 0,1669 & 11859 & 9,381 & & & & \\
\hline Abr/88 & 20,33 & 1,2033 & 0,1851 & 11501 & 9,350 & & & & \\
\hline Mai/88 & 19,51 & 1,1951 & 0,1782 & 11345 & 9,336 & & & & \\
\hline Jun/88 & 20,83 & 1,2083 & 0,1892 & 10839 & 9,291 & & & & \\
\hline Jul/88 & 21,54 & 1,2154 & 0,1951 & 10421 & 9,252 & & & & \\
\hline Ago/88 & 22,89 & 1,2289 & 0,2062 & 9555 & 9,165 & & & & \\
\hline Set/88 & 25,76 & 1,2576 & 0,2292 & 9169 & 9,124 & & . & & \\
\hline Out/88 & 27,58 & 1,2758 & 0,2436 & 9073 & 9,113 & & & & \\
\hline Nov/88 & 27,97 & 1,2797 & 0,2466 & 8665 & 9,067 & & & & \\
\hline Dez/88 & 28,89 & 1,2889 & 0,2538 & 10196 & 9,230 & & & & \\
\hline Jan/89 & 36,56 & 1,3656 & 0,3116 & 9487 & 9,158 & & & & \\
\hline Fev/89 & 11,80 & 1,1180 & 0,1116 & 10742 & 9,282 & & & & \\
\hline Mar/89 & 4,23 & 1,0423 & 0,0414 & 11612 & 9,360 & & & & \\
\hline Abr/89 & 5,17 & 1,0517 & 0,0504 & 13003 & 9,473 & & & & \\
\hline Mai/89 & 12,76 & 1,1276 & 0,1201 & 14224 & 9,563 & & & & \\
\hline Jun/89 & 26,76 & 1,2676 & 0,2372 & 13296 & 9,495 & & & & \\
\hline $\mathrm{Jul} / 89$ & 37,88 & 1,3788 & 0,3212 & 10667 & 9,275 & & & & \\
\hline Ago/89 & 36,48 & 1,3648 & 0,3110 & 9290 & 9,137 & & & & \\
\hline Set/89 & 38,92 & 1,3892 & 0,3287 & 8406 & 9,037 & & & & \\
\hline Out/89 & 39,70 & 1,3970 & 0,3343 & 7878 & 8,972 & & & & \\
\hline Nov/89 & 44,27 & 1,4427 & 0,3665 & 7468 & 8,918 & & & & \\
\hline Dez/89 & 49,39 & 1,4939 & 0,4014 & 9167 & 9,123 & & & & \\
\hline Jan/90 & 71,90 & 1,7190 & 0,5417 & 7465 & 8,918 & & & & \\
\hline Fev/90 & 71,68 & 1,7168 & 0,5404 & 6516 & 8,782 & & & & \\
\hline Mar/90 & 81,32 & 1,8132 & 0,5951 & 6771 & 8,820 & & & & \\
\hline Abr/90 & 11,33 & 1,1133 & 0,1074 & 14251 & 9,565 & & & & \\
\hline Mai/90 & 9,07 & 1,0907 & 0,0869 & 17691 & 9,781 & & & & \\
\hline Jun/90 & 9,02 & 1,0902 & 0,0863 & 18515 & 9,826 & & & & \\
\hline $\mathrm{Jul} / 90$ & 12,98 & 1,1298 & 0,1220 & 16543 & 9,714 & & & & \\
\hline Ago/90 & 12,93 & 1,1293 & 0,1216 & 14815 & 9,603 & & & & \\
\hline Set/90 & 11,72 & 1,1172 & 0,1108 & 16546 & 9,714 & & & & \\
\hline Out/90 & 14,16 & 1,1416 & 0,1324 & 15349 & 9,639 & & & & \\
\hline Nov/90 & 17,45 & 1,1745 & 0,1609 & 13265 & 9,493 & & & & \\
\hline Dez/90 & 16,46 & 1,1646 & 0,1523 & 15344 & 9,638 & & & & \\
\hline Jan/91 & 19,93 & 1,1993 & 0,1818 & 13292 & 9,495 & & & & \\
\hline $\mathrm{Fev} / 91$ & 21,11 & 1,2111 & 0,1915 & 12497 & 9,433 & & & & \\
\hline Mar/91 & 7,25 & 1,0725 & 0,0700 & 14122 & 9,555 & & & & \\
\hline $\mathrm{Abr} / 91$ & 8,74 & 1,0874 & 0,0838 & 13835 & 9,535 & & & & \\
\hline Mai/91 & 6,52 & 1,0652 & 0,0632 & 13632 & 9,520 & & & & \\
\hline Jun/91 & 9,86 & 1,0986 & 0,0940 & 13485 & 9,509 & & & & \\
\hline $\mathrm{Jul} / 91$ & 12,83 & 1,1283 & 0,1207 & 13346 & 9,499 & & & & \\
\hline Ago/91 & 15,49 & 1,1549 & 0,1440 & 12010 & 9,394 & & & & \\
\hline Set/91 & 16,19 & 1,1619 & 0,1501 & 12027 & 9,395 & & & & \\
\hline Out/91 & 25,85 & 1,2585 & 0,2299 & 10541 & 9,263 & & & & \\
\hline Nov/91 & 25,76 & 1,2576 & 0,2292 & 9230 & 9,130 & & & & \\
\hline Dez/91 & 22,14 & 1,2214 & 0,2000 & 10517 & 9,261 & & & & \\
\hline
\end{tabular}




\begin{tabular}{|c|c|c|c|c|c|c|c|c|c|}
\hline DATA & |GP-D| & $\begin{array}{c}\text { FATOR } \\
\text { DO } \\
\text { IGP-DI } \\
\end{array}$ & $\begin{array}{c}\text { LOG } \\
\text { FATOR } \\
\text { DO } \\
\text { IGP-DI } \\
\end{array}$ & $\begin{array}{c}\text { BM MÉDIA } \\
\text { MENSAL A } \\
\text { PREÇOS } \\
\text { CONSTAN- } \\
\text { TES OUT/96 } \\
\end{array}$ & LOG BM & \begin{tabular}{|c|} 
PMPP \\
MÉDIO \\
MENSAL A \\
PREÇOS \\
CONSTAN- \\
TES OUT/96 \\
\end{tabular} & LOG PMPP & $\begin{array}{c}\text { DV MEDIO } \\
\text { MENSAL A } \\
\text { PREÇOS } \\
\text { CONSTAN- } \\
\text { TES } \\
\text { OUT/96 } \\
\end{array}$ & LOG DV \\
\hline $\operatorname{Jan} / 92$ & 26,84 & 1,2684 & 0,2378 & 9163 & 9,123 & 4821 & 8,481 & 10171 & 9,227 \\
\hline Fev/92 & 24,79 & 1,2479 & 0,2215 & 8148 & 9,005 & 4481 & 8,408 & 9323 & 9,140 \\
\hline Mar/92 & 20,70 & 1,2070 & 0,1881 & 7952 & 8,981 & 4178 & 8,338 & 9411 & 9,150 \\
\hline Abr/92 & 18,54 & 1,1854 & 0,1701 & 7958 & 8,982 & 4158 & 8,333 & 9510 & 9,160 \\
\hline Mai/92 & 22,45 & 1,2245 & 0,2025 & 7786 & 8,960 & 3977 & 8,288 & 9411 & 9,150 \\
\hline Jun/92 & 21,42 & 1,2142 & 0,1941 & 7991 & 8.986 & 4291 & 8,364 & 9367 & 9,145 \\
\hline Jul/92 & 21,69 & 1,2169 & 0,1963 & 7941 & 8,980 & 4274 & 8,360 & 9203 & 9,127 \\
\hline Ago/92 & 25,54 & 1,2554 & 0,2275 & 7306 & 8,897 & 3940 & 8,279 & 8734 & 9,075 \\
\hline Set/92 & 27,37 & 1,2737 & 0,2420 & 6967 & 8,849 & 3717 & 8,221 & 8193 & 9,011 \\
\hline Out/92 & 24,94 & 1,2494 & 0,2226 & 7369 & 8,905 & 4109 & 8,321 & 8217 & 9,014 \\
\hline Nov/92 & 24,22 & 1,2422 & 0,2169 & 7068 & 8,863 & 3963 & 8,285 & 8226 & 9,015 \\
\hline Dez/92 & 23,70 & 1,2370 & 0,2127 & 9165 & 9,123 & 5354 & 8,586 & 9938 & 9,204 \\
\hline Jan/93 & 28,73 & 1,2873 & 0,2525 & 7663 & 8,944 & 4102 & 8,319 & 8104 & 9,000 \\
\hline Fev/93 & 26,51 & 1,2651 & 0,2351 & 7190 & 8,880 & 4095 & 8,317 & 8088 & 8,998 \\
\hline Mar/93 & 27,81 & 1,2781 & 0,2454 & 6586 & 8,793 & 3739 & 8,226 & 7257 & 8,890 \\
\hline Abrr/93 & 28,22 & 1,2822 & 0,2486 & 6439 & 8,770 & 3793 & 8,241 & 7568 & 8,932 \\
\hline Mai/93 & 32,27 & 1,3227 & 0,2796 & 6010 & 8,701 & 3432 & 8,141 & 6745 & 8,817 \\
\hline Jun/93 & 30,72 & 1,3072 & 0,2679 & 6130 & 8,721 & 3616 & 8,193 & 6856 & 8,833 \\
\hline Jul/93 & 31,96 & 1,3196 & 0,2774 & 5953 & 8,692 & 3430 & 8,140 & 6303 & 8,749 \\
\hline $\mathrm{Ago} / 93$ & 33,53 & 1,3353 & 0,2892 & 5593 & 8,629 & 3252 & 8,087 & 6289 & 8,747 \\
\hline Set/93 & 36,99 & 1,3699 & 0,3148 & 5336 & 8,582 & 3122 & 8,046 & 5978 & 8,696 \\
\hline Out/93 & 35,14 & 1,3514 & 0,3012 & 5346 & 8,584 & 3163 & 8,059 & 5904 & 8,683 \\
\hline Nov/93 & 36,96 & 1,3696 & 0,3145 & 5325 & 8,580 & 3134 & 8,050 & 5983 & 8,697 \\
\hline Dez/93 & 36,22 & 1,3622 & 0,3091 & 7209 & 8,883 & 4520 & 8,416 & 7189 & 8,880 \\
\hline Jan/94 & 42,19 & 1,4219 & 0,3520 & 5703 & 8,649 & 3447 & 8,145 & 5646 & 8,639 \\
\hline Fev/94 & 42,41 & 1,4241 & 0,3535 & 5710 & 8,650 & 3356 & 8,119 & 5816 & 8,668 \\
\hline Mar/94 & 44,83 & 1,4483 & 0,3704 & 4823 & 8,481 & 2967 & 7,995 & 4995 & 8,516 \\
\hline Abr/94 & 42,46 & 1,4246 & 0,3539 & 4641 & 8,443 & 2935 & 7,985 & 5343 & 8,583 \\
\hline Mai/94 & 40,95 & 1,4095 & 0,3432 & 4912 & 8,500 & 2895 & 7,971 & 5149 & 8,547 \\
\hline Jun/94 & 46,58 & 1,4658 & 0,3824 & 6070 & $8 ; 711$ & 3045 & 8,021 & 5493 & 8,611 \\
\hline Jul/94 & 24,71 & 1,2471 & 0,2208 & 8935 & 9,098 & 4810 & 8,479 & 9050 & 9,110 \\
\hline Ago/94 & 3,34 & 1,0334 & 0,0329 & 12074 & 9,399 & 5883 & 8,680 & 10355 & 9,245 \\
\hline Set/94 & 1,55 & 1,0155 & 0,0154 & 14725 & 9,597 & 6775 & 8,821 & 12439 & 9,429 \\
\hline Out/94 & 2,55 & 1,0255 & 0,0252 & 16406 & 9,705 & 7107 & 8,869 & 13684 & 9,524 \\
\hline Nov/94 & 2,47 & 1,0247 & 0,0244 & 17477 & 9,769 & 7256 & 8,890 & 13727 & 9,527 \\
\hline Dez/94 & 0,57 & 1,0057 & 0,0057 & 21415 & 9,972 & 9670 & 9,177 & 16204 & 9,693 \\
\hline Jan/95 & 1,36 & 1,0136 & 0,0135 & 20636 & 9,935 & 8844 & 9,087 & 15016 & 9,617 \\
\hline Fev/95 & 1,15 & 1,0115 & 0,0114 & 19116 & 9,858 & 8542 & 9,053 & 14329 & 9,570 \\
\hline Mar/95 & 1,81 & 1,0181 & 0,0179 & 18610 & 9,831 & 8095 & 8,999 & 13371 & 9,501 \\
\hline Abr/95 & 2,30 & 1,0230 & 0,0227 & 16884 & 9,734 & 7772 & 8,958 & 12676 & 9,447 \\
\hline Mai/95 & 0,40 & 1,0040 & 0,0040 & 16698 & 9,723 & 7607 & 8,937 & 12183 & 9,408 \\
\hline Jun/95 & 2,62 & 1,0262 & 0,0259 & 16535 & 9,713 & 8007 & 8,988 & 11937 & 9,387 \\
\hline Jul/95 & 2,24 & 1,0224 & 0,0222 & 16962 & 9,739 & 8291 & 9,023 & 12200 & 9,409 \\
\hline Ago/95 & 1,29 & 1,0129 & 0,0128 & 16309 & 9,699 & 8315 & 9,026 & 11766 & 9,373 \\
\hline Set/95 & $-1,08$ & 0,9892 & $-0,0109$ & 16529 & 9,713 & 8799 & 9,082 & 12282 & 9,416 \\
\hline Out/95 & 0,23 & 1,0023 & 0,0023 & 17856 & 9,790 & 9035 & 9,109 & 13418 & 9,504 \\
\hline Nov/95 & 1,33 & 1,0133 & 0,0132 & 18143 & 9,806 & 9333 & 9,141 & 13695 & 9,525 \\
\hline Dez/95 & 0,27 & 1,0027 & 0,0027 & 22420 & 10,018 & 12243 & 9,413 & 16486 & 9,710 \\
\hline Jan/96 & 1,79 & 1,0179 & 0,0177 & 21775 & 9,989 & 11222 & 9,326 & 15580 & 9,654 \\
\hline
\end{tabular}




\begin{tabular}{|c|c|c|c|c|c|c|c|c|c|}
\hline DATA & |GP-DI & $\begin{array}{c}\text { FATOR } \\
\text { DO } \\
\text { IGP-DI }\end{array}$ & $\begin{array}{c}\text { LOG } \\
\text { FATOR } \\
\text { DO } \\
\text { IGP-DI } \\
\end{array}$ & $\begin{array}{l}\text { BM MÉDIA } \\
\text { MENSAL A } \\
\text { PREÇOS } \\
\text { CONSTAN- } \\
\text { TES OUT/96 } \\
\end{array}$ & LOG BM & $\begin{array}{c}\text { PMPP } \\
\text { MÉDIO } \\
\text { MENSAL A } \\
\text { PREÇOS } \\
\text { CONSTAN- } \\
\text { TES OUT/96 } \\
\end{array}$ & LOG PMPP & \begin{tabular}{|c|} 
DV MÉDIO \\
MENSAL A \\
PREÇOS \\
CONSTAN- \\
TES \\
OUT/96 \\
\end{tabular} & LOG DV \\
\hline Fev/96 & 0,76 & 1,0076 & 0,0076 & 19470 & 9,877 & 10698 & 9,278 & 14702 & 9,596 \\
\hline Mar/96 & 0,22 & 1,0022 & 0,0022 & 18954 & 9,850 & 10432 & 9,253 & 14216 & 9,562 \\
\hline Abr/96 & 0,70 & 1,0070 & 0,0070 & 18211 & 9,810 & 10303 & 9,240 & 14593 & 9,588 \\
\hline Mai/96 & 1,68 & 1,0168 & 0,0167 & 18077 & 9,802 & 10347 & 9,244 & 13714 & 9,526 \\
\hline Jun/96 & 1,22 & 1,0122 & 0,0121 & 17701 & 9,781 & 10600 & 9,269 & 13671 & 9,523 \\
\hline $\mathrm{Jul} / 96$ & 1,09 & 1,0109 & 0,0108 & 17761 & 9,785 & 10865 & 9,293 & 13533 & 9,513 \\
\hline $\mathrm{Ago} / 96$ & 0,00 & 1,0000 & 0,0000 & 16905 & 9,735 & 11047 & 9,310 & 12563 & 9,438 \\
\hline Set/96 & 0,13 & 1,0013 & 0,0013 & 17281 & 9,757 & 11424 & 9,343 & 12910 & 9,466 \\
\hline Out/96 & 0,22 & 1,0022 & 0,0022 & 17653 & 9,779 & 11571 & 9,356 & 13498 & 9,510 \\
\hline
\end{tabular}

